University of Tennessee Health Science Center

UTHSC Digital Commons

\title{
Phenotypic And Electrophysiologic Characterization of a Mouse Model of Fragile X Syndrome
}

\author{
Snigdha Roy \\ University of Tennessee Health Science Center
}

Follow this and additional works at: https://dc.uthsc.edu/dissertations

Part of the Congenital, Hereditary, and Neonatal Diseases and Abnormalities Commons, and the Neurosciences Commons

\section{Recommended Citation}

Roy, Snigdha, "Phenotypic And Electrophysiologic Characterization of a Mouse Model of Fragile X Syndrome" (2012). Theses and Dissertations (ETD). Paper 225. http://dx.doi.org/10.21007/ etd.cghs.2012.0268.

This Dissertation is brought to you for free and open access by the College of Graduate Health Sciences at UTHSC Digital Commons. It has been accepted for inclusion in Theses and Dissertations (ETD) by an authorized administrator of UTHSC Digital Commons. For more information, please contact jwelch30@uthsc.edu. 


\title{
Phenotypic And Electrophysiologic Characterization of a Mouse Model of Fragile $X$ Syndrome
}

\author{
Abstract \\ Fragile $\mathrm{X}$ syndrome (FXS) is the most common form of inherited mental retardation. It is caused by a \\ mutation in the fragile X mental retardation (FMR1) gene on the X chromosome. Many children with FXS \\ exhibit autistic behaviors and deficits in motor coordination including speech articulation deficits. The \\ development of the FMR1 knockout (Fmr1 KO) mouse, in which the Fmr1 gene is inactivated, has \\ provided an animal model that can be used to investigate underlying neuro-physiological mechanisms \\ associated with FXS as well as to evaluate potential therapeutic treatments. In this study, quantitative \\ behavioral assays were used, such as long term fluid licking observations, measurements of ultrasonic \\ vocalizations (USV), and 3D tracking of whisker movements to test Fmr1 KO mice for behavioral deficits \\ compared to their Wild type (WT) littermates. Electrophysiological techniques were employed to evaluate \\ the functional properties of the neocortex. Pyramidal neurons in the neocortex of human FXS patients \\ and Fmr1 KO mice are characterized by abnormally long, thin and numerous dendritic spines. Multiple \\ electrode recordings were used to study how loss of Fmr1 expression affects several aspects of the \\ neocortical network activities in Fmr1 KO mice. Single and multi unit spike activities and local field \\ potentials (LFPs) were recorded in the whisker barrel cortex of awake mice. Baseline spike activity was \\ significantly lower in cortical neurons of Fmr1 KO mice. Synchronous activity at the LFP was strongly \\ reduced in Fmr1 $\mathrm{KO}$ mice. Relative power in the delta range frequency band of LFP activity was \\ significantly reduced in the neocortex of Fmr1 $\mathrm{KO}$ mice. Furthermore, relative power in the beta frequency \\ band was significantly higher in Fmr1 KO compared to WT mice. Our behavioral assays identified several \\ phenotypical differences between Fmr1 KO and WT mice. Orofacial behavioral deficits in fluid licking and \\ USV may be comparable to speech deficits in fragile $X$ patients. Severely impaired dynamics of \\ neocortical network activity may be causally linked to the cognitive and sensorimotor impairments \\ associated with fragile $\mathrm{X}$ syndrome. \\ Document Type \\ Dissertation \\ Degree Name \\ Doctor of Philosophy (PhD) \\ Program \\ Biomedical Sciences \\ Research Advisor \\ Detlef H. Heck, Ph.D. \\ Keywords \\ Fragile X, Whisking, USVs, Cortical Network, LFP \\ Subject Categories \\ Congenital, Hereditary, and Neonatal Diseases and Abnormalities | Diseases | Medical Sciences | \\ Medicine and Health Sciences | Neurosciences

\section{Comments} \\ Two year embargo expired May 2014
}

This dissertation is available at UTHSC Digital Commons: https://dc.uthsc.edu/dissertations/225 


\title{
PHENOTYPIC AND ELECTRO-PHYSIOLOGIC CHARACTERIZATION OF A MOUSE MODEL OF FRAGILE X SYNDROME
}

\author{
A Dissertation \\ Presented for \\ The Graduate Studies Council \\ The University of Tennessee \\ Health Science Center \\ In Partial Fulfillment \\ Of the Requirements for the Degree \\ Doctor of Philosophy \\ From The University of Tennessee
}

By

Snigdha Roy

May 2012 
Portions of Chapter 2 (C) 2011 American Psychological Association. Portions of Chapter 4 (C) 2011 by Frontiers Media SA.

Portions of Chapter 5 (C) 2009 by Elsevier B.V.

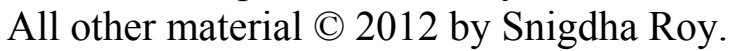
All rights reserved. 


\section{DEDICATION}

This dissertation is dedicated to my wonderful family. Particularly I want to dedicate this dissertation to my understanding and patient husband, Koushik, for his love and support that helped me achieve this major goal and to our two beautiful daughters Emily and Elina, who are the joy of our lives. I must also thank my loving parents and my terrific in-laws who have helped so much with baby-sitting and have given me their fullest support. 


\section{ACKNOWLEDGEMENTS}

I would like to express my gratitude to my advisor, Dr. Detlef H. Heck, for his valuable guidance and continuous support throughout the course of my work. I am grateful to my thesis committee members, Dr. Robert Waters, Dr. Robert Foehring, Dr. John Boughter and Dr. Fu-ming Zhou for their valuable comments and insightful suggestions. I am thankful to our technician Ms. Suhua Qui for her generous help. I thank my coworkers Jason Jerome and Dr. Ying Cao for their constant help with my experiments. I am appreciative of all the contributions of the faculty members and my friends in the Department of Anatomy and Neurobiology that have helped me to complete my studies.

I would also like to thank to The University of Tennessee Health Science Center Clinical and Translational Science Institute (CTSI) for providing me T32 Scholar award in 2009 and The University of Tennessee Health Science Center Neuroscience Institute for providing me travel award in 2011.

I am indebted to my parents, brother, and family members for their inspiration throughout my graduate studies. Finally, I would like to thank my husband, Dr. Koushik Roy, for his inspiration, love and mental support without which it would be quite impossible to finish this work. 


\begin{abstract}
Fragile X syndrome (FXS) is the most common form of inherited mental retardation. It is caused by a mutation in the fragile X mental retardation (FMR1) gene on the X chromosome. Many children with FXS exhibit autistic behaviors and deficits in motor coordination including speech articulation deficits. The development of the FMRI knockout ( Fmrl KO) mouse, in which the Fmrl gene is inactivated, has provided an animal model that can be used to investigate underlying neuro-physiological mechanisms associated with FXS as well as to evaluate potential therapeutic treatments. In this study, quantitative behavioral assays were used, such as long term fluid licking observations, measurements of ultrasonic vocalizations (USV), and 3D tracking of whisker movements to test Fmrl KO mice for behavioral deficits compared to their Wild type (WT) littermates. Electrophysiological techniques were employed to evaluate the functional properties of the neocortex. Pyramidal neurons in the neocortex of human FXS patients and Fmrl KO mice are characterized by abnormally long, thin and numerous dendritic spines. Multiple electrode recordings were used to study how loss of Fmrl expression affects several aspects of the neocortical network activities in Fmrl KO mice. Single and multi unit spike activities and local field potentials (LFPs) were recorded in the whisker barrel cortex of awake mice. Baseline spike activity was significantly lower in cortical neurons of Fmrl KO mice. Synchronous activity at the LFP was strongly reduced in Fmrl KO mice. Relative power in the delta range frequency band of LFP activity was significantly reduced in the neocortex of Fmrl KO mice. Furthermore, relative power in the beta frequency band was significantly higher in Fmrl KO compared to WT mice. Our behavioral assays identified several phenotypical differences between Fmrl KO and WT mice. Orofacial behavioral deficits in fluid licking and USV may be comparable to speech deficits in fragile X patients. Severely impaired dynamics of neocortical network activity may be causally linked to the cognitive and sensorimotor impairments associated with fragile $\mathrm{X}$ syndrome.
\end{abstract}




\section{TABLE OF CONTENTS}

CHAPTER 1. INTRODUCTION .....................................................................................1

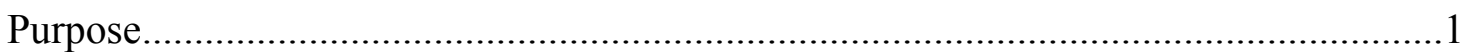

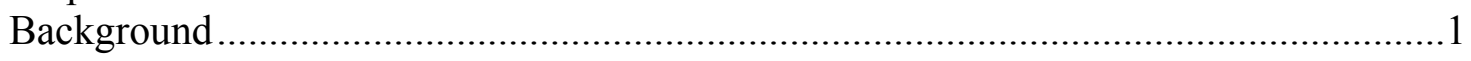

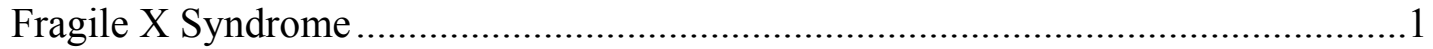

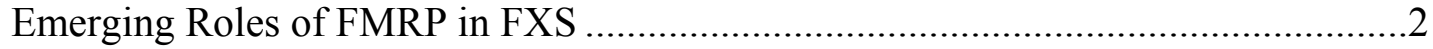

FMR1 KO Mouse, a Mouse Model of Fragile X Syndrome ..................................... 3

Primary Somatosensory Cortex in Humans and Rodents .........................................4

Specific Aims .................................................................................................. 5

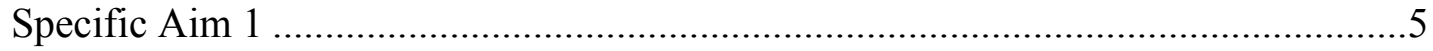

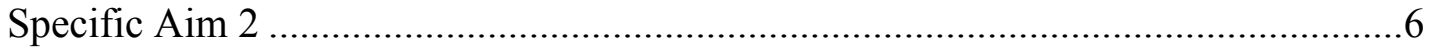

CHAPTER 2. LONG TERM FLUID LICKING STUDY ..........................................7

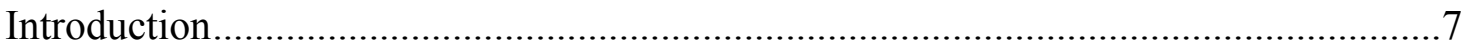

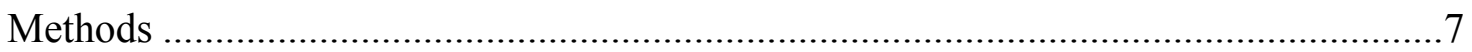

Animals Used ............................................................................................

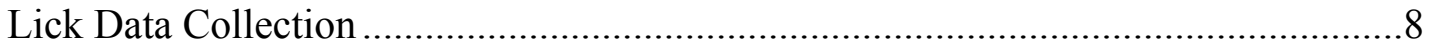

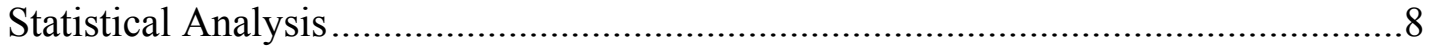

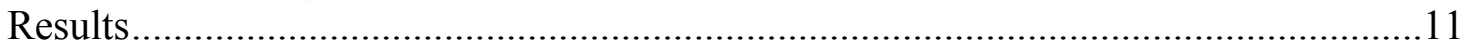

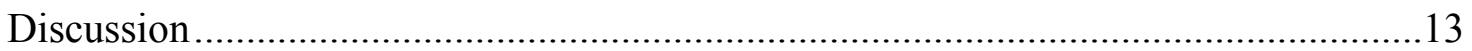

Oromotor Function...................................................................................... 13

A Possible Neuronal Substrate for Oromotor Deficits.......................................13

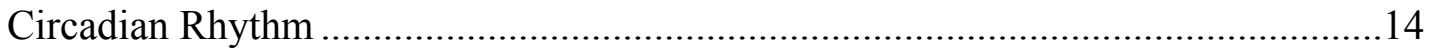

\section{CHAPTER 3. ULTRASONIC VOCALIZATION STUDY ON NEONATES ..........16}

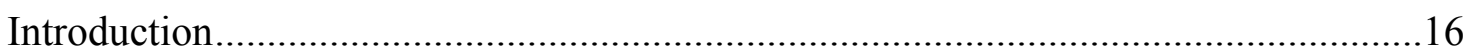

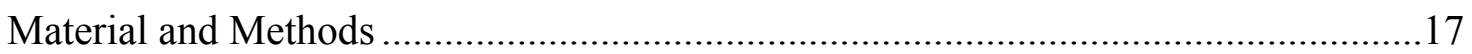

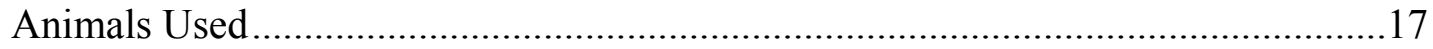

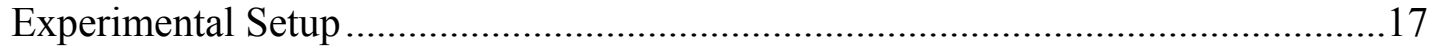

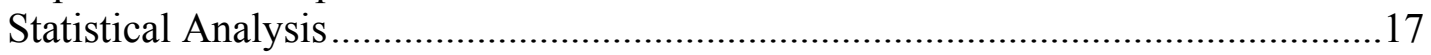

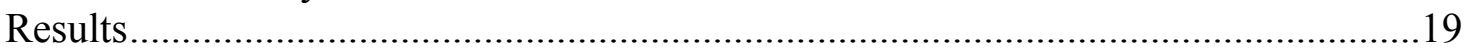

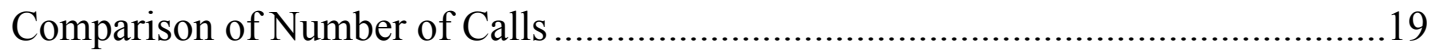

Comparison of Carrier Frequency in Flat Calls ..................................................19

Comparison of Frequency Modulation in Complex Calls ......................................19

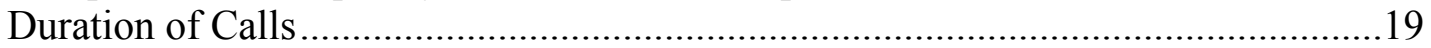

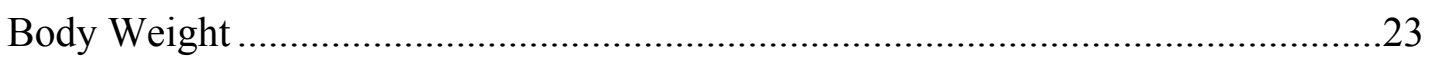

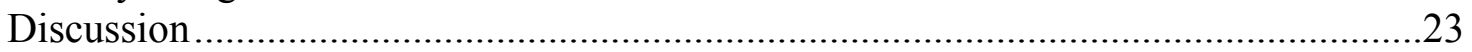

\section{CHAPTER 4. BILATERAL 3-DIMENSIONAL COORDINATION OF MOUSE}

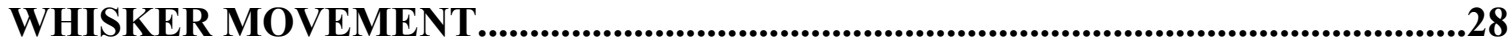

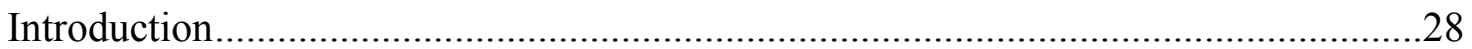

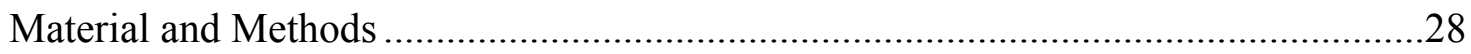

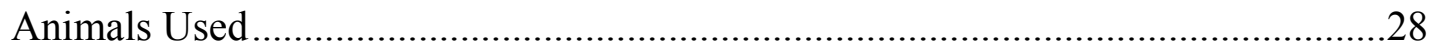


Motion Capture System ……………….............................................................29

Camera Setup and Calibration .........................................................................29

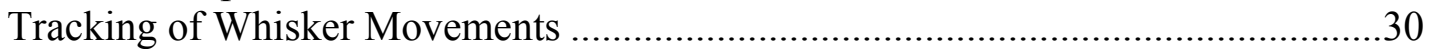

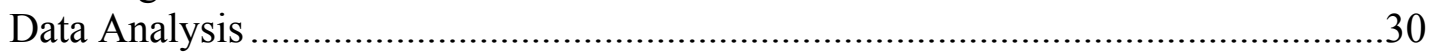

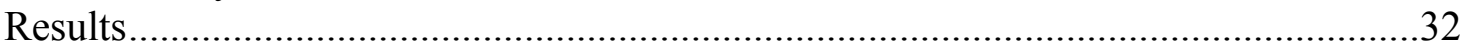

Comparison of Whisker Trajectories between WT and KO Mice.............................32

Maximum Velocity and Acceleration Comparison ………….....................................32

Whisking Frequency Comparison........................................................................35

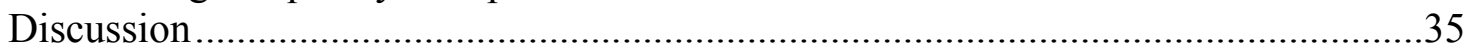

CHAPTER 5. ELECTROPHYSIOLOGICAL CHARACTERIZATIONS................39

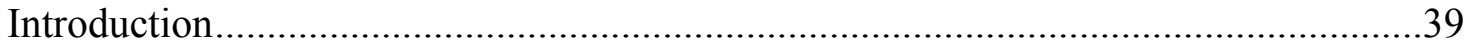

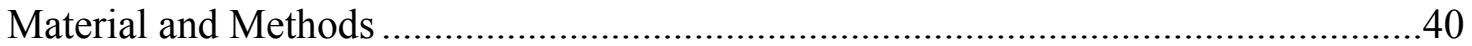

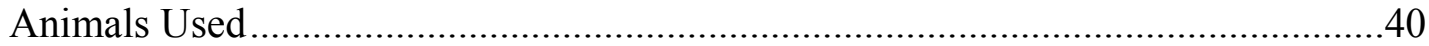

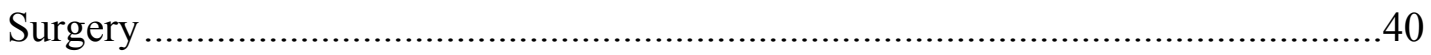

Training and Experimental Procedures...............................................................41

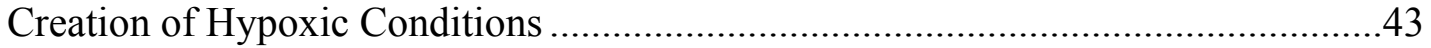

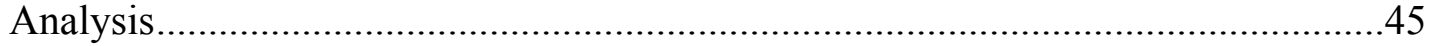

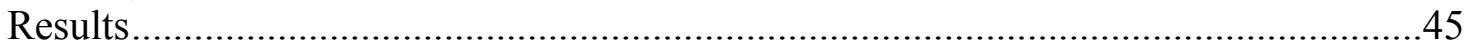

Relative Power of the LFP Signals in Different Frequency Bands ...........................45

Autocorrelation Analysis of LFPs in WT Mice ........................................................47

Relationship between Breathing and Delta Band Oscillation in LFP.......................47

Delta Rhythm in LFP during Normal Breathing and Elevated Breathing ..................47

Relationship between Breathing and Delta Band Oscillation in OB Mice .................47

Spike Frequency Analysis in WT and Fmr1 KO Mice ...............................................47

Rhythm Abnormalities in Fmr1 KO Mice .............................................................53

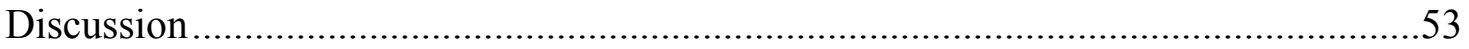

Relative Power of the LFP Signals in Different Frequency Bands ...........................53

Relationship between Respiration and $3 \mathrm{~Hz}$ Oscillation..........................................54

Role of Olfactory Bulb in Delta Band Oscillation.....................................................55

Abnormalities in Fmr 1 Brain and Its Impact on Spontaneous Firing ........................55

Rhythm Abnormalities in Fmr1 KO Mice ...........................................................56

CHAPTER 6. SUMMARY .........................................................................................58

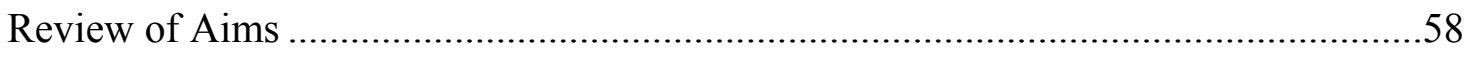

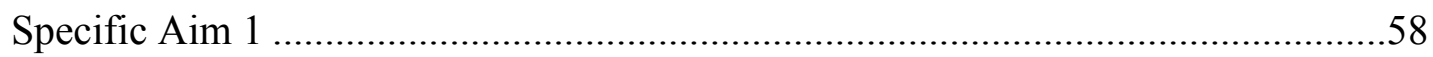

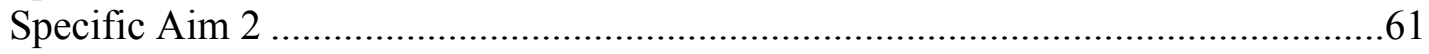

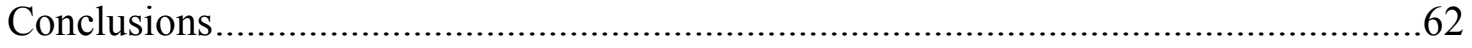

LIST OF REFERENCES..............................................................................................64

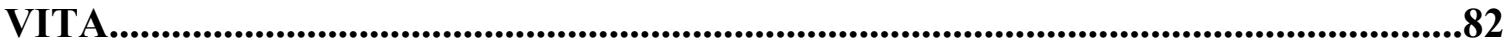




\section{LIST OF TABLES}

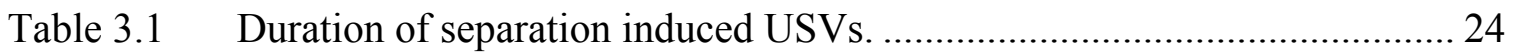

Table 4.1 Correlation coefficients of 3D bilateral whisker movement..................... 34 


\section{LIST OF FIGURES}

Figure 2.1 Experimental setup to measure lick events........................................... 9

Figure 2.2 Example of long term recordings of licking behavior of two WT mice.... 10

Figure 2.3 Rhythmic licking and water consumption behavior. .............................. 12

Figure 3.1 Arrangement to measure USVs. ......................................................... 18

Figure 3.2 Comparison of number of calls........................................................... 20

Figure 3.3 Peak frequency and frequency modulation of vocalizations. .................... 21

Figure 3.4 Duration of separation induced ultrasonic vocalizations......................... 22

Figure 3.5 Body weight comparison between WT and in Fmrl-KO mice. ................ 25

Figure 4.1 Arrangement of whisker tracking system. .......................................... 31

Figure 4.2 Different viewing angles for 3D reconstructions of whisker movements. . 33

Figure 4.3 Maximum velocity and acceleration of 3D whisker movement................ 36

Figure 4.4 Frequency comparison of 3D whisking in WT and KO mice. .................. 37

Figure 5.1 Experimental setup and evidence of electrophysiological study.............. 42

Figure 5.2 Raw data examples of spike and local field potential signals.................... 44

Figure 5.3 Relative power analysis of local field potential (LFP) signals. ................. 46

Figure 5.4 Auto-correlogram of local field potential (LFP) ..................................... 48

Figure 5.5 Relationship between respiration and delta band oscillation in LFP......... 49

Figure 5.6 Relation between breathing and LFP of WT mice................................. 50

Figure 5.7 Comparison of breathing-LFP relationship in WT and OB mice.............. 51

Figure 5.8 Spike frequency and spike characteristics analysis. ............................... 52 


\section{LIST OF ABBREVIATIONS}

\begin{tabular}{|c|c|}
\hline ADOS & Autism diagnostic observation scale \\
\hline ASD & Autism spectrum disorder \\
\hline $\mathrm{CV}$ & Coefficient of variation \\
\hline FMRP & Fragile $\mathrm{X}$ mental retardation protein \\
\hline FXS & Fragile $\mathrm{X}$ syndrome \\
\hline FXTAS & Fragile $\mathrm{X}$ associated tremor ataxia syndrome \\
\hline GP & Globus pallidus \\
\hline GS & Granule cells \\
\hline ILI & Inter-lick-intervals \\
\hline IVI & Inter-visit interval \\
\hline $\mathrm{KO}$ & Knock out \\
\hline LFP & Local field potentials \\
\hline mGluR & Metabotropic glutamate receptor \\
\hline $\mathrm{OB}$ & Olfactory bulb \\
\hline PD & Parkinson's disease \\
\hline $\mathrm{SE}$ & Standard error of the mean \\
\hline sIPSC & Spontaneous inhibitory postsynaptic currents \\
\hline USV & Ultrasonic vocalization \\
\hline WT & Wild type \\
\hline
\end{tabular}




\section{CHAPTER 1. INTRODUCTION}

\section{Purpose}

Fragile X syndrome (FXS) is a well-recognized form of inherited human mental retardation (Krueger et al. 2011). Clinical features include, anxiety (Katarzyna LesniakKarpiak et al. 2003), mental retardation (Feng et al. 1997) motor coordination (Koukoui and Chaudhuri 2007) and speech articulation deficits (Abbeduto et al. 2007; Barnes et al. 2006; Newell et al. 1983; Paul et al. 1987). Besides these phenotypic abnormalities, FXS patients are also characterized by a high incidence of cortical EEG abnormalities and seizure syndromes resembling benign childhood epilepsy with centrotemporal spikes, also known as "Rolandic" epilepsy (Berry-Kravis 2002; Berry-Kravis et al. 2010; Musumeci et al. 1994; Musumeci et al. 1999). These pathological findings indicate neural circuit dysfunction in a number of key brain regions, including the cerebral cortex, and in particular, imbalances in excitatory and inhibitory neurotransmission (Paluszkiewicz et al. 2011a). Neuronal network abnormalities and synaptic dysfunctions are proposed to play a central role in a number of brain disorders including FXS and autism spectrum disorder (ASD) (Belmonte and Bourgeron 2006; Rubenstein and Merzenich 2003; Zoghbi 2003).

The mouse model of FXS has been shown to replicate the cognitive deficits, neuroanatomical abnormalities and macroorchidism (Krueger, Osterweil, Chen, Tye, \& Bear 2011; Slegtenhorst-Eegdeman et al. 1998) found in human FXS. But it is not known whether the mouse models of FXS also display appendicular and oromotor deficits comparable to the ataxia and dysarthric speech seen in FXS patients. Study is also needed to investigate whether FXS mice suffer any abnormality in neuronal activity across the network and thus impair network function. No previous studies have used awake behaving animal models to find this answer.

\section{Background}

\section{Fragile X Syndrome}

Fragile X syndrome (FXS) affects approximately 1 in 4,000 males and 1 in 8,000 females (de Vries et al. 1997). In 1943, FXS was first described by the British physician James Purdon Martin and the British human geneticist Julia Bell, and was initially known as Martin-Bell syndrome. The gene responsible for FXS (called Fmrl) was discovered in 1991 (Fu et al. 1991; Kremer et al. 1991; Verkerk et al. 1991). At least 98\% of the cases of FXS are reported to be due to a mutation in which a DNA segment (CGG triplet repeats) is expanded within the Fmrl gene (Gunter et al. 1998). Normally this DNA segment is repeated from 5 to 40 times, while in people with FXS the CGG segment is repeated more than 200 times. The site of expansion on the $\mathrm{X}$ chromosome looks fragile when examined cytogenetically, so it is called "Fragile X syndrome". The abnormal 
expansion and hypermethylation of the CGG repeat segment turns off the Fmrl gene, and stops the production of fragile $\mathrm{X}$ mental retardation protein (FMRP).

The syndrome is characterized clinically by cognitive impairment, developmental delay, attention deficits, hyperactivity, anxiety, obsessive-compulsive behaviors, deficits in short-term memory and linguistic processing, poor motor coordination, heightened sensitivity to tactile irritation, and increased incidence of epilepsy (Koukoui \& Chaudhuri 2007). Autistic behaviors are found in $20-30 \%$ of FXS patients (Hagerman et al. 2005). Although FXS is a single gene disorder, it causes disruption of many cellular processes. Many cognitive disabilities in FXS likely result from altered neocortical functions. In human FXS, the brain is grossly normal but dendritic spines in cortical pyramidal cells and other neurons are longer, more tortuous, and immature in appearance (Hinton et al. 1991; Irwin et al. 2001; Rudelli et al. 1985).

\section{Emerging Roles of FMRP in FXS}

FMRP is widely expressed in adult and fetal tissues, with the highest expression in the brain and testis (Devys et al. 1993). It is mostly found in the cytoplasm, but a functional nuclear localization signal and a nuclear export signal have been identified in its sequence. This suggests that the protein might shuttle between the nucleus and the cytoplasm (Jin and Warren 2003). FMRP has a high RNA binding capacity and it is known to bind to RNA homopolymers and other brain transcripts in vitro (Ashley, Jr. et al. 1993). FMRP is found to make a complex with translating polysomes in an RNAdependent manner via messenger ribonuleoprotein particles (mRNP). FMRP regulates the translation of a subset of dendritic mRNAs into proteins (Santoro et al. 2012). A missense mutation in the RNA binding motif of FMRP prevents this polyribosome association, resulting in abnormal protein synthesis and severe mental retardation (Comery et al. 1997; Santoro, Bray, \& Warren 2012). This suggests that the association of FMRP with polyribosomes is functionally important for neuronal development.

The morphological changes in human brains due to FXS have long been studied. The dendritic spines of neocortical and hippocampal neurons are immature in FXS patients (Comery, Harris, Willems, Oostra, Irwin, Weiler, \& Greenough 1997). The same pattern was observed in FMRP knock-out mice (Wilson and Cox 2007). Dendritic spines on layer $\mathrm{V}$ pyramidal cells in occipital cortex were longer in fragile $\mathrm{X}$ knockout mice compared to wild-type mice. Moreover, the dendritic spines of the knockout mice were often thin and tortuous (Comery, Harris, Willems, Oostra, Irwin, Weiler, \& Greenough 1997). This suggests that FMRP expression is required for normal spine development. Recently, Lee et al. reported the first detailed 3D maps of the effects of the fragile $\mathrm{X}$ mutation on brain structure using tensor-based morphometry (TBM) (Lee et al. 2007). TBM visualizes the deficits of brain structure automatically, without time-consuming specification of regions of interest. They compared 36 FXS patients with 33 age-matched healthy controls. Statistical maps showed increased caudate and lateral ventricular volumes. In affected females, they found direct correlation between volume increase and reduction in systematic FMRP level. Decreased FMRP correlated with ventricular 
expansion suggests that FMRP plays a vital role in the formation of normal ventricular structure.

FMRP shows more than $60 \%$ similarity in amino acid sequence with its two autosomal homologs, fragile X-related proteins 1 and 2 (FXR1P and FXR2P)

(Kirkpatrick et al. 2001). FXR1P and FXR2P are localized in the cytoplasm and often interact with FMRP (Zhang et al. 1995). Due to their similarities, it was assumed that FXR1P and FXR2P may partially compensate for the loss of FMRP under fragile X conditions (Feng et al. 1995). However, the FXR2P level is not significantly altered in the absence of FMRP (Zhang et al. 2009) Furthermore, FXR1P and FXR2P are differently expressed than FMRP in many tissues during developmental stages. All three proteins have some common binding partners such as cytoplasmic Fmrl-interacting protein 2, whereas cytoplasmic Fmrl-interacting protein 1 specifically binds to FMRP. These findings suggest that although FXR1P and FXR2P are structurally close to FMRP, they may have different functions in the body (Zhang, Hou, Klann, \& Nelson 2009). Expression of FMRP is greater in neurons than glia and primarily found in the cytoplasm near rough endoplasmic reticulum.

\section{FMR1 KO Mouse, a Mouse Model of Fragile X Syndrome}

The fragile X (Fmrl KO) mouse was created by Dr. Ben Oostra of Erasmus University, Rotterdam (Bakker et al. 1994). To create these mice, a targeting vector containing a portion (exons 4-9) of the mouse Fmrl gene with a neo expression cassette inserted into exon 5 was transfected into embryonic stem cells. A positive clone was then injected into $\mathrm{C} 57 \mathrm{Bl} / 6 \mathrm{~J}$ blastocysts, which were transferred to pseudo pregnant female, and mutant mice were selected and verified. Fmrl KO mice do not express FMRP and they exhibit a number of cellular and behavioral phenotypes consistent with clinical manifestations in FXS patients. So, the development of the Fmrl KO mouse, has provided an animal model that can be used to investigate underlying neuro-physiological mechanisms associated with FXS.

Like FXS patients Fmrl KO mice are also characterized by the presence of immature, dysmorphic dendritic spines, as well as elevated spine density (Comery, Harris, Willems, Oostra, Irwin, Weiler, \& Greenough 1997; McKinney et al. 2005), consistent with the known role of FMRP in the regulation of translation of synaptic proteins, and thus, spine maturation.

Fmrl KO mice have a multifaceted phenotype; including mild learning deficits, increased locomotor activity, reduced habituation in open field assays (Huber 2006), and increased susceptibility to auditory seizures (Musumeci et al. 2000; Yan et al. 2004). These animals are also considered a possible model of autism (Bernardet and Crusio 2006). The principal findings have been the same in Fmrl KO mice created in FVB (Comery, Harris, Willems, Oostra, Irwin, Weiler, \& Greenough 1997; Irwin et al. 2002) and C57Bl/6 backgrounds (McKinney, Grossman, Elisseou, \& Greenough 2005; Yan, Asafo-Adjei, Arnold, Brown, \& Bauchwitz 2004). 
The Fmr1-KO is available on different genetic backgrounds (FVB versus C57BL/6). When I started working on this project, FVB mice were only available in the lab. FVB is a strain commonly used in transgenic experiments that carries two recessive mutations affecting vision. One is retinal degeneration (rd) which is due to a retroviral insertion into the cyclic guanosine monophosphate phosphodiesterase gene (Bowes et al. 1993). The other is albinism (tyr2c) which is due to a mutation that inactivates the tyrosinase gene (Kwon et al. 1987). But the mice that we got from Jackson Lab were made in such a way that they were unaffected by retinal degeneration. At the beginning, long term fluid licking assay was performed in FVB background. I also started my electrophysiology study in that background. Fmr1 KO mice are also available in another background C57BL/6(B6). There are some contradictory reports on the behavior of Fmr1 $\mathrm{KO}$ mice when studied in different genetic backgrounds. For example, Fmr1-KO mice have been reported to display enhanced (Spencer et al. 2005), normal (McNaughton et al. 2008; Mineur et al. 2002), or reduced levels of social interest and interaction (Mines et al. 2010; Mineur et al. 2006). Other study showed enhanced (Frankland et al. 2004; Nielsen et al. 2002; Qin et al. 2005; Zupan and Toth 2008), unchanged (Yan, Asafo-Adjei, Arnold, Brown, \& Bauchwitz 2004), or reduced (de Vrij et al. 2008) prepulse inhibition, accompanied by reduced (Frankland, Wang, Rosner, Shimizu, Balleine, Dykens, Ornitz, \& Silva 2004; Nielsen, Derber, McClellan, \& Crnic 2002; Qin, Kang, \& Smith 2005; Zupan \& Toth 2008) or unaltered (de Vrij, Levenga, van der Linde, Koekkoek, De Zeeuw, Nelson, Oostra, \& Willemsen 2008; Yan, Asafo-Adjei, Arnold, Brown, \& Bauchwitz 2004) startle reactivity. Not only the behavioral differences, studies have demonstrated that the Fmr1 mutation had opposite effects on the sizes of the hippocampal intra- and infrapyramidal mossy fiber terminal fields, depending on the background (Ivanco and Greenough 2002; Mineur, Sluyter, de, Oostra, \& Crusio 2002). In the occipital cortex significantly increased dendritic spine density observed in individuals with FXS (Irwin, Patel, Idupulapati, Harris, Crisostomo, Larsen, Kooy, Willems, Cras, Kozlowski, Swain, Weiler, \& Greenough 2001) and in adult Fmrl KO mice bred in a C57BL/6 background(McKinney, Grossman, Elisseou, \& Greenough 2005) did not reach statistical significance in Fmrl KO mice bred in an FVB background (Irwin, Idupulapati, Gilbert, Harris, Chakravarti, Rogers, Crisostomo, Larsen, Mehta, Alcantara, Patel, Swain, Weiler, Oostra, \& Greenough 2002). According to Mckinney (McKinney, Grossman, Elisseou, \& Greenough 2005), Fmrl KO mice bred in a C57BL/6 background may more closely model the human FXS condition than those bred in an FVB background. It appears that the genetic background modulated the effects of the Fmrl deletion. Like all other research groups (Pietropaolo et al. 2011) we also came to the conclusion that the C57BL/6 background may be more suitable for further research. So I performed rest of my study using Fmr1-OK mice on C57BL/6 background.

\section{Primary Somatosensory Cortex in Humans and Rodents}

The cerebral cortex is of primary importance in FXS, in the light of many phenotypes that are suggestive of cortical dysfunction, including cognitive impairment (Hagerman and Stafstrom 2009), sensory hypersensitivity (Miller et al. 1999), and elevated incidences of epileptic seizure syndromes (Berry-Kravis, Raspa, Loggin-Hester, 
Bishop, Holiday, \& Bailey 2010). The rodent primary somatosensory cortex is often referred to as the "barrel" cortex or whisker barrel cortex. The whisker barrel cortex is a highly organized structure that is visible in layer IV and comprises a somatotopic map of the whiskers on the contralateral snout (Woolsey and Van der Loos 1970). Sensory information flows from whiskers to cortex. Sensory fibres from the whisker follicle run to brainstem, which project to the contralateral thalamus, which in turn project to somatosensory cortex. Thalamic inputs synapse primarily onto neurons in layer IV, which in turn transmit information vertically and horizontally within the cortical structure. Diverse populations of inhibitory interneurons control the flow of excitation between cortical layers and across radial cortical columns via powerful and dynamic feedforward and feedback inhibition (Markram et al. 2004). Abnormally long, thin dendritic spines have been reported in pyramidal neurons during early development of the somatosensory cortex (Galvez and Greenough 2005; Nimchinsky et al. 2001). Spines are neuronal protrusions, each of which receives input typically from one excitatory synapse. They contain neurotransmitter receptors, organelles, and signaling systems essential for synaptic function and plasticity (Nimchinsky et al. 2002). Aberrant developmental pruning of the layer IV spiny stellate dendrites also has been described in Fmrl knockout mice (Galvez et al. 2003). So, it is crucial to test how the cellular alteration in barrel cortex of Fmrl KO mice affects normal cortical function.

Neural circuits require a precise balance of excitatory and inhibitory interactions among circuit elements to function normally. It is now well established that the normal excitatory/inhibitory balance is disrupted in the Fmrl KO mouse, including evidence for increased membrane excitability in excitatory neurons and decreased drive for local fastspiking inhibitory neurons in barrel cortex (Gibson et al. 2008). Diminished GABAergic neurotransmission has been demonstrated in the amygdala, including decreased glutamate dehydrogenase and decreased GABA availability in the cell and at the synaptic cleft (Olmos-Serrano et al. 2010). The overall effect of these imbalances is local circuit hyperexcitability, which is consistent with the high incidence of epilepsy, sensory hypersensitivity, and anxiety in patients with FXS (Pfeiffer and Huber 2009).

\section{Specific Aims}

Two specific aims will be addressed in this dissertation. The goal of this study is to establish whether the animal model of fragile $\mathrm{X}$ has symptoms similar to those found in human fragile $\mathrm{X}$ patients.

\section{Specific Aim 1}

The first aim of this dissertation is to test the hypothesis that loss of Fmrl expression in mice causes behavioral deficits that might be related to deficits observed in fragile $\mathrm{X}$ patients.

To address this problem, the following experiments will be performed: 
(1) Long term fluid licking analysis will compare the fluid licking patterns in terms of licking frequency and duration between $\mathrm{KO}$ and WT mice. This will be a potential approach to identify the oromotor deficits in $\mathrm{KO}$ mice, which is also prevalent in human patients with FXS.

(2) Ultrasonic vocalization (USV) analysis will measure the high pitch vocalization emitted by suckling mice as a measure of distress when they are separated from their mother. Any difference of USV between KO and WT mice could be correlated to the observed speech abnormalities in FXS children (Zajac et al. 2006).

(3) Whisker movement tracking will measure three-dimensional (3D) trajectories of bilateral whisker movements with the help of optical motion capture technology. 3D trajectories of vibrissae movements will give us some insights on how the orofacial sensory activities in $\mathrm{KO}$ mice are different from their WT littermates.

\section{Specific Aim 2}

The second aim of this study was to test the hypothesis that the cellular alteration in neocortical neurons affects the cortical network activity in fragile X mice, especially network synchronization and oscillatory neuronal activity.

Pyramidal neurons in the neocortex of Fmrl $\mathrm{KO}$ mice and human fragile $\mathrm{X}$ patients are characterized by abnormally long and numerous dendritic spines (Grossman et al. 2006). Spines are the site of excitatory synaptic contacts. The morphological anomalies may affect the spread of excitatory activities across the network and thus impair network functions. Multiple electrode recording technique was used to collect single unit as well as multi-unit spike data from 3 to 5 recording sites simultaneously in the whisker barrel cortex of awake mice. At the same time, local field potentials (LFPs) were also recorded using the same electrode. Correlation analysis was used to detect neuronal synchrony and oscillatory activity deficits, which would reveal whether these activities were compromised by the loss of Fmrl expression. 


\section{CHAPTER 2. LONG TERM FLUID LICKING STUDY*}

\section{Introduction}

Many children with FXS exhibit autistic behaviors and deficits in motor coordination including speech articulation deficits (Dobkin et al. 2000; Fiala et al. 2002; Koekkoek et al. 2005; Paradee et al. 1999; Yan, Asafo-Adjei, Arnold, Brown, \& Bauchwitz 2004). Swallowing difficulties are common in FXS patients, especially in later stages of fragile X associated tremor ataxia syndrome (FXTAS) (Hagerman et al. 2008). Based on the above findings, I hypothesized that oromotor coordination in the fragile $\mathrm{X}$ knockout mice is also disrupted. To test my hypothesis, I used a novel long-term fluid licking assay that measures various aspects of fluid licking behavior of fragile $\mathrm{X}$ and wild type mice.

\section{Methods}

\section{Animals Used}

Breeding pairs of FVB.129P2-Fmr $1^{\text {tm } I C g r} / \mathrm{J}$ mice were purchased from the Jackson Laboratory (stock \# 004624) and bred by pairing wild type males with heterozygous females in a conventional mouse vivarium at the University of Tennessee Health Science Center using harem breeding trios. Pups were kept with the dam until weaning at postnatal day 21 (P21). Juveniles were housed by gender in standard plastic cages not exceeding four per cage. All mice used in this study were raised and all experiments performed in accordance with procedural guidelines approved by the University of Tennessee Health Science Center Animal Care and Use Committee and outlined in Principles of Laboratory Animal Care (NIH publication No. 86-23, rev. 1996). Only male WT and Fmr 1-KO littermates were used for testing to avoid variability in behavioral performances because of mosaicism of the mutant allele due to X-inactivation or the estrous cycle in females. All the long-term lick experiments were performed with 7-15 weeks old mice (mean age $=11.994$ weeks, $\mathrm{SE}=0.392$ ). All mice were weighed before behavioral testing began and the body weights were compared between fmrl KO and WT mice. Behavioral testing was performed by investigators blinded to phenotype. After completion of behavioral tests, tails were collected from the animals and processed for genotyping (Transnetyx Inc., Cordova, TN).

"Adapted with permission from American Psychological Association Roy, Zhao, Allensworth, Farook, Ledoux, Reiter, \& Heck (2011b). Comprehensive motor testing in Fmr1-KO mice exposes temporal defects in oromotor coordination. Behav.Neurosci., 125 , (6) $962-969$. 


\section{Lick Data Collection}

Male Fmrl-KO mice $(\mathrm{N}=14)$ and their WT littermates $(\mathrm{N}=14)$ were singly housed in their home cage environment while spontaneous water licking behaviors were electronically monitored for an uninterrupted $72 \mathrm{~h}$ period as previously described (Heck et al. 2008). The normal 12:12 light/dark cycle continued as before (light: 6 am to $6 \mathrm{pm}$ ). Dark and light periods were registered in the same data file as licking data in the form of the voltage output from a photovoltaic cell. Mice had unrestricted access to food and water during the entire test period. The cages were modified to detect contact between the mouse's tongue and the waterspout based on the junction potentials (Hayar et al. 2006). The modifications included the placement of a metal wire mesh $(10 \times 15 \mathrm{~cm})$ on the floor underneath the waterspout to serve as an electrical reference (Figure 2.1). The size of the wire mesh was sufficient to ensure that the mouse had to stand on the mesh in order to access the waterspout. Mesh and waterspout were connected to ground and the signal input of a BNC connector socket of an analogue to digital converter (CED 1401, Cambridge Electronic Design, Cambridge, UK). During fluid-licking, each tongue-towaterspout contact resulted in a junction potential of $0.1-1 \mathrm{~V}$ amplitude that would last as long as the tongue-to-waterspout contact continued. The junction potential signals (Figure 2.2) were digitized at 1200-2000 Hz and stored on hard disk. Lick events were analyzed off-line using Spike2 software (Cambridge Electronic Design, Cambridge, UK). The following quantitative parameters were extracted from the licking data: 1) The mean duration of inter-lick-intervals (ILI) was used as a measure for the speed of the lick rhythm. Only ILI durations ranging from 40 to $250 \mathrm{msec}$ were included in the ILI statistical analysis in order to omit pauses between lick bursts and intervals between visits. 2) The coefficient of variation of the inter-lick-interval distribution (again limited to intervals between 40 and $250 \mathrm{msec}$ ) was used as a measure for the variability of the lick rhythm. 3) For a more comprehensive statistical comparison of ILI distributions that incorporate each individual ILI, we performed a log-rank survival analysis on 500 ILIs per animal using data from $5 \mathrm{WT}$ and $5 \mathrm{Fmrl}$-KO mice. Thus a total of 2500 ILIs from each group were analyzed. 4) The number of licks a mouse performed during each visit to the water spout was counted. A visit was defined as a single lick or a train of licks preceded by a lick free period of at least $60 \mathrm{sec}$. 5) The number of lick bursts per visit to the waterspout was counted. A lick burst was defined as a single lick or a train of licks preceded by a lick free period of at least $0.5 \mathrm{sec}$. 6) The number of licks per burst and 7) the distribution of inter-visit-interval durations were also determined. 8) Finally, as a measure for circadian changes in water consumption, the number of licks performed during the active dark and the less active light periods were counted and the ratios were calculated. For this analysis, 48 hours' data was used from 5 WT and 5 Fmrl-KO mice recorded during the same session.

\section{Statistical Analysis}

Statistical analyses to compare quantitative behavioral measures of WT and Fmrl-KO mice were performed using either SigmaStat (ver. 3.5, Systat, San Jose, CA) or 


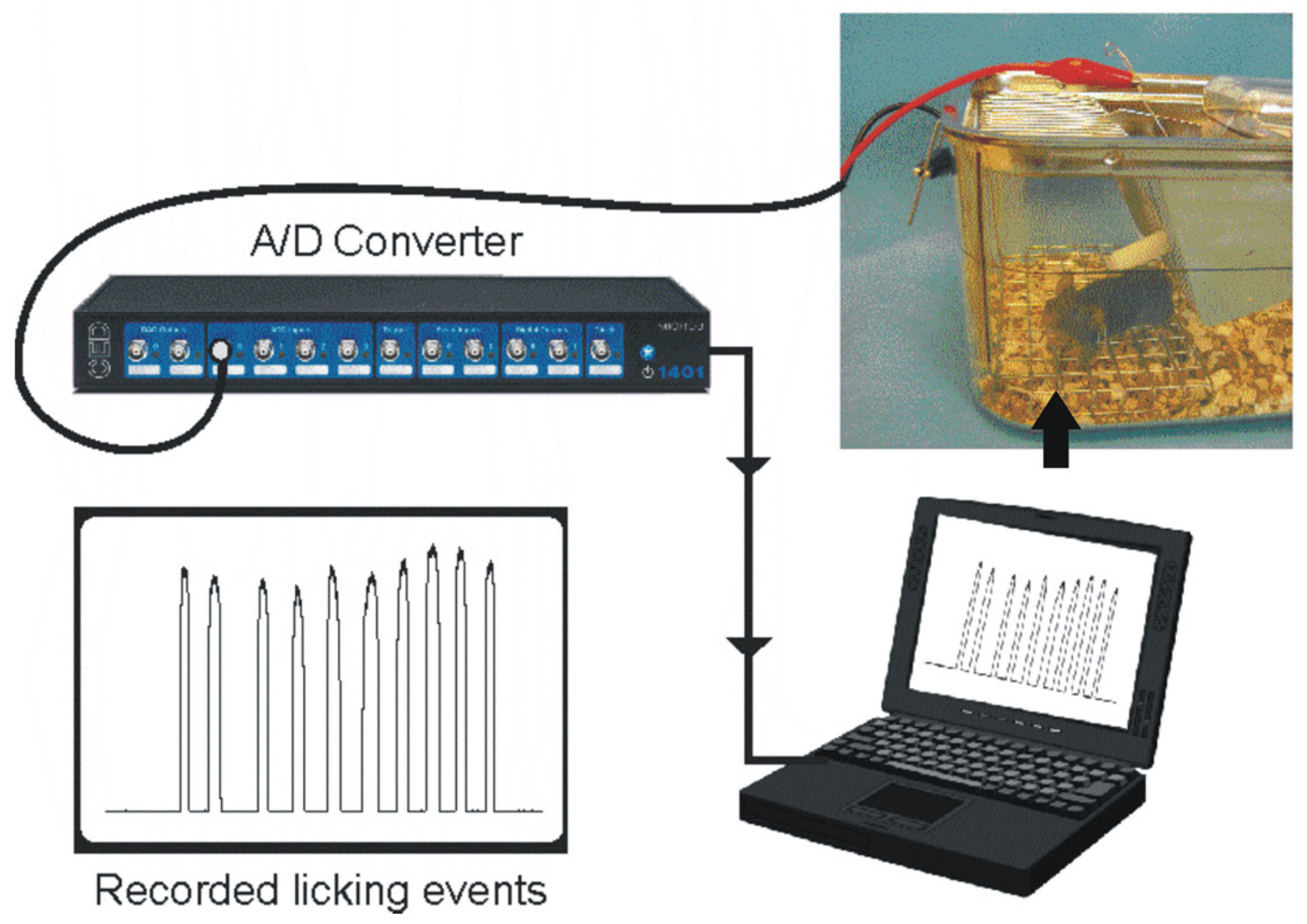

Figure 2.1 Experimental setup to measure lick events.

Schematic diagram showing the experimental setup to measure lick events in the home cage environment. The home cage was equipped with a metal grid (arrow) placed underneath the water spout on which the mouse must stand while drinking. A metal wire was pierced through the rubber stopper of the bottle till it touched water inside the bottle. The grid and wire were connected to the ground and core of a BNC input of an A/D converter. Whenever the mouse licked, it closed the electrical circuit, and a junction potential was developed between the metal wire and the water which was measured as lick signal. The water spout was made of plastic to reduce noise. 


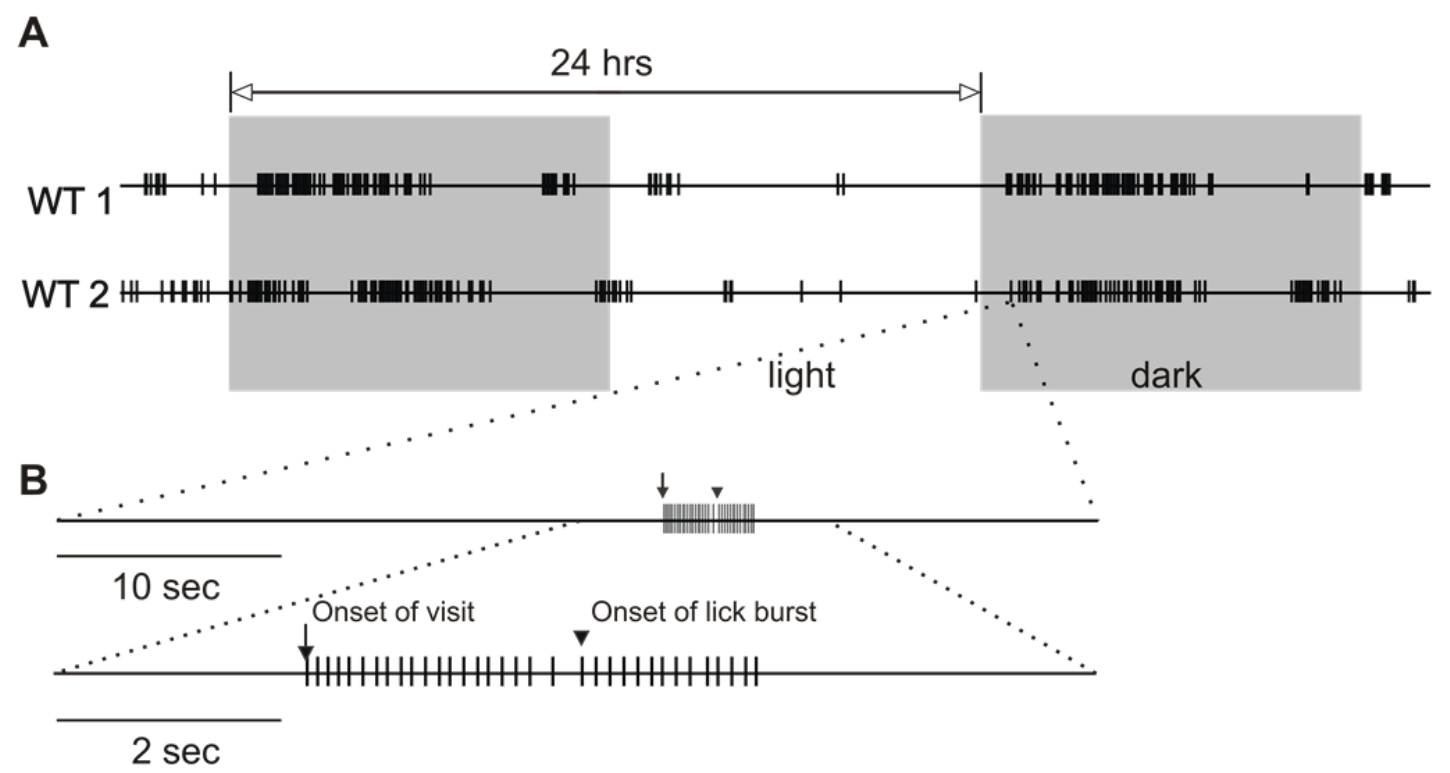

Figure 2.2 Example of long term recordings of licking behavior of two WT mice.

(A) Licking behavior was observed for 3 days, starting in the afternoon. Mice were singly housed in their standard home cages in a 12-12hr light-dark cycle. Gray fields indicate dark periods. Each horizontal trace in (A) and (B) represents the licking record of one mouse. Short vertical dashes represent licks. (B) Expanded views of visits to the waterspouts. Arrows indicate the onset of a visit; arrowheads indicate the onsets of lick bursts. 
SAS software (SAS Institute Inc., Cary, NC). Statistical significance $(\alpha)$ was set at $\mathrm{p} \leq 0.05$. Body weight was measured only once and this measurement was used to compare the two groups of mice with a one-factor analysis of variance (ANOVA).

Parameters derived from the long-term fluid-licking assay were analyzed using Student's $t$-test if the data were normally distributed and had equal variance. Those conditions were satisfied for inter-lick-interval duration, number of licks per visit, number of licks per burst, number of bursts per visit and number of licks during the day and night cycle. Mann-Whitney U-test was used to compare median values of inter-visitintervals. Log-rank survival analyses of inter-lick-interval (ILI) durations were performed on the first 500 licks from $5 \mathrm{WT}$ and $5 \mathrm{Fmrl}$-KO mice. Thus a total of 2500 ILIs per group were analyzed for differences in the probability of interval occurrence as a function of interval duration (i.e. "survival times").

\section{Results}

Fmr1-KO mice had significantly slower lick rhythms, i.e. longer inter lick interval (ILI) durations than their WT littermates (WT: mean ILI duration $=102.76 \mathrm{~ms}, \mathrm{SE}=$ 1.01; Fmr 1-KO: mean ILI duration $=107.98 \mathrm{~ms}, \mathrm{SE}=0.82$; Student's $t$-test: $t(26)=$ $3.99, p<0.001$ ) (Figure 2.3A). There was also a significant difference in the variability (i.e. coefficient of variation) of lick rhythms between WT and Fmrl-KO mice (WT: mean $\mathrm{CV}=0.20, \mathrm{SE}=0.01 ; F m r 1-\mathrm{KO}$ : mean $\mathrm{CV}=0.24$, SE $=0.01$; Student's $t$-test: $t$ $(26)=-3.20, p=0.005)$. Survival analysis (Figure 2.3C) revealed significantly different ILI survival probabilities between Fmrl-KO mice and their WT littermates $(\mathrm{p}<=0.001$ ).

On a longer time-scale, licking behavior was organized in visits to the waterspout. Visits were organized in bursts of licks, which could consist of anywhere between a few licks to more than 100 licks. There was no significant difference between Fmrl-KO and WT mice in the average number of licks generated per visit to the waterspout (WT: $\mathrm{M}=$ 49.37, $\mathrm{SE}=2.84 ; F m r l-\mathrm{KO}: \mathrm{M}=45.14, \mathrm{SE}=3.03$; Student's $t$-test: $t(26)=1.02, p=$ 0.317) (Figure 2.3B). Mice would typically generate several lick bursts during visits to the waterspout. There was no significant difference between Fmrl-KO and WT mice in the average number of bursts per visit (WT: $\mathrm{M}=5.75, \mathrm{SE}=0.56 ;$ Fmrl-KO: $\mathrm{M}=6.62$, $\mathrm{SE}=0.42$; Student's $t$-test: $t(26)=-1.26, p=0.22)$ or in the average number of licks per burst (WT: $\mathrm{M}=20.33, \mathrm{SE}=1.33 ; F m r 1-\mathrm{KO}: \mathrm{M}=18.03, \mathrm{SE}=1.74$; Student's $t$-test: $t$ $(26)=1.05, p=0.304)$. Intervals between visits could be several hours long, particularly during the mouse's inactive day-time hours. Comparison of inter-visit interval (IVI) distributions revealed no significance difference between median IVIs of Fmr 1-KO and WT mice (WT: median5.88; Fmrl-KO: median 5.82; U = 2929437.0, $n$ (big) $=2404$, $\mathrm{n}($ small $)=2483, p=0.264)$.

Both WT and Fmrl-KO mice showed a significantly higher number of licks during the dark period, i.e. when they were highly active, than during the light or resting period (WT: mean count light period 588.3, $\mathrm{SE}=101.9$, mean count dark period 1181.2, $\mathrm{SE}=219.4$; Student's $t$-test: $t(8)=-2.45, p=0.04$. Fmrl-KO: mean count light period 
A

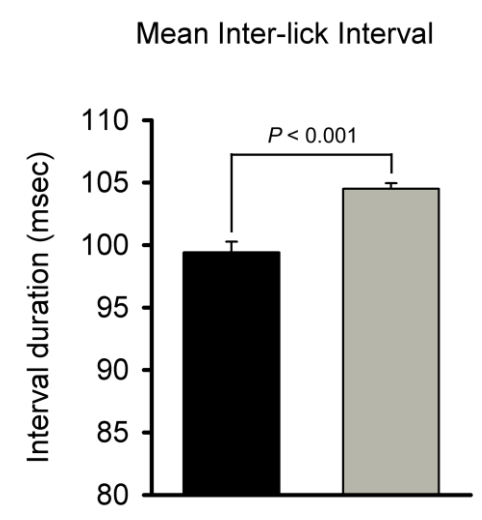

B

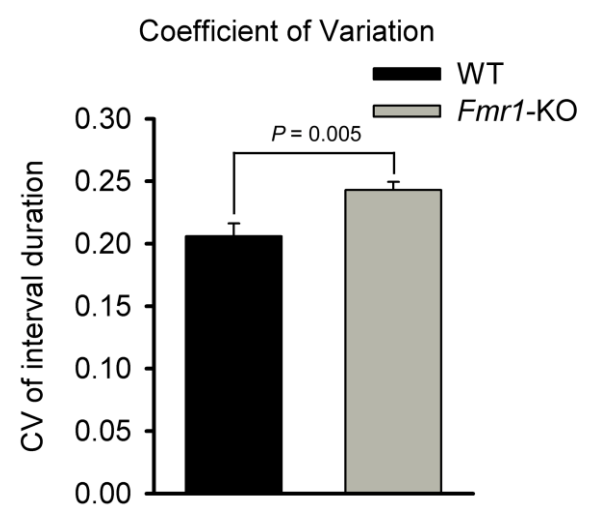

C

Log-rank Survival Analysis

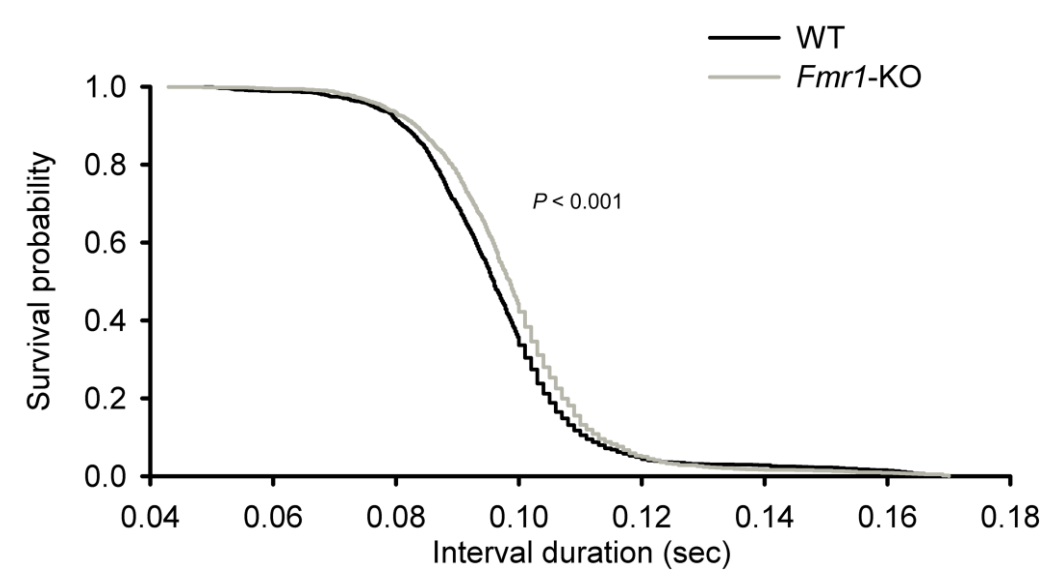

\section{Figure 2.3 Rhythmic licking and water consumption behavior.}

The rhythm of fluid-licking movements was significantly slower in Fmr l-KO mice but long-term aspects of fluid consumption behavior were similar in Fmr l-KO and WT mice. (A) The average ILI duration was significantly increased and hence the rhythm was significantly slower in Fmr 1-KO compared to WT littermates. (B) Variability in lick rhythm, as determined by the coefficient of variation (CV) of ILI, was higher in Fmr IKO mice compared to their WT littermates. Error bars in A and B represent the standard error of mean (SE). (C) Log-rank survival plot of mean ILI confirms that the licking rhythm is slower in Fmrl KO than WT mice using a statistical tool that takes all intervals into account, not just the mean values. Reprinted with permission from American Psychological Association Roy, Zhao, Allensworth, Farook, Ledoux, Reiter, \& Heck (2011b). Comprehensive motor testing in Fmr1-KO mice exposes temporal defects in oromotor coordination. Behav.Neurosci., 125, (6) 962-969. 
429.3, $\mathrm{SE}=112.1$, mean count dark period: $1279.0, \mathrm{SE}=208.13$; Student's $t$-test: $t(8)=$ $-3.59, P=0.007)$. There was no significant difference in light/dark lick-count ratios in WT and $F m r l-\mathrm{KO}$ mice (WT: $\mathrm{M}=0.54, \mathrm{SE}=0.12 ; F m r 1-\mathrm{KO}: \mathrm{M}=0.34, \mathrm{SE}=0.06 ; t$ $(8)=1.48, P=0.176$ ), indicating that the circadian rhythm of fluid consumption behavior was not affected by the Fmrl mutation.

\section{Discussion}

\section{Oromotor Function}

The main goal of this study was to examine whether a genetic mouse model of fragile X syndrome expresses oromotor deficits, which is commonly observed in FXS patients. Swallowing difficulties are common in FXS patients, especially in later stages of fragile $\mathrm{X}$ associated tremor ataxia syndrome (FXTAS) (Hagerman, Hall, Coffey, Leehey, Bourgeois, Gould, Zhang, Seritan, Berry-Kravis, Olichney, Miller, Fong, Carpenter, Bodine, Gane, Rainin, Hagerman, \& Hagerman 2008). We tested one type of orofacial behavior, fluid licking. Fluid licking in rats and mice is a highly stereotyped movement involving rhythmic protrusions and retractions of the tongue, and opening and closing of the jaw (Bryant et al. 2010). Licking constitutes an ideal behavioral paradigm for the study of motor control as it is a readily quantifiable natural behavior of rodents. Though there is no direct link between swallowing and licking, swallowing movements are known to be highly coordinated with fluid licking movements in rats. During licking fluid is accumulated in the oral cavity and swallowing occurs at irregular intervals every sixth to eighth lick (Weijnen et al. 1984). In the present work we have shown that mice lacking Fmrl expression have significantly slower rhythmic fluid-licking movements and increased variability in their lick rhythms compared to their WT littermates. This finding suggests that loss of Fmrl expression in mice might selectively affect brain circuits involved in rhythmic oromotor behavior.

A previous study on rhythmic licking behavior in the Ube $3 a$ deficient mouse model of Angelman syndrome also revealed a significantly slower licking rhythm in Ube3a deficient mice compared to WT mice (Heck, Zhao, Roy, LeDoux, \& Reiter 2008). This finding is consistent with the suggestion by Zhao et al. that these two disorders (FXS and Angelman syndrome) share behavioral and molecular characteristics and results from a common cerebellar neuropathology (Zhao et al. 2007).

\section{A Possible Neuronal Substrate for Oromotor Deficits}

The neuronal mechanisms controlling human speech articulation or mouse oromotor function are poorly understood. However, several lines of evidence suggest that the cerebellum plays an important role in oromotor behavior in both species. Licking, swallowing, suckling and breathing movements are controlled by a brainstem central pattern generator (Cifra et al. 2009; Nistri et al. 2006; Travers et al. 1997). Projections 
from the cerebellar nuclei to the brainstem, including the areas containing licking, swallowing and respiratory pattern-generating circuits provide a possible anatomical substrate for a cerebellar coordination of brainstem pattern generators (Asanuma et al. 1983; Teune et al. 2000). In rats and mice, rhythmic fluid-licking behavior is widely represented in the cerebellum (Bryant et al. 2010; Vajnerova et al. 2000; Welsh et al. 1995). Welsh and colleagues suggested that the olivo-cerebellar system would be essential for controlling the timing of licks (Welsh, Lang, Suglhara, \& Llinas 1995). Two different groups have shown that pharmacological inactivation of the deep cerebellar nuclei causes a significant reduction of licking frequencies in mice and rats (Bryant, Boughter, Gong, Ledoux, \& Heck 2010; Vajnerova, Zhuravin, \& Brozek 2000). Hence, our present data of altered lick rhythm pattern in Fmr1 KO mouse is consistent with the above finding. Altered cerebellar anatomy has been shown to be associated with Fmrl deficiency. Using imaging techniques, investigators have found significantly reduced sizes of two deep cerebellar nuclei (medial and interpositus) in Fmrl-KO mice (Ellegood et al. 2010). We predict that our observed altered licking pattern in Fmrl KO mouse may be due the reduced volumes of deep cerebellar nuclei.

The cerebellum is well known to play a crucial role in speech articulation (Spencer and Slocomb 2007). Cerebellar neuropathologies are consistently found in human fragile X patients (Mostofsky et al. 1998; Zingerevich et al. 2009). Speech articulation deficits are common problem in FXS patients (Abbeduto, Brady, \& Kover 2007; Barnes, Roberts, Mirrett, Sideris, \& Misenheimer 2006; Newell, Sanborn, \& Hagerman 1983; Paul, Dykens, Leckman, Watson, Breg, \& Cohen 1987) suggests that the ormotor deficits in Fmr I-KO mice described here and the speech articulation deficits in fragile $\mathrm{X}$ patients might have common neuronal causes associated with cerebellar dysfunction.

\section{Circadian Rhythm}

Sleep abnormalities are frequently diagnosed in FXS patients but the level of severity varies widely (Hagerman et al. 2002). Our data show no difference in the circadian rhythmicity of fluid-licking behavior between WT and Fmr 1-KO mice. Both groups had significantly higher counts of licks during the dark compared to the light periods and the ratios of light and dark period lick counts were not significantly different between WT and Fmrl-KO mice. Thus we detect no difference between Fmrl-KO and WT in the circadian rhythmicity of fluid-licking. This is consistent with the results of Zhang et al. (2008), who studied circadian rhythmicity in fragile-X related single and double mutants. The human Fmrl gene has two paralogs in mice, the Fmrl and Fmr2 genes. Zhang and colleagues monitored running activities in Fmrl-KO, Fmr2-KO, Fmrl/Fmr2 double $\mathrm{KO}$ and $\mathrm{Fmrl}-\mathrm{KO} / \mathrm{Fmr} 2$ heterozygous mice over a $48 \mathrm{hr}$ period in a 12:12 light/dark cycle, and reported a complete absence of circadian rhythmicity in locomotor activities in the Fmrl/Fmr2 double knockout and Fmrl-KO/Fmr2 heterozygous mice. Fmrl-KO and Fmr2-KO mice had normal circadian locomotor activities when kept in a 12:12 light/dark cycle but displayed a shorter free-running period of running activity when kept in total darkness. Our Fmrl-KO mice were kept in a 
12:12 light/dark cycle while we were monitoring their licking behaviors. It is possible that they would show a shorter free-licking period of licking activity if kept in complete darkness. Our conclusion about a normal circadian rhythmicity in licking behavior is thus limited to the 12:12 light/dark cycle conditions that we tested. 


\section{CHAPTER 3. ULTRASONIC VOCALIZATION STUDY ON NEONATES}

\section{Introduction}

FXS affects approximately $1 / 4000$ males and about $1 / 8000$ females and the phenotypes are usually more apparent in males than in females (Crawford et al. 2001). Due to the mosaicism of the $\mathrm{x}$-linked mutation, symptoms are typically milder in females. Most male fragile X patients have moderate to severe delays in the onset of speech and language. Articulation deficits are found in both male and female FXS patients, (Loesch and Hay 1988; Madison et al. 1986). Males with FXS do not articulate significantly faster than chronological age (CA)-matched males but use significantly shorter utterances and have tendencies to pause less often than CA-matched males (Zajac, Roberts, Hennon, Harris, Barnes, \& Misenheimer 2006). Speech articulation problems impact social communication in these patients because the generation of socially meaningful spoken language includes the ability to modulate tone, volume and prosody (ups and downs of the voice). Approximately $30 \%$ of male FXS patients also have autism, as determined by the standardized criteria of the Autism Diagnostic Observation Scale (ADOS) and the Autism Diagnostic Interview (ADI-R) (Hagerman et al. 2010; Harris et al. 2008; Rogers et al. 2001). An additional $30 \%$ of boys have pervasive developmental disorder, not otherwise specified (PDD-NOS) (Hagerman, Hoem, \& Hagerman 2010). Among the remaining patients with FXS, of those who do not meet the criteria for an autism spectrum disorder (ASD), the majority have one or more autistic features (Hagerman, Hoem, \& Hagerman 2010).

Mice begin vocalizing shortly after birth, with a peak in vocalization rates occurring around postnatal day 8 (P8). They continue vocalizing, albeit at reduced rates, throughout adulthood (Shair 2007). Here, I hypothesized that the ultrasonic vocalizations (USVs) in pups of Fmrl-KO mice will be qualitatively different from the WT mice. USV emission is one of the major modes of mouse social communication (Wohr et al. 2011b). Reduced levels of calling or unusual calling patterns have been reported in several mouse models of autism spectrum disorders (Fujita et al. 2008a; Scattoni et al. 2009; Scattoni et al. 2011; Wohr et al. 2011a), which could be indicative of communication impairments.

Mouse pups produce a number of different shapes/categories of USVs when they are separated from their mother and siblings (Scattoni et al. 2008). Scattoni and colleagues (Scattoni, Gandhy, Ricceri, \& Crawley 2008) classified individual pup calls into 10 categories (Complex, Flat, Frequency Steps, Composite, Shorts, Chevron, Downward, Upward, Two-syllable and Harmonic). Their classification scheme was used in the present study to categorize and compare pup vocalizations of Fmrl-KO and WT mice. We found specific qualitative and quantitative deficits in the production of isolation-induced USVs in pups of Fmrl-KO mice compared to their wild type litter mates. 


\section{Material and Methods}

\section{Animals Used}

Breeding pairs of B6.129P2-Fmrltm $1 \mathrm{Cgr} / \mathrm{J}$ mice were purchased from Jackson Laboratory (stock \# 003025) and were bred by pairing wild type males with heterozygous females in a conventional mouse vivarium at the University of Tennessee Health Science Center using harem breeding trios. Pups were kept with the dam until weaning at Postnatal Day 21 (P21). Juveniles were housed by gender in standard plastic cages not exceeding four per cage. All mice used in this study were raised and all experiments performed in accordance with procedural guidelines approved by the University of Tennessee Health Science Center Animal Care and Use Committee Principles of Laboratory Animal Care (NIH publication No. 86-23, rev. 1996) were followed. Only male WT and Fmrl-KO littermates were used for testing to avoid variability in behavioral performances because of mosaicism of the mutant alleles due to Xinactivation in females. All experiments were performed with 8-day-old pups (6 WT, 6 $\mathrm{KO})$. All mice were weighed before behavioral testing began and the measurements were used for statistical comparison of body weights between Fmrl-KO and WT mice. Behavioral testing was performed by investigators blinded to phenotype. Recordings were performed during afternoon sessions $(1-5 \mathrm{pm})$ held constant across mice. After completion of behavioral tests, small pieces of tails were collected from the animals and processed for genotyping (Transnetyx, Inc, Cordova, TN).

\section{Experimental Setup}

For USV recording of social calls (Yang et al. 2007), 8 day old pups were separated from their mothers and placed inside a sound attenuating styrofoam box (Figure 3.1). The box had an ultrasound microphone in the center of the lid about $10 \mathrm{~cm}$ above the floor. Vocalization was recorded over a 3 minute period using an ultrasoundrecording system (Avisoft Bioacoustics, Berlin, Germany). We evaluated the number of calls generated during the 3 minute observation period and the duration of calls. Power spectral density analysis was used to determine the frequency at peak power of each call. Average values of all parameters were calculated for each mouse and used for the statistical comparison of Fmrl-KO and wild-type mice. Analysis was performed offline using the Avisoft SASLab Pro software (Avisoft Bioacoustics, Berlin, Germany).

\section{Statistical Analysis}

Statistical analyses to compare USVs of WT and Fmr l-KO mice were performed using SigmaStat (ver. 3.5, Systat, Sanjose, CA) software. Statistical significance $(\alpha)$ was set at 0.05. Error bars were given as standard error of mean (SE). For statistical comparison an average was calculated from 10 calls of each category of mouse. As the data were normally distributed, student's t-test was used for analysis. 


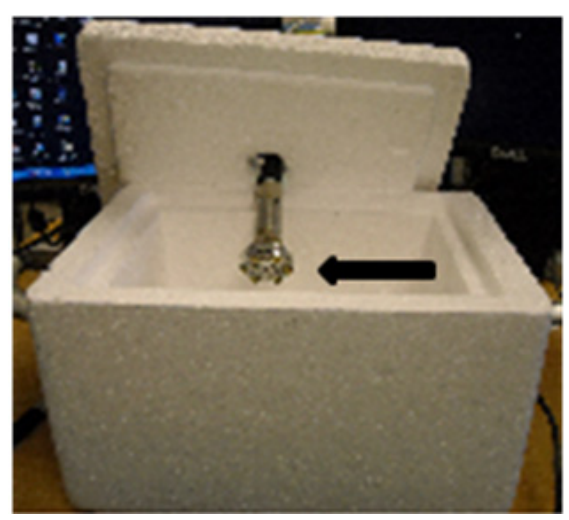

Figure 3.1 Arrangement to measure USVs.

Photograph showing the arrangement to measure USVs. Arrow indicates an Avisoft ultrasonic vocalization detector microphone mounted above a Styrofoam box where USV was recorded from 8 day old mouse pups after isolating it from its mother and littermates. 


\section{Results}

USV calls were classified into 10 types (Complex, Flat, Frequency Steps, Composite, Shorts, Chevron, Downward, Upward, Two-syllable and Harmonic) according to the classification scheme proposed by Scattoni et al. (Scattoni, Gandhy, Ricceri, \& Crawley 2008). Based on this classification three deficits in USV calls were identified in pups of Fmrl KO mice.

\section{Comparison of Number of Calls}

The number of downward call emissions was reduced in Fmrl-KO mice compared to their WT littermates. While the percentage of downward calls in pups of WT mice amounts to almost $1 / 3$ of all calls, that fraction was less than $12 \%$ in pups of Fmrl-KO mice. (WT: N=6, mean \% downward call $=29.79, \mathrm{SE}=3.72 ;$ Fmrl-KO: N=6, mean $\%$ downward call $=11.26, \mathrm{SE}=1.94$; Student's $t$-test: $t(10)=4.416, p=0.001)$ (Figure 3.2).

\section{Comparison of Carrier Frequency in Flat Calls}

To compare the average carrier frequencies of calls, only flat calls were compared, because this category of calls maintains a single carrier frequency throughout the call. This data shows that the average carrier frequency of flat calls emitted by KO mice was significantly higher than in WT animals (WT: $\mathrm{N}=6$, median $82.40 \mathrm{~Hz} ; \mathrm{Fmrl}$ $\mathrm{KO}$ : $\mathrm{N}=6$, median $91.4 \mathrm{~Hz} ; \mathrm{U}=0.00001, n(\mathrm{big})=6, \mathrm{n}(\mathrm{small})=6, p$ (exact) $=0.008)$

(Figure 3.3A).

\section{Comparison of Frequency Modulation in Complex Calls}

In order to analyze the frequency modulation of calls, i.e. the width of the frequency band covered by frequency modulation within calls, the differences between the lowest and the highest frequency within calls were measured (Wohr, Roullet, \& Crawley 2011a; Wohr, Roullet, Hung, Sheng, \& Crawley 2011b). For this purpose only complex calls were analyzed as these types of calls show the most prominent frequency modulation. Call frequency modulation was significantly increased in complex calls of Fmrl-KO compared to WT pups (WT: n=6, mean $=27.060 \mathrm{~Hz}, \mathrm{SE}=1.569 ;$ Fmr 1-KO: $\mathrm{n}=6$, mean $33.193 \mathrm{sec}, \mathrm{SE}=1.810$; Student's $t$-test: $t(10)=-2.560, \mathrm{p}=0.034)$ (Figure 3.3B).

\section{Duration of Calls}

Durations of calls were measured for complex, upward, downward, chevron, shorts, composite and flat calls (Figure 3.4). There was no effect of genotypes on the 


\section{Relative frequency of different calls}

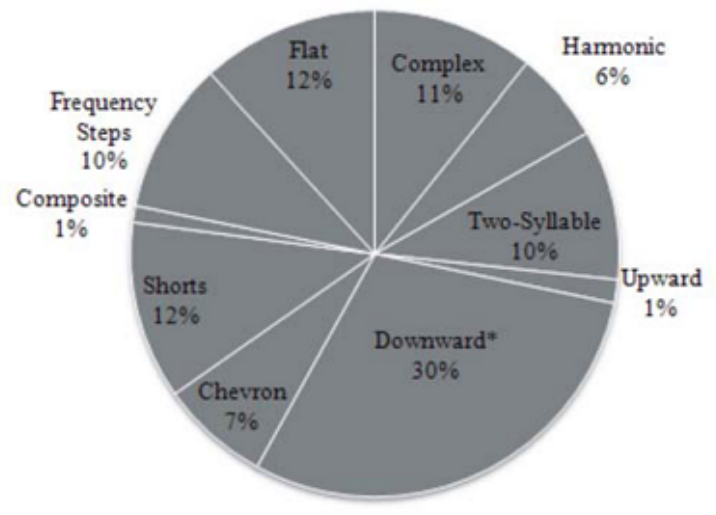

WT

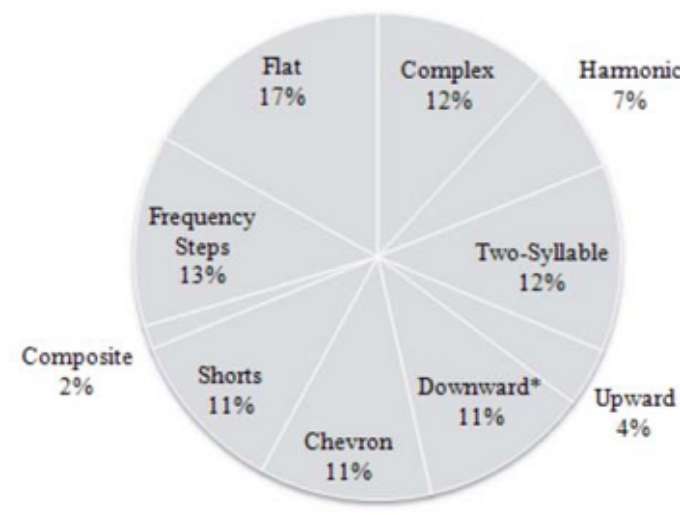

KO

\section{Figure 3.2 Comparison of number of calls.}

Pie graphs show the percentages of the different call categories within the genotype. Percentages were calculated in each genotype as: (number of calls in each category for each subject/total number of calls analyzed in each subject) X 100. Percentage of downward calls produced by KO animals were significantly lower compared to the WT animals. 

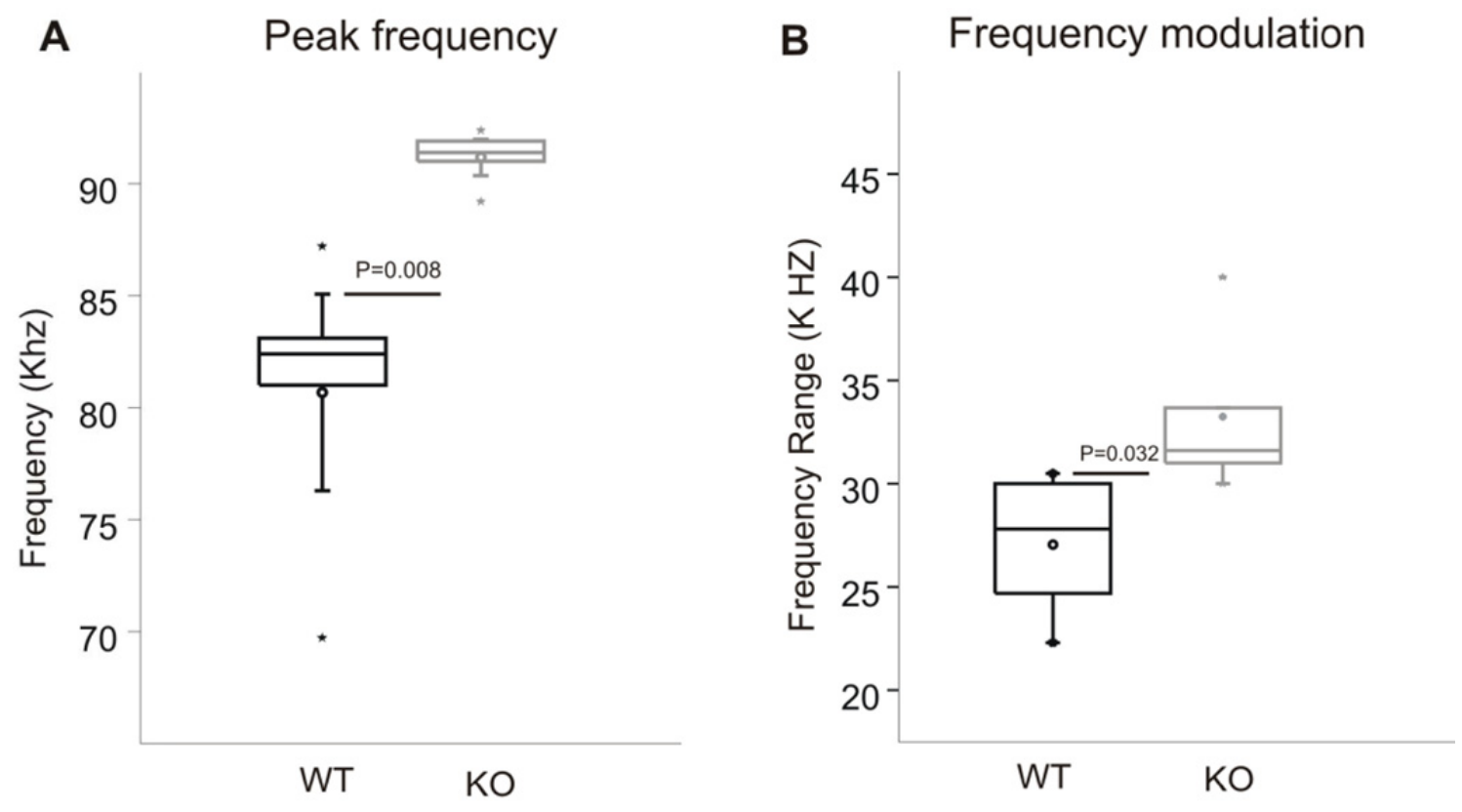

Figure 3.3 Peak frequency and frequency modulation of vocalizations.

(A) Box plot showing the mean carrier frequency of flat calls (open circle) together with the $25^{\text {th }}$ to $75^{\text {th }}$ percentile (box height) and median (horizontal line). Asterisks at the top and bottom indicate 99 and 1 percentile, respectively. Error bars represent standard error of mean (SE). Mean carrier frequency was calculated from first ten flat calls during isolation. Black box: WT littermate control mice; gray box: Fmrl-KO. (B) Box plot as in (A) but showing the mean range of frequency modulation of complex calls Black box: WT littermate control mice; gray circles: Fmrl-KO. Dashes (-) are for minimum and maximum value. 


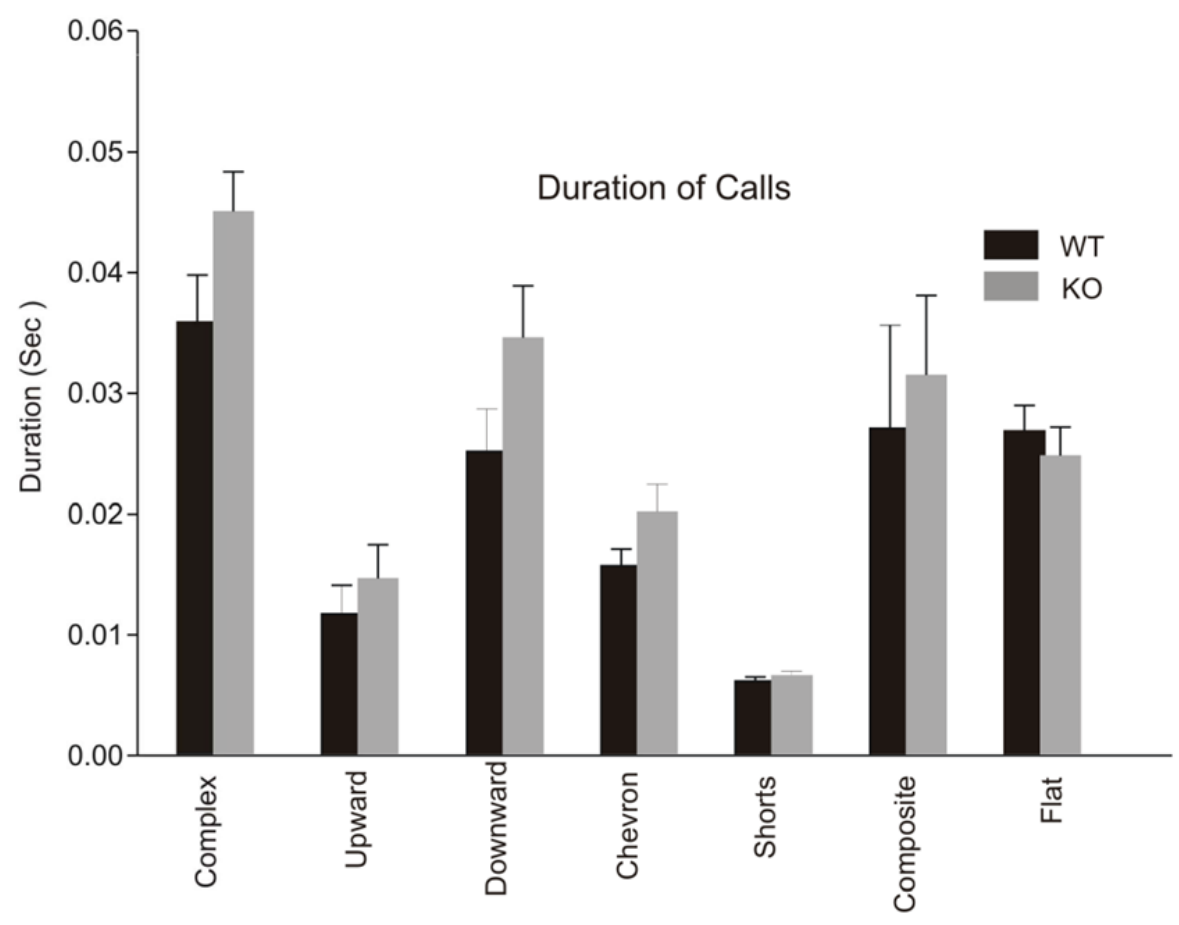

Figure 3.4 Duration of separation induced ultrasonic vocalizations.

The average duration measurements were obtain from 6 mice of each genotype, averaging 10 calls of each category per mouse. Black bar: WT littermates; gray bar: Fmrl-KO mice. Error bars represent standard error of mean (SE). There was no significant difference in the duration of any call type between the genotypes. 
duration of calls for any of those call subtypes (Table 3.1).

\section{Body Weight}

The body weights of mouse pups tested for isolation induced USV calls were not significantly different between genotypes $(\mathrm{t}(20)=-1.864 ; \mathrm{P}=0.076)$ (Figure 3.5) but there was a trend for Fmrl-KO pups to be heavier than their wild type litter mates. Body weight was not correlated with the number of USV emitted $(r=0.353, p=0.287)$.

\section{Discussion}

Our findings revealed call-type specific deficits in the production of isolation induced USVs in Fmrl-KO mouse pups, a mouse model of FXS. The 8 day old Fmr 1KO pups emitted fewer downward calls compared to their WT littermates while the percentages of all other call types were similar in both genotypes. Scattoni et al (Scattoni, Gandhy, Ricceri, \& Crawley 2008) performed a similar study on the BTR $\mathrm{T}+\mathrm{tf} / \mathrm{j}$ (BTBR) mouse strain that displayed social abnormalities and repetitive behaviors analogous to the first and third diagnostic criteria of autism. They compared BTBR mice with multiple standard strains including $\mathrm{C} 57 \mathrm{BL} / 6 \mathrm{~J}, \mathrm{FVB} / \mathrm{NJ}$ and $129 \mathrm{X} 1$, and found that 8 day old BTBR pups produced the highest number of calls compared to all other strains. In BTBR mice, $3 \%$ of all calls were downward calls compared to $14 \%$ downward calls in $\mathrm{C} 57 \mathrm{BL} / 6 \mathrm{~J}$ mice, a strain with a high level of social interaction. Thus, a reduced number of downward calls produced by knockout out pups might be correlated to their altered social behaviors. However, more mouse models with different levels of altered social behaviors need to be examined to test whether this altered pattern in USVs is useful as a phenotypic signature of social interest or interaction in mouse models of autism spectrum disorders.

There was no genotypic difference in the duration of calls between Fmrl-KO and WT pups. There are reports of longer (Scattoni, Gandhy, Ricceri, \& Crawley 2008; Young et al. 2010a) and shorter duration of calls produced by different mouse models of autism. Call duration is socially relevant as the mother's behavioral response requires minimal call duration. Smith et al. (Smith 1976) showed that mothers preferred a call with $80 \mathrm{~ms}$ duration over a call with $15 \mathrm{~ms}$ duration. Ehret et al (Ehret 1992) found that mothers responded to calls with durations higher than $30 \mathrm{~ms}$, but not to shorter ones. Thus, based on their call durations Fmrl-KO mice are not expected to be at a disadvantage in eliciting the mother's response through USVs.

The average carrier frequency of flat calls emitted by KO mice was higher compared to their WT littermates. It is unclear if this change has an effect on the retrieval behavior of the mother. Mouse pup calls incorporate some properties that suggest they could serve some of the same functions as the crying of human babies, especially their abilities to elicit parental retrieval behaviors (Brouette-Lahlou et al. 1992; Brunelli et al. 1994; Ehret G 1986; Farrell and Alberts 2002; Hahn and Lavooy 2005). Researchers have 
Table 3.1 Duration of separation induced USVs.

\begin{tabular}{cccc}
\hline Call Types & $\begin{array}{c}\text { WT } \\
\text { Mean } \pm \text { Std Dev }\end{array}$ & $\begin{array}{c}\text { KO } \\
\text { Mean } \pm \text { Std Dev }\end{array}$ & $\begin{array}{c}\text { P } \\
\text { Value }\end{array}$ \\
\hline Complex & $0.036 \pm 0.009$ & $0.045 \pm 0.008$ & 0.103 \\
Upward & $0.012 \pm 0.005$ & $0.015 \pm 0.006$ & 0.464 \\
Downward & $0.025 \pm 0.009$ & $0.035 \pm 0.011$ & 0.121 \\
Chevron & $0.016 \pm 0.003$ & $0.020 \pm 0.005$ & 0.118 \\
Short & $0.006 \pm 0.001$ & $0.006 \pm 0.001$ & 0.374 \\
Composite & $0.027 \pm 0.028$ & $0.032 \pm 0.015$ & 0.783 \\
Flat & $0.027 \pm 0.005$ & $0.025 \pm 0.025$ & 0.536 \\
\hline
\end{tabular}




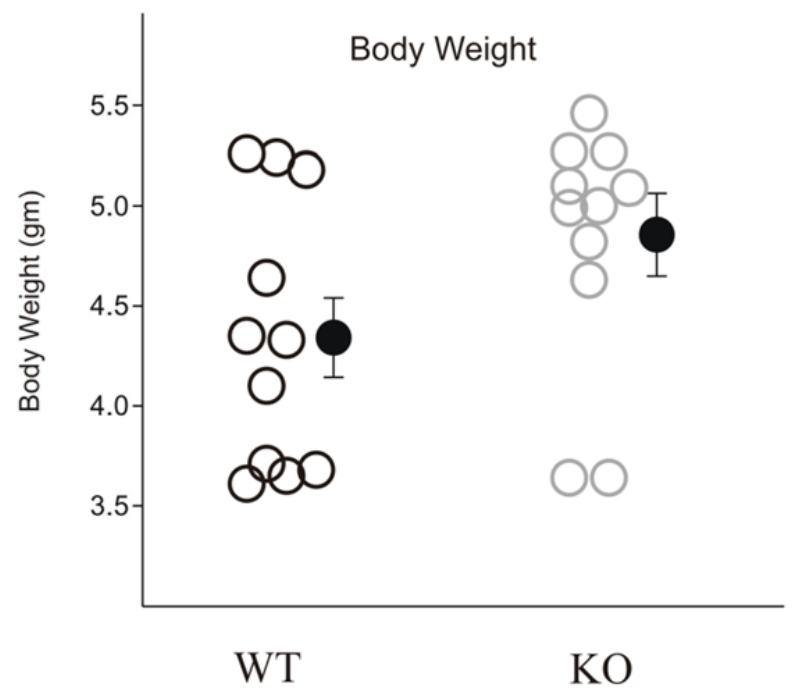

Figure 3.5 Body weight comparison between WT and in Fmr1-KO mice.

Body weights of pups were measured on post natal day eight. Black circles: WT littermates; Gray circles: Fmrl-KO mice. Error bar represents the standard error of mean (SE). 
been able to differentiate 80 measures of human infant crying, but frequency or pitch turned out to be the most important variable in facilitating adult recognition of infant needs (Zeskind 1988). Subjects who were later diagnosed with autism emitted higher pitched cries than those subjects with typical or delayed development, and autistic children's cries elicited greater negative states in their listeners (Young et al. 2010b). Whether the elevated pitch in cries of autistic infants and in flat USV calls of Fmrl-KO mice are functionally related or caused by related changes in neuronal control mechanisms remains to be shown.

Calls emitted by Fmr1-KO mice were frequency modulated over wider frequency ranges than calls emitted by WT pups. Brudzynski et al (Brudzynski et al. 1999) postulated that the degree of frequency modulation could be important for the efficacy of maternal search and retrieval behavior. According to Wohr et al. (Wohr, Roullet, Hung, Sheng, \& Crawley 2011b) it may be easier for the mother to detect and localize a high frequency modulated call than a steady sound at a constant frequency. In humans, the SHANK gene family has been associated with autism (Abrahams and Geschwind 2008; Persico and Bourgeron 2006). Wohr and colleagues found isolation induced USV calls emitted by pups of Shank $1^{-/-}$mutant mice to be less frequency modulated than the calls of their WT littermates. This is in contrast to our findings that pups of Fmrl-KO mice have increased frequency modulation compared to their WT littermates, a difference that remains to be explained. Linking the specific USV differences reported here and in other studies to specific neuronal or genetic mechanisms will require more in-depth studies. Currently, USV analysis of mouse models of autism spectrum disorders are still in their infancy.

Body weight has been speculated to affect USVs, e.g. through differences in lung capacity (Scattoni, Gandhy, Ricceri, \& Crawley 2008). Here we can exclude an effect of bodyweight on our results as there was no difference in body weight at the time of testing between Fmrl KO and WT mice.

The neuronal mechanisms controlling human speech articulation and mouse oromotor/ vocalization behavior are poorly understood. Several lines of evidence suggest that the cerebellum may play an important role in oromotor and vocalization/ articulation in both species. In mice, the cerebellum has been shown to be critically involved in the generation of ultrasonic vocalizations (Fujita et al. 2008b). In humans, speech articulation deficits (dysarthria) are common in patients with cerebellar disorders (Gordon 1996). Cerebellar neuropathologies, which are consistently found in fragile X patients (Mostofsky, Mazzocco, Aakalu, Warsofsky, Denckla, \& Reiss 1998; Zingerevich, GreissHess, Lemons-Chitwood, Harris, Hessl, Cook, \& Hagerman 2009), might be partially responsible for speech articulation deficits in FXS patients (Abbeduto, Brady, \& Kover 2007; Barnes, Roberts, Mirrett, Sideris, \& Misenheimer 2006; Newell, Sanborn, \& Hagerman 1983; Paul, Dykens, Leckman, Watson, Breg, \& Cohen 1987). In previous studies we found oromotor deficits in a Ube3a deficient mouse model of Angelman syndrome (Heck, Zhao, Roy, LeDoux, \& Reiter 2008) and in Fmrl KO mice (Roy et al. $2011 b)$. Sensory mapping studies and recordings in awake behaving rodents have shown that the orofacial area is strongly represented in the cerebellum of rats and mice (Bryant, 
Boughter, Gong, Ledoux, \& Heck 2010; Shambes et al. 1978; Welsh, Lang, Suglhara, \& Llinas 1995). Thus, cerebellar deficiency due to the reduced volume of the medial and interposed nuclei of Fmrl-KO mouse (Ellegood, Pacey, Hampson, Lerch, \& Henkelman 2010) likely contributes to USV articulation deficits in mouse. Cerebellar neuropathology is also a common finding in fragile X patients (Reiss et al. 1991) and may thus contribute to speech articulation deficits in humans. 


\section{CHAPTER 4. BILATERAL 3-DIMENSIONAL COORDINATION OF MOUSE WHISKER MOVEMENT*}

\section{Introduction}

One of the most common clinical features of FXS is higher sensitivity to sensory stimulation (Miller, McIntosh, McGrath, Shyu, Lampe, Taylor, Tassone, Neitzel, Stackhouse, \& Hagerman 1999). Altered sensitivity to sensory stimulation might reflect underlying abnormalities in the maturation of synaptic connections in sensory circuits. Frankland et al. (Frankland, Wang, Rosner, Shimizu, Balleine, Dykens, Ornitz, \& Silva 2004) showed that young males with FXS have significantly impaired sensorimotor gating. Anatomical studies also found that fragile X patients, both male and female, had significantly smaller cerebellar vermis volume (Allan L Reiss et al. 1988; Reiss, Aylward, Freund, Joshi, \& Bryan 1991). The cerebellar vermis in turn is an important component of the functional brain systems subserving sensory and motor integration, learning, and modulation of affect, motivation, and social behavior (Reiss et al. 1988) . The vermis receives major afferents from vestibular nuclei, spinal and trigeminal sensory tracts, and multiple cortical sensory areas (Reiss et al. 1988).

Mice are nocturnal animals that spend most of the daylight hours in elaborate underground burrow systems. They therefore rely heavily on somatosensation and olfaction for orientation in their dark environment. The mystacial vibrissae system is a major source of tactile information in rodents (Brecht 2007), and thus highly relevant for the mouse's survival. Neurogenetic disorders affecting sensorimotor pathways can therefore be ideally studied in the vibrissae system. Here we examine whether the FXS mouse has deficits in whisker movement because mystical vibrissa movement is essential for the collection of sensory information. Whisker movements are not only confined to a single plane, rather the whiskers move in at least two dimensions: horizontal and vertical. Our detailed study of whisker movements using full 3D whisker trajectories allowed us to determine potential deficiencies in whisker movements associated with loss of Fmrl expression.

\section{Material and Methods}

\section{Animals Used}

Breeding pairs of B6.129P2-Fmrl tmCgr/J mice were purchased from the Jackson Laboratory (stock \# 003025) and were bred by pairing wild type males with heterozygous

*Adapted with permission from Frontiers Media SA. Roy, Bryant, Cao, \& Heck (2011a). High-precision, three-dimensional tracking of mouse whisker movements with optical motion capture technology. Front Behav.Neurosci., 5, 27 available from: PM:21713124. 
females in a conventional mouse vivarium at the University of Tennessee Health Science Center using harem breeding trios. Pups were kept with the dam until weaning at postnatal day 21 (P21). Juveniles were housed by gender in standard plastic cages not exceeding four per cage. All the mice were raised and all the experiments were performed in accordance with procedural guidelines approved by the University of Tennessee Health Science Center Animal Care and Use Committee. Principles of Laboratory Animal Care (NIH publication No. 86-23, rev. 1996) were followed. Only male WT and Fmrl-KO littermates were used for testing to avoid variability in behavioral performances because of mosaicism of the mutant allele due to X-inactivation or the estrous cycle in females. All the 3-D whisker tracking experiments were performed with 10-20 weeks old mice.

One week prior to experiments, an aluminum head post was surgically mounted to the skull and secured with acrylic cement anchored to the skull using 3 small machine screws. The aluminum post was used to fix the mouse's head to a metal holder during the experiment. A detailed description of the head fixation procedure has been published previously (Bryant et al. 2009).

\section{Motion Capture System}

The 3D tracking system used here (Hawk Digital Real Time System, Motion Analysis Corp., Santa Rosa, CA, USA) was equipped with the minimally required twocameras in conjunction with the Cortex analysis software (Motion Analysis, CA, USA). The $\mathrm{X}, \mathrm{Y}$, and $\mathrm{Z}$ coordinates of whisker-attached retro-reflective markers were digitized and stored on the computer hard drive together with video recordings of the marker movements. The markers were fashioned from a retro-reflective tape backed with adhesive (Motion Analysis Corp., Santa Rosa, CA, USA) and fastened onto the whiskers using the tape's adhesive. Markers were fixed to the whisker at a distance of about $1 \mathrm{~cm}$ from the base. Reliable 3D tracking requires a marker be visible at all times by both cameras. This condition can be satisfied in head-fixed mice where the orientation of the mouse to the cameras remains fixed. The system was connected to a dual processor Windows-based computer for data collection. Trajectory information was available in the form of X, Y, and Z components of marker trajectories that were exported off-line from the Cortex software into a spreadsheet format and then imported into a Spike2 (Cambridge Electronic Design, Cambridge, UK) data file for further analysis. To provide a temporal alignment for the imported trajectory components into the Spike2 data format, analog timing signal provided by the Hawk cameras were recorded in the Spike2 data format in real-time using a CED1401 analog/digital converter (Cambridge Electronic Design, Cambridge, UK) and the Spike2 software.

\section{Camera Setup and Calibration}

Cameras were positioned $90 \mathrm{~cm}$ in front and about $40 \mathrm{~cm}$ above the platform supporting the head-fixed mouse, separated by about $30 \mathrm{~cm}$, resulting in a viewing angle 
of about $24^{\circ}$. Cameras were adjusted to cover a volume viewed by both cameras (the capture volume) that contained the entire expected range of marker movements (gray box in Figure 4.1C). The size of the capture volume was typically in the range of $\pm 6 \mathrm{~cm}$ lateral of the mid sagittal plane of the mouse and $\pm 3 \mathrm{~cm}$ above and below the head. The cameras tracked marker movements in real-time at $200 \mathrm{fps}$ by capturing infrared light emitted from the retro-reflective marker surface. Infrared light was emitted from an array of LEDs mounted directly on the cameras, surrounding the lenses.

\section{Tracking of Whisker Movements}

After 3-5 days of recovery from surgery, mice were trained to adapt to headfixation as described previously (Bryant et al. 2009). Head-fixation involved clamping the head post to a metal holder using a setscrew. On the day of the experiment, the mouse was head-fixed and small pieces of reflective markers with diameters of 2-3 $\mathrm{mm}$ and less than $1 \mathrm{mg}$ weight were attached to the $\mathrm{C} 4$ whisker on one or both sides of the face. We used two methods for attaching marker tape to the whiskers. In one method the tape was either directly folded over the whisker - with the adhesive side toward the whisker using fine forceps. The second method involved covering a $2-\mathrm{cm}$ section of silicon tubing (1.5 mm outer diameter) with marker tape and cutting a 2 to 3 -mm section off the covered tubing. The short section of tubing was then slid over the whisker and secured in place with a small drop of Super Glue gel (3M, St. Paul, MN, USA) applied to one end of the tubing (Figure 4.1B). Both methods yielded similar results in terms of tracking quality. Placing the tubing on the whisker is, however, more difficult and adds slightly more weight. Most mice will initially attempt to remove the markers until they were adapted to their presence. Reaching for the markers was prevented by taping a $1.5-\mathrm{cm} \times$ $5-\mathrm{cm}$ piece of cardboard in front of the forepaws. Attempts to remove markers typically ceased after 10-15 min. Movements of the $\mathrm{C} 4$ whiskers were recorded over several minutes. Data were collected from $5 \mathrm{WT}$ and $5 \mathrm{KO}$ mice.

\section{Data Analysis}

I compared the velocity, acceleration, and frequency components of whisker movements in Fmrl KO and WT mice. Frame-by-frame values of velocity and acceleration were calculated by the Motion Capture data analysis software (Cortex) as follows:

The velocity vector is calculated as a central difference for each dimension.

$$
\left.V_{\mathrm{x}}=\text { Frame Rate } * \operatorname{Position}_{\mathrm{x}}(\text { Center Frame }+\mathrm{i})-\operatorname{Position}_{\mathrm{x}}(\text { Center Frame-i })\right) /(2 * \mathrm{i})
$$

$V_{\mathrm{x}}$ is the velocity vector for the $x$-axis, Position $_{\mathrm{X}}$ is the position of the marker in a specified frame and $2 * i$ is the number of frames averaged. In our experiments the frame rate was always set to $200 \mathrm{~Hz}$ and $i$ was set to 5 . Velocities for the $y$-and $z$-axes were calculated in the same way. 

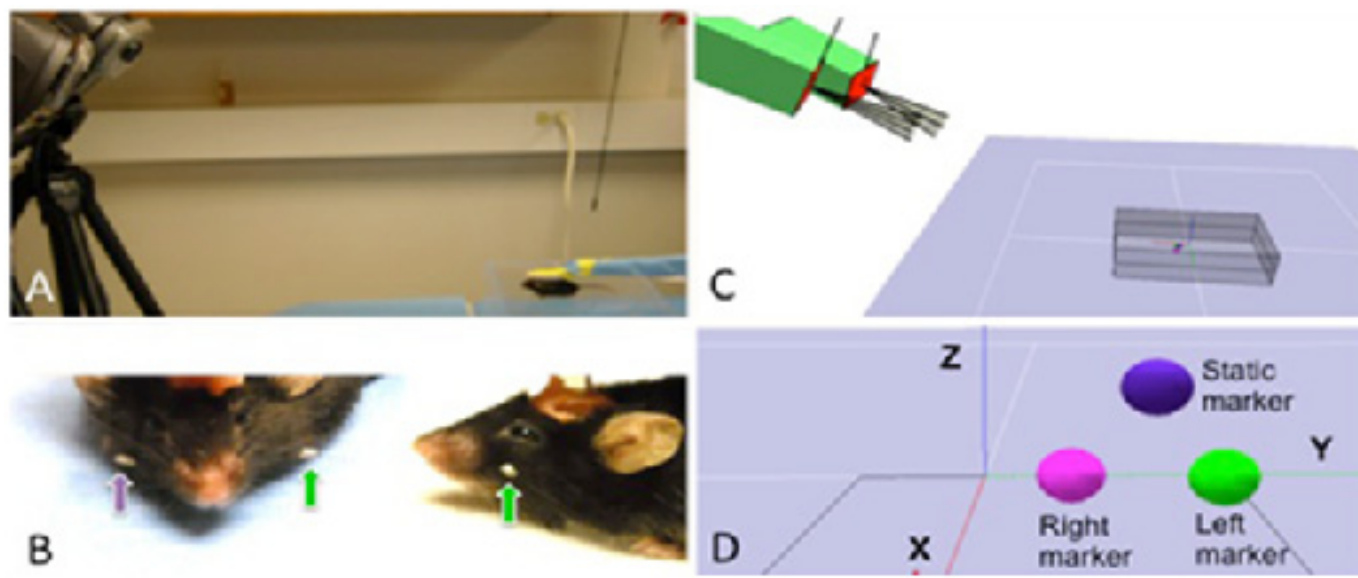

Figure 4.1 Arrangement of whisker tracking system.

(A) Photograph showing two high speed cameras (on the left) with infrared lights placed $0.8-1.2 \mathrm{~m}$ from the mouse (bottom right). The 2 camera's sightlines converge on the mouse at an approximate $24^{\circ}$ angle. The mouse's head is immobilized with a head post. (B) Photographs showing close-up front and side views of retro-reflective marker tape affixed to the left (green arrows) and right (purple arrow) C4 whisker of a WT mouse. Acrylic cement used to mount the head post is partially visible on top of the mouse's head. (C) Screenshot from the Cortex Software during calibration showing the positions of the two cameras (green boxes) relative to each other, outlines of their fields of view and the volume viewed by both cameras for 3D tracking. (D) Screenshot from the Cortex Software during the calibration process showing the digital representation of three retroreflective markers, one static and two attached to the left and right $\mathrm{C} 4$ whiskers.

Reprinted with permission from Frontiers Media SA. Roy, Bryant, Cao, \& Heck (2011a). High-precision, three-dimensional tracking of mouse whisker movements with optical motion capture technology. Front Behav.Neurosci., 5, 27 available from: PM:21713124. 
In a similar way, the acceleration vector is calculated from three frames. The resultant is the magnitude of the acceleration vector.

$$
\begin{gathered}
\mathrm{A}_{\mathrm{x}}=(\text { Frame Rate } / \mathrm{i}) *(\text { Frame Rate } / \mathrm{i}) *\left(\text { Position }_{\mathrm{X}}[\mathrm{i} \text { CenterFrame }+\mathrm{i}]-\right. \\
\left.2 * \text { Position }_{\mathrm{X}}[\mathrm{i} \text { Center Frame }]+\text { Position } \mathrm{X}[\mathrm{iCenter} \text { Frame }-\mathrm{i}]\right) \\
A_{\mathrm{x}} \text { is the acceleration vector for the } x \text {-axis; } \\
\text { Resultant (magnitude })=\operatorname{sqrt}\left(\mathrm{A}_{\mathrm{x}} * \mathrm{~A}_{\mathrm{x}}+\mathrm{A}_{\mathrm{y}} * \mathrm{~A}_{\mathrm{y}}+\mathrm{A}_{\mathrm{z}} * \mathrm{~A}_{\mathrm{z}}\right)
\end{gathered}
$$

The Cortex software did not allow power spectral or correlation analysis. For further analysis $\mathrm{X}, \mathrm{Y}$, and $\mathrm{Z}$ coordinates of the marker trajectories can be readily exported in ascii format to a spreadsheet (Microsoft Excel). We transferred the data to Origin (Origin Lab, North Hampton, MA, USA) data analysis software to generate 3D plots of the whisker movements and for correlation analysis of bilateral whisker movements. Correlation analysis was used to quantify the bilateral symmetry of whisker movements. Data were imported into the Spike2 software for power spectral analysis. We used power spectral density analysis and spectrogram plots to analyze and visualize the frequency components of whisker movements.

\section{Results}

\section{Comparison of Whisker Trajectories between WT and KO Mice}

Trajectories of whisker movements on both sides (using corresponding whiskers) were recorded. Whiskers on both sides had very similar trajectories. Figure 4.2 shows 3D plots of the trajectories of both genotypes of two simultaneously tracked C4 whiskers on each side of the face from different viewing angles (Figure 4.2). Based on visual inspection, whisker trajectories did not differ between WT and KO mice.

The static 3D images don't provide information about the dynamics and symmetry of bilateral whisker movements. As a quantitative measure for the symmetry or asymmetry of bilateral whisker movements, we calculated the correlation coefficients for all three directional components of the whisker trajectory. Using measurements from 5 different WT and KO mice, we calculated average bilateral correlations for the anteriorposterior component, the medio-lateral component (y-axis) and for the superior-inferior component (z-axis). No statistically significant differences were found between two genotypes (Table 4.1).

\section{Maximum Velocity and Acceleration Comparison}

The maximum velocity and the maximum acceleration along three different axes were extracted from the continuous recordings of the 3D trajectories of $\mathrm{C} 4$ whiskers and averaged across WT $(n=5)$ and $\mathrm{KO}(\mathrm{n}=5)$ mice. As the data was normally distributed, 

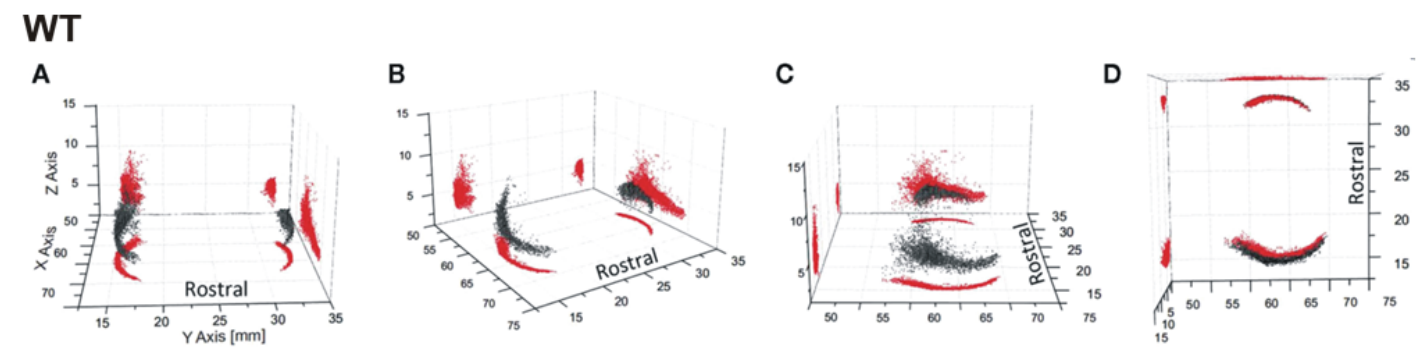

KO
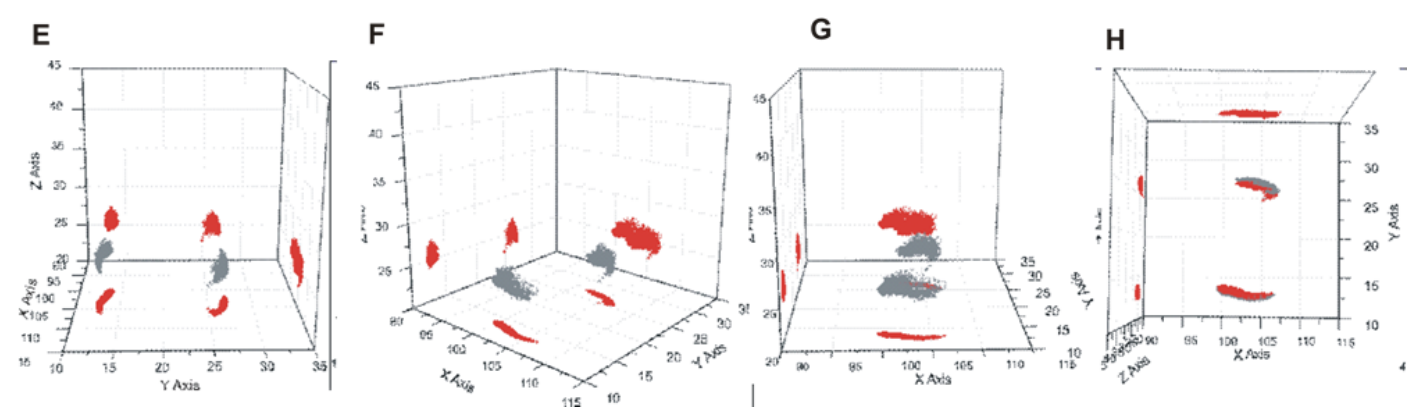

Figure 4.2 Different viewing angles for 3D reconstructions of whisker movements.

(A) \& (E): Frontal view of the marker positions during $100 \mathrm{~s}$ (20000 frames) of whisker movements of WT and KO mice, respectively. Markers were attached to the left and right $\mathrm{C} 4$ whiskers. Black (WT) and gray (KO) dots in these and all other plots represent 3D marker positions. Red dots are projections of the 3D positions onto each of three planes. (B) \& (F): Side view of A \& E (rotated $35^{\circ}$ ) respectively. (C) \& (G): Side view of (A) \& (E) (rotated $90^{\circ}$ ) respectively. (D) \& (H): Top down view (along the z-axis) of (C) \& (H) respectively. Adapted with permission from Frontiers Media SA.(Roy et al. 2011a). Highprecision, three-dimensional tracking of mouse whisker movements with optical motion capture technology. Front Behav.Neurosci., 5, 27 available from: PM:21713124. 
Table 4.1 Correlation coefficients of 3D bilateral whisker movement.

\begin{tabular}{cccc}
\hline Axes & $\begin{array}{c}\text { WT } \\
\text { Mean } \pm \text { Std Dev }\end{array}$ & $\begin{array}{c}\text { KO } \\
\text { Mean } \pm \text { Std Dev }\end{array}$ & P Value \\
\hline $\begin{array}{l}\text { Left X Vs Right } \\
\text { X Pearson Corr. }\end{array}$ & $0.113 \pm 0.25$ & $0.434 \pm 0.26$ & 0.195 \\
Left Y Vs Right & $0.186 \pm 0.15$ & $0.094 \pm 0.33$ & 0.250 \\
Y Pearson Corr. & & & \\
Left Z Vs Right & $-0.206 \pm 0.43$ & $0.05 \pm 0.14$ & 0.379 \\
Z Pearson Corr. & & & \\
\hline
\end{tabular}


student's t-test was used for statistical comparison between genotypes. Average maximum velocity and acceleration values for all axes were shown in Figure 4.3. No statistically significant differences were found in maximum velocity and acceleration between two genotypes.

\section{Whisking Frequency Comparison}

For a detailed comparison of whisking frequency, we computed power spectral density plots of whisker movement. Figure 4.4A represents one of these computed for both WT and KO mice. For this comparison we used five WT and five KO mice. Power spectral density analysis of whisking frequency of $\mathrm{C} 4$ whiskers revealed that whisker movements occur at modal frequencies of $11-16 \mathrm{~Hz}$ in each dimension for both genotypes. The power spectral density shows a peak for both WT and KO animals within this range. For the KO mice, an additional peak occurs within the $5-10 \mathrm{~Hz}$ range, which was absent in WT animals. To quantify this difference we calculated the relative power within the $5-10 \mathrm{~Hz}$ (Figure 4.4B) and 11-20 Hz (Figure 4.4C) frequency bands and performed a statistical comparison. Within the low frequency range the average power of $\mathrm{KO}$ mice whisker movements was higher than in WT mice, but only along X-axis (rostrocaudal axis), whereas the $\mathrm{Y}$ and $\mathrm{Z}$ components of whisker movements showed no difference in relative power. No differences between WT and $\mathrm{KO}$ mice were found in the relative power within the higher $(10-20 \mathrm{~Hz})$ frequency band.

\section{Discussion}

An early study found that fragile X patients had a history of at least a moderate degree of autistic symptoms beginning in childhood that included preoccupation with unusual sensory stimuli, motor stereotypes and deficits in social interaction (Allan L Reiss, Shilpesh Patel, Ashok Kumar, \& Lisa Freund 1988). Because of the extreme sensitivity of fragile $\mathrm{X}$ patients to sensory stimuli, the sensory responsiveness of fragile $\mathrm{X}$ mice has already been studied (Chen and Toth 2001). This study revealed hypersensitivity of fragile X mice to auditory stimuli. In this study, sensory hyperactivity of fragile $\mathrm{X}$ mice was demonstrated by a high seizure susceptibility to auditory stimulation.

Rodents show rhythmic bouts of vibrissal protractions and retractions, referred to as whisking, that are among the fastest movements performed by mammals. The rodent whisker system is a widely used model for study of sensory motor processing in the mammalian nervous system. Many groups studied whisking movements of rodents. Welker had described whisker movement in rats in a very detailed manner. He reported that when the nose contacted an object, the vibrissae were fully protracted, the tip of the nose was fully retracted, and the peak of inhalation occurred at this moment (Welker WI 1964). Similarly, when the animal withdrew from the object, the vibrissae retracted the tip of the nose protracted, and the animal exhaled. The mystacial vibrissae provide a continuous stream of information about environmental features encountered within the 

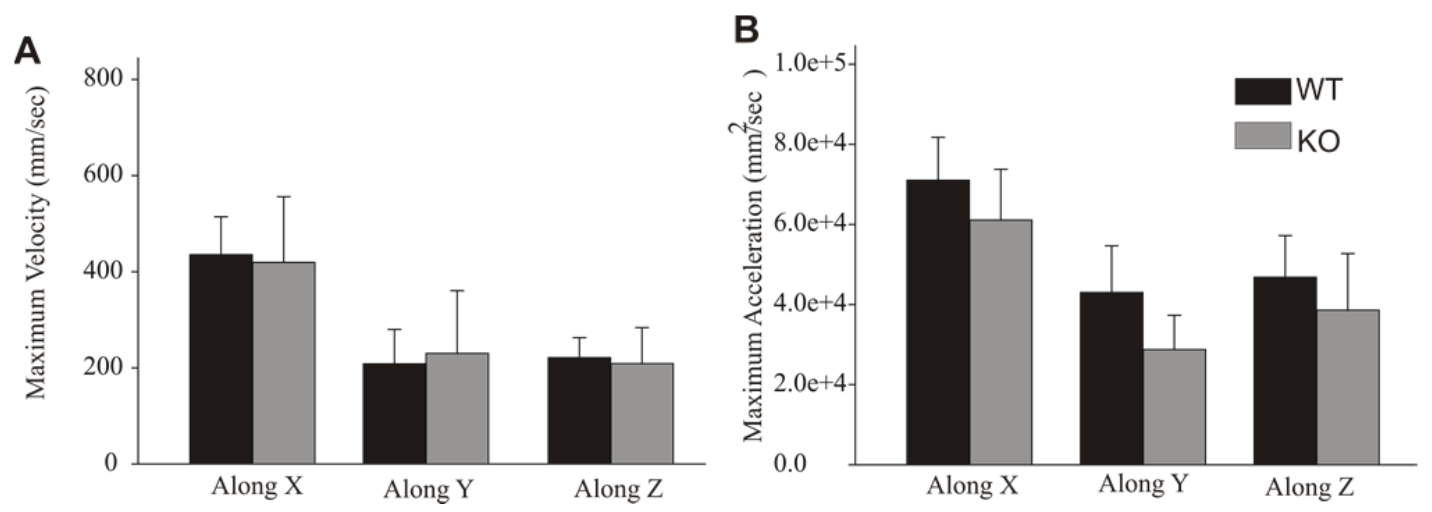

Figure 4.3 Maximum velocity and acceleration of 3D whisker movement.

(A) Bar graphs are showing average maximum velocity values of whisker movements along all axes. (B) Bar graphs are showing average maximum acceleration values of whisker movements along all directions (axes). 
A
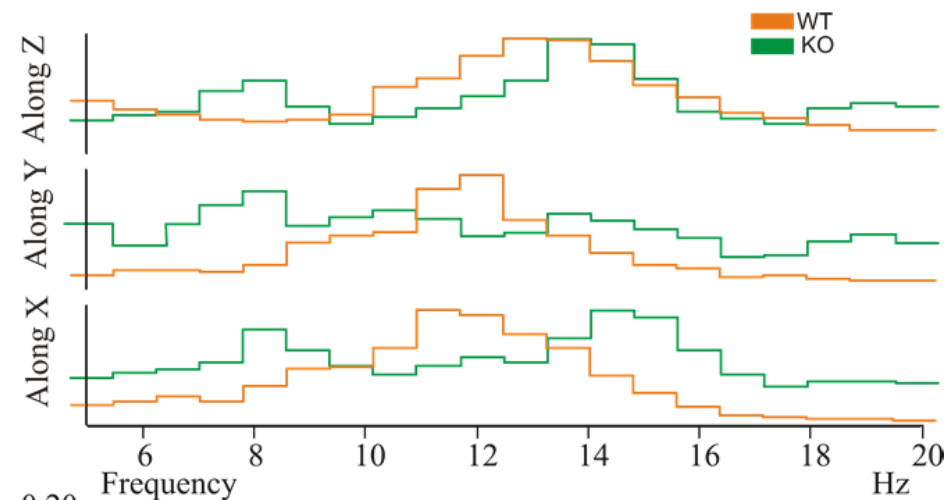

B
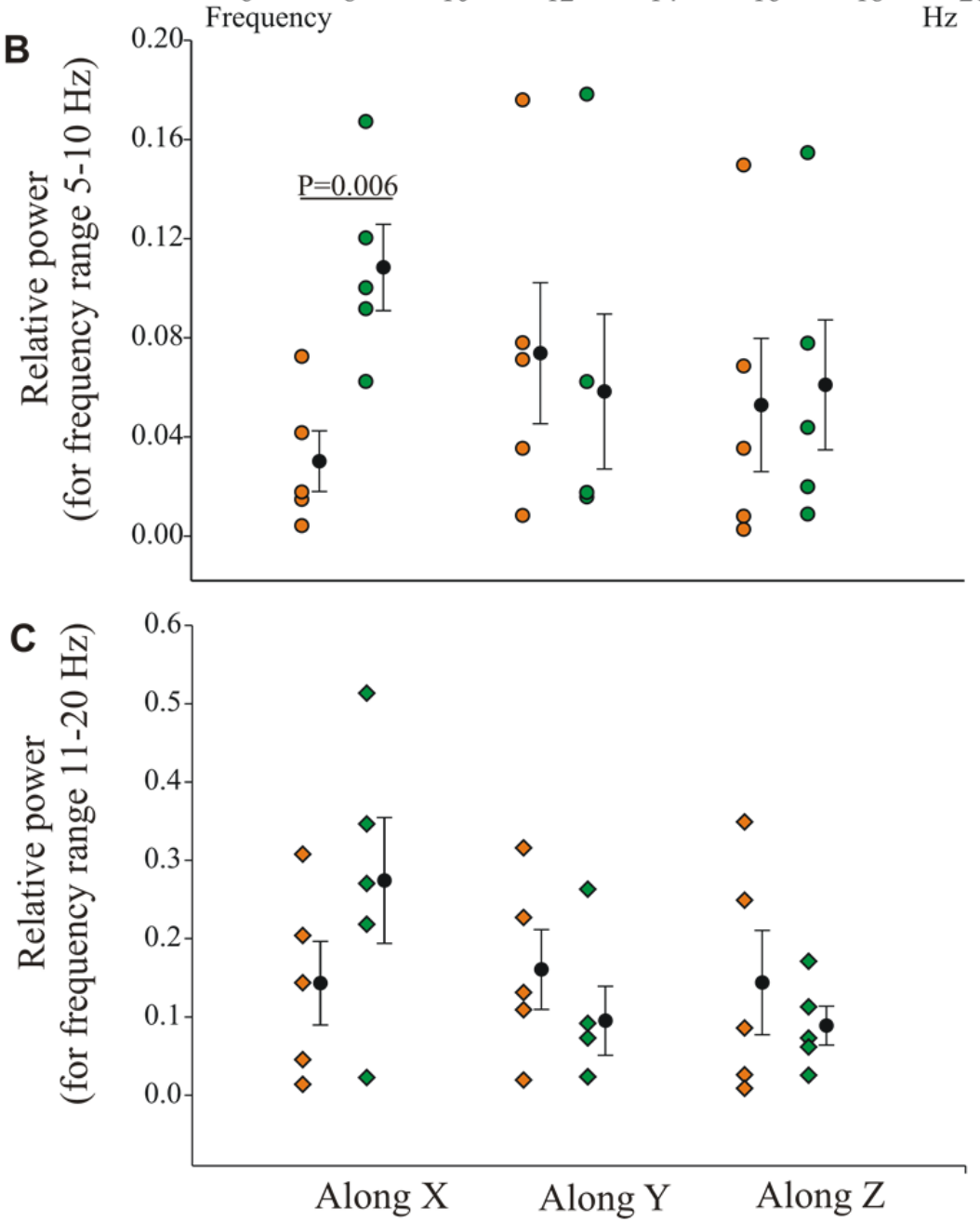

Figure 4.4 Frequency comparison of 3D whisking in WT and KO mice.

(A) Power spectral density plots of whisking in WT and KO mice. (B) \& (C) Relative power of power spectral density plot comparison for frequency range 5-10 Hz and 11-20 $\mathrm{Hz}$, respectively. 
sensory penumbra created by the rhythmic, exploratory movements of the whisker array (Bermejo et al. 2002; Carvell and Simons 1990; Lawrence E.Wineski 1983). The dynamics of whisker movement is very important for the collection of sensory information.

In this study, I compared the in-air whisker movements in two genotypes, as they are typically observed during free exploration. Our ability to track whisker positions allowed quantitative assessment of kinematic parameters of the whisker movement and quantification of asymmetries and asynchronies between whiskers on either side of the face. This information is critically important to understand what information is available at higher levels of processing (Ganguly and Kleinfeld 2004). Our cross correlation analysis of $\mathrm{X}, \mathrm{Y}$ and $\mathrm{Z}$ components of bilateral whisker movements revealed no significant difference in bilateral coordination. We also compared maximum velocity and maximum acceleration of whisker movement between two genotypes. Because velocity is the greatest determinant of neural responsiveness in the cortex, by shifting the phase of maximum velocity, the rat can shift the phase of the whisk when the largest activity is induced in the cortex (Moxon 2008). We did not find any statistically significant differences were found in maximum velocity and acceleration between two genotypes. Power spectral density analysis of whisking frequency revealed that whisker movements occur at modal frequencies of $11-16 \mathrm{~Hz}$ in each dimension for both genotypes. The average frequency of whisker movements in our hands was in the same range as reported by Voigts and colleagues (Voigts et al. 2008). They tracked whisker movements using high-speed video cameras in freely behaving animals during haptic object exploration. Peak frequencies of large-amplitude whisker movements were mostly distributed between 10 and $15 \mathrm{~Hz}$. Furthermore, our power spectral density analysis of whisking frequency showed one extra peak at the frequency range $5-10 \mathrm{~Hz}$ in each dimension only for $\mathrm{KO}$ mice. This appearance of one additional peak in each dimension for $\mathrm{KO}$ mice indicates that the dynamics of 3-D whisker movement is different in $\mathrm{KO}$ mice than their WT littermates. As we found that the rhythmicity of the whisker movements is disrupted in $\mathrm{KO}$ mice, loss of Fmr1 expression in mice may result in impairment of whisker movement which is important for sensory exploration. 


\section{CHAPTER 5. ELECTROPHYSIOLOGICAL CHARACTERIZATIONS*}

\section{Introduction}

Anatomical studies of FXS humans and Fmrl gene KO mice suggest a possible role for FMRP in synaptic development. Pyramidal neurons in the neocortex of human FXS patients and Fmrl knock-out mice are characterized by abnormally long, thin and numerous dendritic spines (Nimchinsky, Oberlander, \& Svoboda 2001). Spines are the site of excitatory synaptic contacts. These morphological anomalies at the cellular level may impair synaptic transmission, and in turn, affect the spread of activities across the neocortical network, and thus disrupt normal network functions. The cortical LFP reflects the summed dendritic currents of the pyramidal cells in a local neuronal assembly (Bressler et al. 2007; Elul 1971). The high degree of recurrent excitation within the assembly, balanced by local inhibition, as well as re-entrant excitation between cortical assemblies, causes the LFP to fluctuate with a high degree of variability (Arieli et al. 1996; Leopold and Logothetis 2003). Thus LFP signals provide a valuable link between single neuron recordings and larger-scale neurophysiological signals such as EEG, fMRI, and ECoG (David et al. 2010). These latter signals also offer a means to measure synchronous neural activity both within a single brain area (Gray et al. 1989; Kayser et al. 2007) and among different brain areas (Pesaran et al. 2008; Siegel et al. 2008). Clinical evidence suggests that abnormal synchrony and oscillatory activities in the neocortex are common to several cognitive disorders such as mental retardation, autism and schizophrenia (Rojas et al. 2008; Uhlhaas et al. 2009; Uhlhaas and Singer 2006a). In this chapter we discuss the studies that were performed to find out how loss of Fmr 1 expression affected the neocortical network activity in a mouse model of FXS.

Sensory integration problems are present even in very young children with fragile $\mathrm{X}$ syndrome. The whisker barrel cortex of the mouse is a well-studied major sensory area with highly organized anatomical structures. Dendritic abnormalities have been detected in somatosensory cortical barrels in a mouse model of FXS (Galvez, Gopal, \& Greenough 2003), the Fmrl null mouse. It is very important to test how cellular alterations in the sensory area of the cortex in FXS affect normal cortical functions. To investigate potential pathological activity in the whisker sensory cortex of the Fmrl KO mice, multiple electrode recording techniques were employed, using up to 5 extracellular electrodes to record single and multi unit spike activities and local field potentials (LFPs). LFPs represent the sum of excitatory and inhibitory postsynaptic potentials in many cells in the neighborhood of the electrode's tip. We used cross correlation analysis of local field potentials (LFPs) and single unit spike activities recorded at different sites separated by 0.3 to $1.2 \mathrm{~mm}$ to quantify synchronous and oscillatory neuronal activities. Network activity in $\mathrm{Fmrl} \mathrm{KO}$ mice was significantly different from that in wild-type mice.

*Adapted with permission from Elsevier B.V. (Bryant, Roy, \& Heck 2009).A technique for stereotaxic recordings of neuronal activity in awake, head-restrained mice. J.Neurosci.Methods, 178, 75-79). 
Synchronous activity at the LFP and single unit level was strongly reduced in Fmrl KO mice. Delta range oscillatory activity, which was reliably seen in wild-type mice, was absent in the neocortex of Fmrl KO mice. Our results suggest that loss of Fmrl expression severely impairs the dynamics of neocortical network activity, an effect that may be causally linked to the typical behavioral, cognitive and sensorimotor deficits associated with fragile $\mathrm{X}$ syndrome.

\section{Material and Methods}

\section{Animals Used}

Breeding pairs of B6.129P2-Fmr $1 \mathrm{tm} 1 \mathrm{Cgr} / \mathrm{J}$ mice were purchased from the Jackson Laboratory (stock \# 003025) and were bred by pairing wild type males with heterozygous females in a conventional mouse vivarium at the University of Tennessee Health Science Center using harem breeding trios. Pups were kept with the dam until weaning at postnatal day 21 (P21). Juveniles were housed by gender in standard plastic cages not exceeding four per cage. All mice used in this study were raised and all experiments were performed in accordance with procedural guidelines approved by the University of Tennessee Health Science Center Animal Care and Use Committee. Principles of Laboratory Animal Care (NIH publication No. 86-23, rev. 1996) were followed. Only male WT and Fmr I-KO littermates were used for testing to avoid variability in behavioral performances because of mosaicism of the mutant alleles due to $\mathrm{X}$-inactivation or the estrous cycle in females. Data was collected from $6 \mathrm{WT}$ and $6 \mathrm{Fmrl}$ $\mathrm{KO}$ mice for this study. All animals went through surgery and recovery period before data collection.

\section{Surgery}

Mice were initially anesthetized with 3\% Isoflurane (Baxter Pharmaceutical Products, Deerfield, IL). Core body temperature was measured using rectal thermometer and maintained between 36.5 and $38.0^{\circ} \mathrm{C}$ with a feedback controlled heating pad (FHC Inc, Bowdoinham, ME). The depth of anesthesia was adjusted until the mice failed to show a reflex withdrawal of the hind paw to a strong pinch. The anesthetized mouse was positioned in a stereotaxic head mount and the anesthesia was continued with $1-2.5 \%$ Isoflurane vaporizer from Highland Medical Equipment, CA (via nose cone). Standard surgical techniques were used to secure 3 small machine screws in the skull (1/8' dome head, $0.8 \mathrm{~mm}$ diameter, $2 \mathrm{~mm}$ long, Small Parts, Inc, Miami Lakes, FL). A small craniotomy (diameter, $1-2 \mathrm{~mm}$ ) was made $1 \mathrm{~mm}$ posterior from bregma and $3.5 \mathrm{~mm}$ lateral from the midline on the right hemisphere. The exposed dura was covered with Triple Antibiotic (Walgreens, US) to keep the dura moist. A cylindrical plastic chamber $(0.45 \mathrm{~cm}$ diameter and $8 \mathrm{~mm}$ height) was fashioned from a drinking straw, surface sterilized with $100 \% \mathrm{ETOH}$, and placed over the skull opening. The chamber was filled with Triple Antibiotic to help keep the dura moist and prevent infection. A metal 
headpost was mounted relative to Bregma. The chamber and head post were secured into place with dental acrylic as described in detail earlier (Bryant, Roy, \& Heck 2009). Mice were injected with $5 \mathrm{mg} / \mathrm{kg}$ analgesic Torbugesic (Fort Doege, USA) to alleviate pain and $0.5 \mathrm{ml}$ of lactated ringer solution (s.c.) as a fluid supplement twice within the first 24 hours of the surgery. After a 3-4 day recovery period, mice were adapted to the headfixed situation during 2 sessions of head fixation of $15 \mathrm{~min}$ each.

For olfactory-bulbectomized mouse $(\mathrm{OB})(\mathrm{N}=6)$ preparation, each animal was anesthetized as before and a midline incision was made for exposing the bregma suture. Then bilateral drill holes were made over the olfactory bulbs (A: $9 \mathrm{~mm}$; L: 1mm; D-V: 4 $\mathrm{mm}$, from bregma) and the olfactory bulbs were removed by subpial suction through the craniotomy. The intracranial space was filled with Avitene, a microfibrillar collagen hemostat (Davol Inc., Cranston, Rhode Island). All other surgical procedures were the same as above.

\section{Training and Experimental Procedures}

After 3-4-days of recovery period, mice were adapted to the head-restrained experimental position during 2 sessions of head fixation of 15 min duration performed on the same day at 9 a.m. and 3 p.m. During these sessions the head was held fixed and the body was covered with a loose fitting plastic half-tube $(5 \mathrm{~cm}$ diameter, $10 \mathrm{~cm} \mathrm{long})$ to limit body movements. Mice typically adapted to the head fixation within 2-3 sessions as judged from observations of markedly reduced walking and running movements during the third session compared to the first or second.

During experiments the mouse's head was immobilized by affixing the head post to a custom-made plastic head post clamp, which was attached to a metal stand. The metal stand was attached to the surface of a vibration isolation table with 4 machine screws. All components of the head-fixation assembly were custom built by the machine shop of the Department for Biomedical Engineering at the University of Tennessee Health Science Center.

After the headpost was fixed, the mouse's body was covered with a plastic halftube. The triple antibiotic filling was removed from the recording chamber (Figure 5.1). Then, the chamber was rinsed and filled with Ringer's solution. Recording electrodes (glass insulated tungsten/platinum, impedance: 3.5-5.0 M $\Omega$ ) were advanced through the intact dura into the brain using a computer controlled microdrive (MiniMatrix, Thomas Recording, Germany). Multiple recording electrodes (maximum of five) were advanced into the barrel cortex to record LFP, and single and multi-unit neuronal activity. Cells were identified based on their locations and firing characteristics such as mean firing frequencies $13.6 \pm 0.9 \mathrm{~Hz}$ (Meis et al. 2012). Single unit isolation was obtained on one electrode and attempted on at least one more. The remaining electrodes were used to measure multi-unit spike activities. All electrodes measured LFPs. Respiratory behavior was monitored based on temperature change associated with the expiration of warm air. A fast thermistor (response time 200 ms, Measurement Specialties Inc, Boston, MA, 


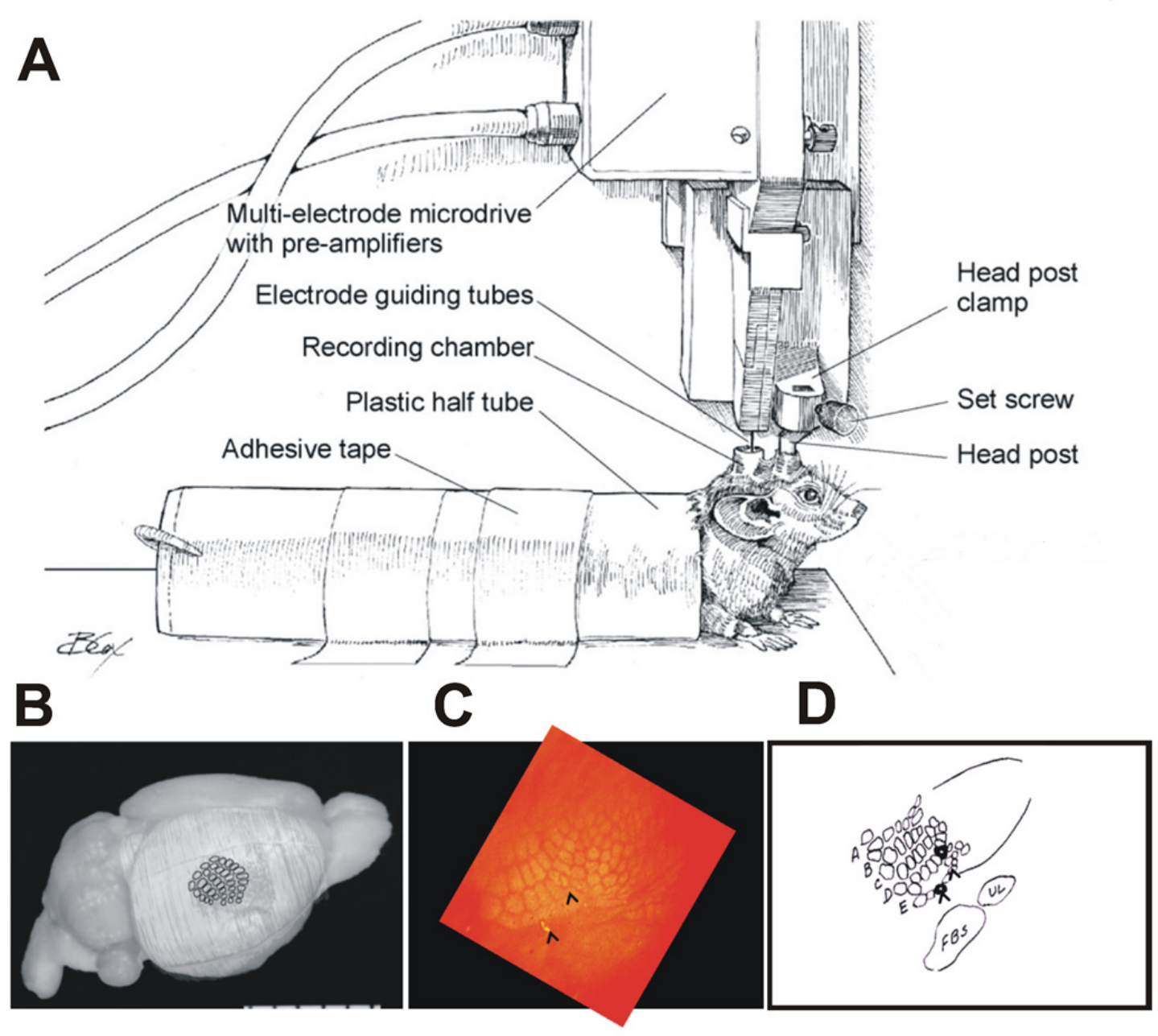

Figure 5.1 Experimental setup and evidence of electrophysiological study.

(A) Experimental setup for recording from awake, head fixed mice (Bryant, Roy, \& Heck 2009) (Adapted with permission from Elsevier B.V. Bryant, Roy, \& Heck (2009). A technique for stereotaxic recordings of neuronal activity in awake, head-restrained mice. J.Neurosci.Methods, 178, 75-79). (B) Barrel pattern shown over whisker barrel cortex of a mouse brain. (C) Barrel field stained for cytochrome c oxidase showing lesions at two recording sites (arrows). (D) Drawing of the barrel field shown in (C) with labeling of the 5 main rows of barrels (A-E). Sites marked by arrows correspond to recording sites marked in $(\mathrm{C})$. 
USA) was placed in front of one nostril and breathing cycles could reliably be measured as positive-negative temperature change pattern during exhale and inhale movements respectively. To allow the mouse to accommodate to the head fixed situation, we waited for 30 min before starting recordings. During this period the mouse calmed down as judged by the significantly reduced number of attempts to walk or run. The raw respiratory signal was digitized at $1 \mathrm{kHz}$ and stored to hard drive using a CED power $1401 \mathrm{~A} / \mathrm{D}$ converter and Spike2 software (both Cambridge Electronic Design, Cambridge, UK). A data example from a recording with three electrodes, two with single unit spike isolation, is shown in Figure 5.2. Spike and LFP data was band-pass filtered before digitization at $0.1-200 \mathrm{~Hz}$ and $0.1-200 \mathrm{~Hz}$ (CED 1401, Cambridge Electronic Design, UK) respectively. Spike data was digitized at $25 \mathrm{kHz}$ and LFP data was digitized at $2 \mathrm{kHz}$. Filtered and digitized data was finally stored in the same data file for off-line analysis (Spike2, CED, UK).

At the end of the experiment electrode depth was recorded and the recording sites were marked with small electrolytic lesions $(1 \mu \mathrm{A}$ for $10 \mathrm{sec})$ to identify recording locations. Two example lesion sites in layer IV are indicated by arrows in Figure 5.1. To avoid confusing lesion marked recording sites, each animal was used for two recording sessions only. At the end of the second recording session the mouse was transcardially perfused, and the right barrel cortex was cut into $40 \mu \mathrm{m}$ thick horizontal sections and stained for cytochrome c oxidase (Figure 5.1C, D) to visualize the lesion sites relative to the barrel fields (Land and Simons 1985). From these sections together with the measured penetration depth during recording, we were able to locate the cortical layers of the recording sites as well as their location within or between whisker barrels.

Upon completion of each recording session, the Ringer's solution was removed and the recording chamber was again filled with triple antibiotic. The mouse was then returned to its home cage. Each animal typically participated in experiments for 1-2 weeks. Within this time-frame, triple antibiotic maintained the accessibility of the tissue by keeping the dura soft and free of infection.

Primary analyses of the electrophysiological data involved identification of units and local field potentials (LFP) simultaneously and the correlation of LFP activities to the respiration. Spike2 software (Cambridge Electronic Device, CED, UK) was used for autocorrelation analysis of the baseline LFP and breathing activity. Cross correlation analyses were also performed between two different LFP activities and LFP to breathing activities. Correlation analysis was performed to determine if LFP activity was modulated during respiration.

\section{Creation of Hypoxic Conditions}

While continuously recording local field potentials we increased the frequency of respiratory activity by exposing the mice for 1 min to hypoxic air. To this end a specially designed plastic cover was placed over the mouse leaving an opening at the top for access to the head post and the recording chamber. Respiratory behavior was continuously 


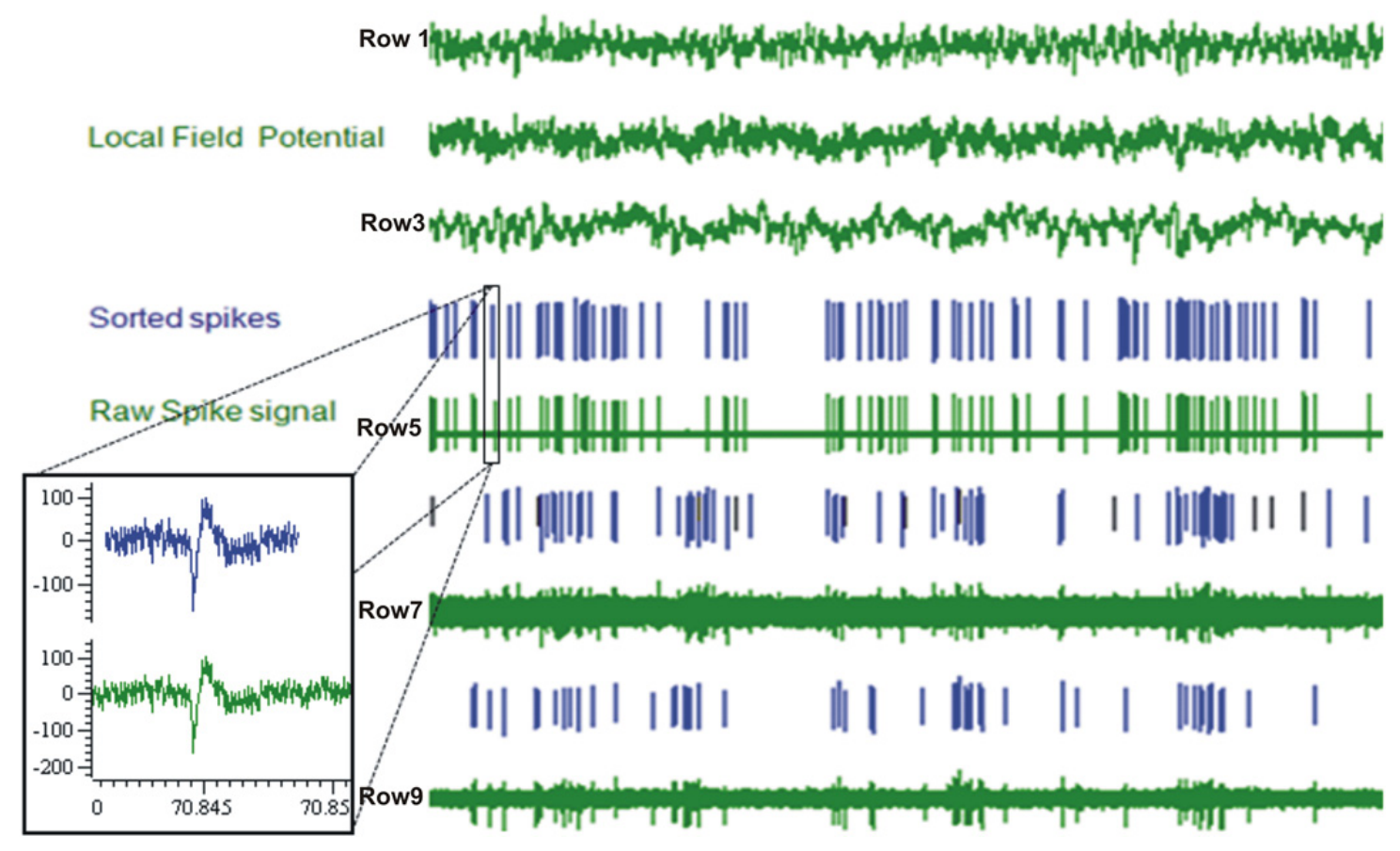

Figure 5.2 Raw data examples of spike and local field potential signals.

Traces from top to bottom show: Local field potential (top three rows), spike activity (rows 5, 7 and 9). LFP and spike signals were recorded on the same electrode, separated by hardware filter $(0.1-200 \mathrm{~Hz}, 200 \mathrm{~Hz}-8 \mathrm{kHz}$, respectively) and digitized at $2 \mathrm{kHz}$ and $25 \mathrm{kHz}$, respectively. Blue vertical lines (rows 4,6 and 8) represent spike signals isolated from the raw data based on the shape and amplitude of spike waveforms. 
monitored as described above. The atmosphere within the plastic chamber was controlled by mixing air with nitrogen from gas tanks. For the normoxic condition only air was used and for the hypoxic condition, the ratio of air and nitrogen was 1:2. Gas flowed into the chamber at a rate of $11 / \mathrm{min}$. An $\mathrm{O}_{2}$ analyzer (Teledyne Analytical Instruments; model\# GB-300) continuously monitored the $\mathrm{O}_{2}$ concentration in the chamber. Following at least 5 min of stable LFP recording, the mouse was exposed to hypoxia $\left(10 \% \mathrm{O}_{2}\right)$ for $1 \mathrm{~min}$ followed by normoxic air. Respiratory frequency, blood $\mathrm{O}_{2}$ saturation and heart beat were measured before, during and after the hypoxia using a MouseOx (Starr Life Science, Oakmont, PA), a small animal vital signs monitor.

\section{Analysis}

Single-units were identified based on spike shapes using the Spike2 software (CED, Cambridge, UK) (Figure 5.2). Single-unit spike activity was characterized by 1) simple-spike amplitudes exceeding 5 standard deviations (SD) of the baseline signal voltage distribution measured during brief epochs without spikes and 2) by the presence of a refractory period of at least $2 \mathrm{~ms}$ as determined from the inter-spike interval distribution. If either of these criteria were not met, data were categorized as multi-unit activity. Occasionally movement artifacts occurred which compromised the careful analysis of spike activity, resulting in the exclusion of the data from further analysis. Local field potentials (LFP) signals were cleaned from $60 \mathrm{~Hz}$ using notch filter (IIR digital filter). Spike2 software (Cambridge Electronic Device, CED, UK) was used for autocorrelation analysis of the baseline LFP and breathing activity. Cross correlation analyses were also performed between two different LFP activities and LFP to breathing activities. Correlation analysis was performed to determine if LFP activity was modulated during respiration. Calculation of the power spectrum from LFP recordings was done using the Matlab platform.

\section{Results}

\section{Relative Power of the LFP Signals in Different Frequency Bands}

We compared the relative powers.(the total power of each file, summed across frequency bands, was normalized to unity) of the LFP signals within different frequency bands [Delta (1-4 Hz), Theta $(5-10 \mathrm{~Hz})$, Beta $(10-30 \mathrm{~Hz})$, Gamma $(30-80 \mathrm{~Hz})]$ were in WT $(\mathrm{n}=10)$ and Fmrl KO $(\mathrm{n}=10)$ mice. Compared to WT mice, Fmrl KO mice had significantly lower power in the delta frequency band $(\mathrm{P}=0.006)$ and significantly higher power in the beta frequency band $(\mathrm{P}=0.008)$. No significant differences in powers were found in the theta and gamma bands (Figure 5.3). 


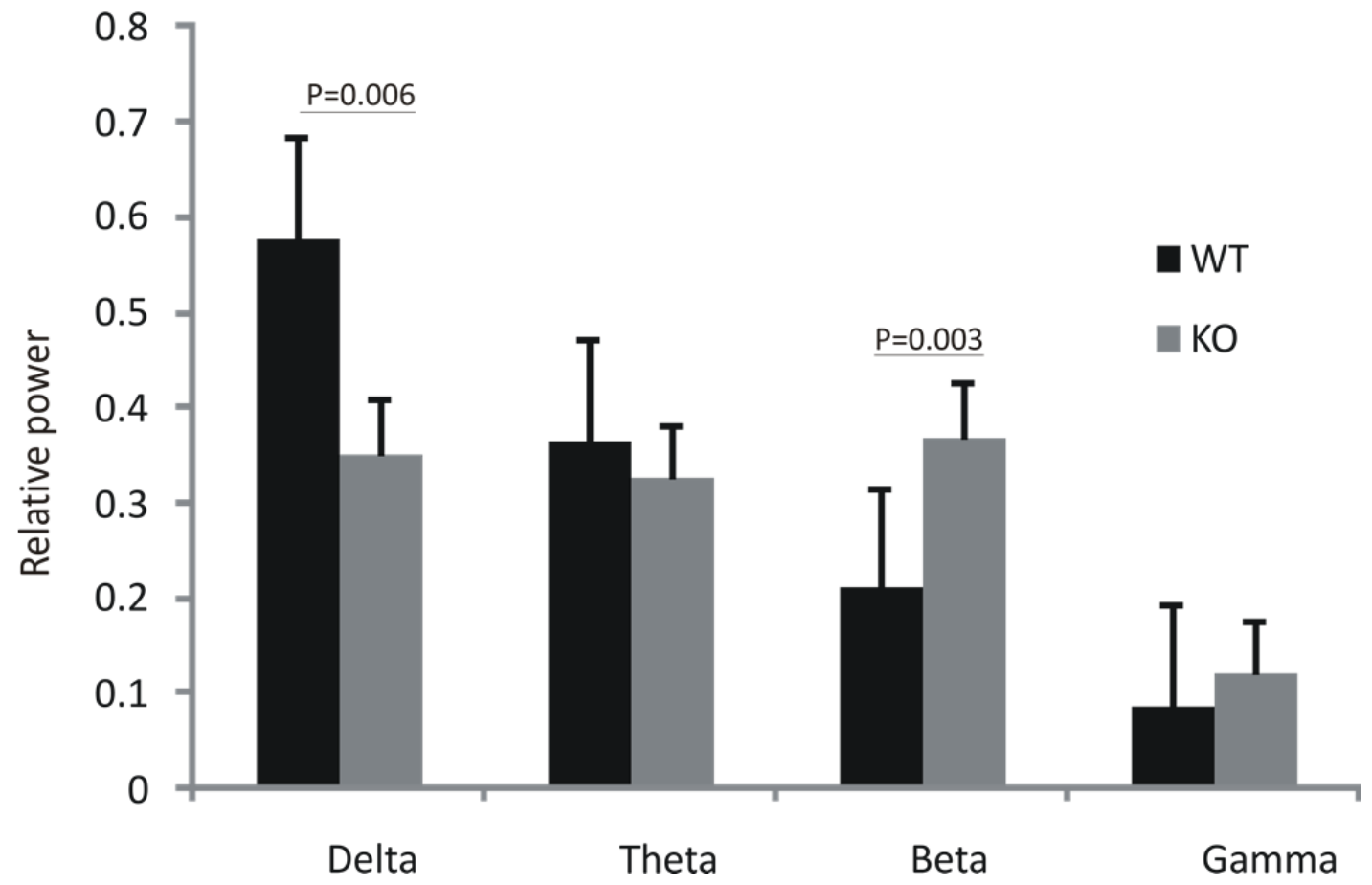

Figure 5.3 Relative power analysis of local field potential (LFP) signals.

Relative power in the LFP signals by frequency bands [Delta $(1-4 \mathrm{~Hz})$, Theta $(5-10 \mathrm{~Hz})$, Beta $(10-30 \mathrm{~Hz})$, Gamma $(30-80 \mathrm{~Hz})]$ of local field potentials (LFPs) in WT and Fmrl $\mathrm{KO}$ mice. KO animals show lower delta power and higher beta power compared to WT animals. 


\section{Autocorrelation Analysis of LFPs in WT Mice}

Auto-correlation analysis of local field potentials showed WT mice (Figure 5.4) exhibit multiple equidistance side peaks which indicates LFP signals are very rhythmic. Appearance of three peaks during $1 \mathrm{sec}$. time period suggests that the frequency of that rhythm is approximately $3 \mathrm{~Hz}$.

\section{Relationship between Breathing and Delta Band Oscillation in LFP}

In the present study we also collected breathing data while recording LFP from the whisker barrel cortex of WT and KO mice (Figure 5.5). Breathing data revealed that WT mice breathe rhythmically at $3 \mathrm{~Hz}$ frequency. These breathing signals were highly correlated to LFP signals recorded from whisker barrel cortex. Autocorrelation analysis of breathing and LFP signals show multiple equidistance side peaks, that indicates that LFP signals are functionally linked to the breathing mechanism. Appearance of three peaks during $1 \mathrm{sec}$. time period suggests that the frequency of that rhythm was $3 \mathrm{~Hz}$.

\section{Delta Rhythm in LFP during Normal Breathing and Elevated Breathing}

LFP signals were recorded from barrel cortices of five healthy WT mice. Breathing signals were also recorded simultaneously. Data were collected during two different types of breathing conditions, i.e. normal breathing and hypoxia induced elevated/fast frequency breathing. For both conditions it was found that delta band oscillation in LFP signals recorded in barrel cortex was phase locked to the respiratory rhythm (Figure 5.6).

\section{Relationship between Breathing and Delta Band Oscillation in OB Mice}

Breathing and LFP signals were also compared in six olfactory bulbectomized (OB) mice. Breathing data revealed that the breathing frequencies of OB mice (Figure

5.7D) were slower compared to healthy WT mice (Figure 5.7A). Rhythms of LFP signals were also reduced (Figure 5.7E). Breathing and LFP cross correlation analysis suggests that breathing activity still correlated to LFP in barrel cortex. But values of cross correlation coefficients of breathing-LFP signals were smaller in bulbectomized mice compared to healthy WT animals (Figure 5.7C, F).

\section{Spike Frequency Analysis in WT and Fmr1 KO Mice}

We compared the firing rates of barrel cortex neurons across all cortical layers (Figure 5.8A) between WT and KO mice. Data were collected from 10 mice in each group. For this analysis only single unit data was used. The overall firing rates, averaged across all trial epochs (overall) revealed that firing frequencies of barrel cortex neurons 

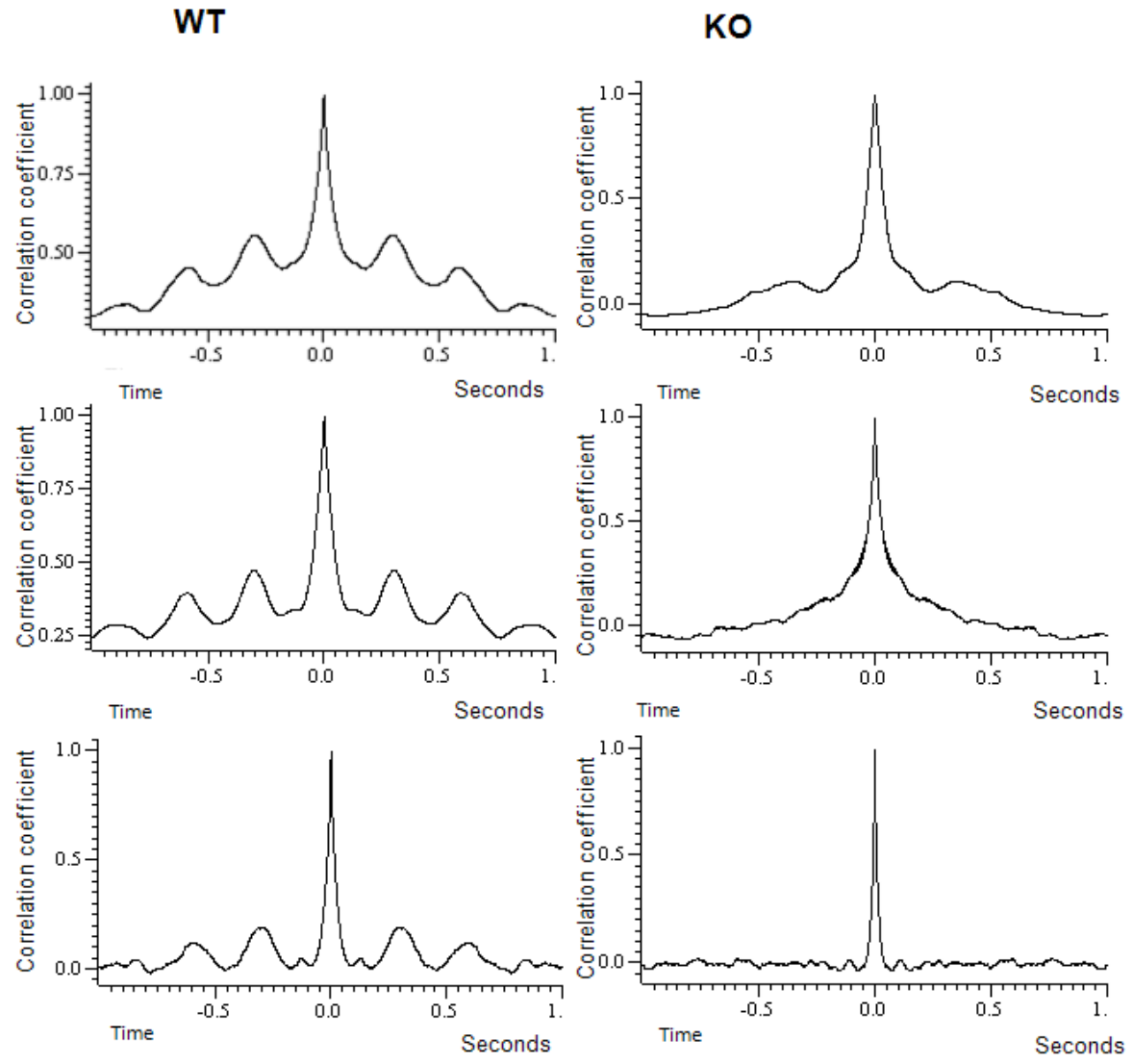

\section{Figure 5.4 Auto-correlogram of local field potential (LFP).}

Left and right columns show results for wild type (WT) and Fmrl knock-out (KO) mice, respectively. LFPs were recorded simultaneously from three channels of a single animal. Each row represents LFPs from 1 of 3 channels. LFP of the WT mouse shows a prominent spectral peak in the delta frequency band $(3.3 \mathrm{~Hz})$ in all channels. This is reflected in the oscillatory side lobes of the respective auto-correlograms. LFP of the KO mouse lacks this feature. 

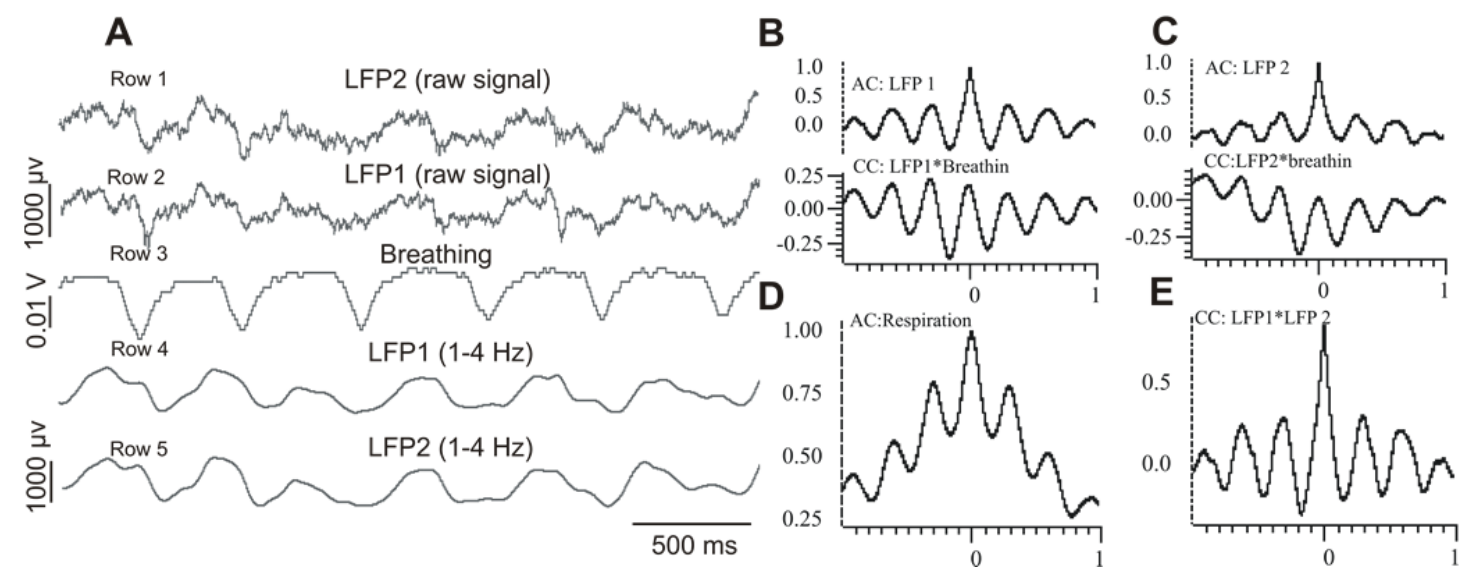

Figure 5.5 Relationship between respiration and delta band oscillation in LFP.

(A) Traces from top to bottom show: Local field potential (top two rows), breathing activity (row 3 ) and filtered LFP signals (row 4 and row 5). LFPs were recorded on the same electrode, separated by hardware filter $(0.1-200 \mathrm{~Hz}, 200 \mathrm{~Hz}-8 \mathrm{kHz}$, respectively) and digitized at $2 \mathrm{kHz}$ and $25 \mathrm{kHz}$, respectively. (B) \& (C) Auto-correlograms of two different LFP signals (top row) recorded simultaneously from two channels from a single animal and cross-correlograms of LFP and breathing signals (bottom row). (D) Autocorrelogram of the breathing signal. (E) Cross-correlation between two different LFP signals recorded simultaneously from two different channels from a single animal. 

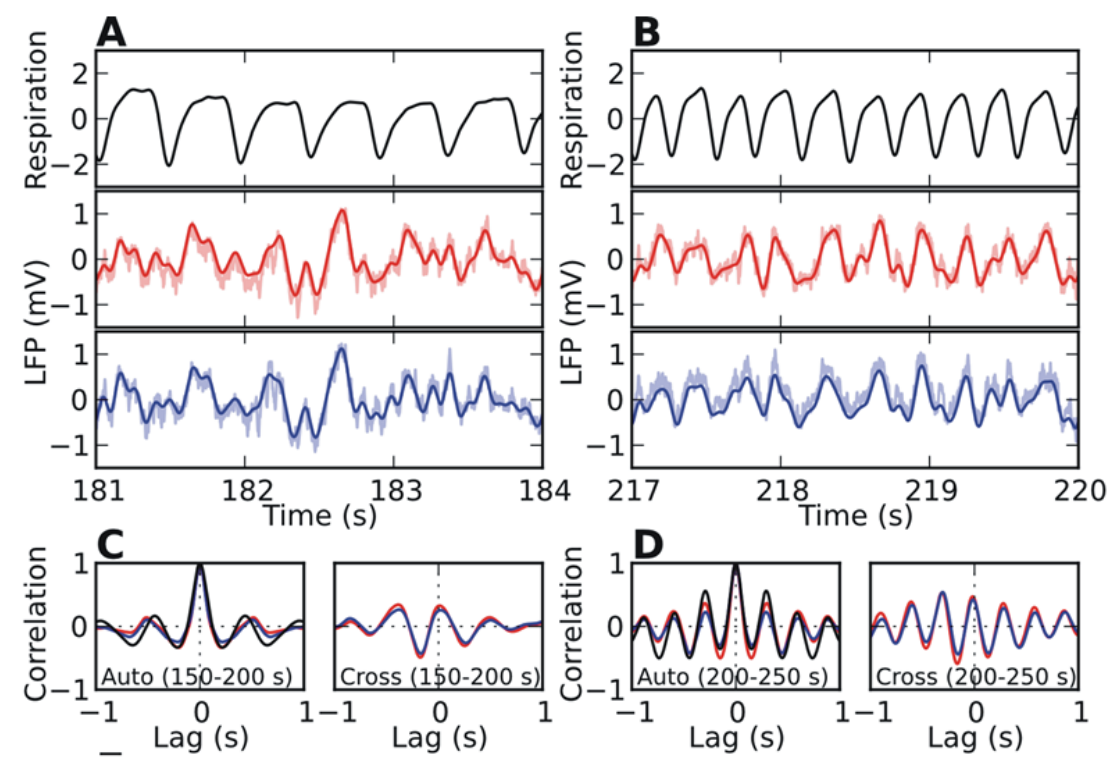

\section{Figure 5.6 Relation between breathing and LFP of WT mice.}

(A) Respiration (top) and LFP (bottom two) traces during normal breathing. The respiration signal was recorded with a thermistor and its units are arbitrary. LFP recording sites were 610 um apart. Solid curves are the signals after band-pass filtering (0.5-10 Hz). Raw LFP signals are plotted with shaded colors. (B) Same as A, but during accelerated breathing after hypoxia. (C) Auto-correlation of the respiration and autocorrelations of the LFP signals (left) and cross-correlation between the respiration signal and each of the LFP signals (right) during normal breathing. (D) Same as (C) but during accelerated breathing. 


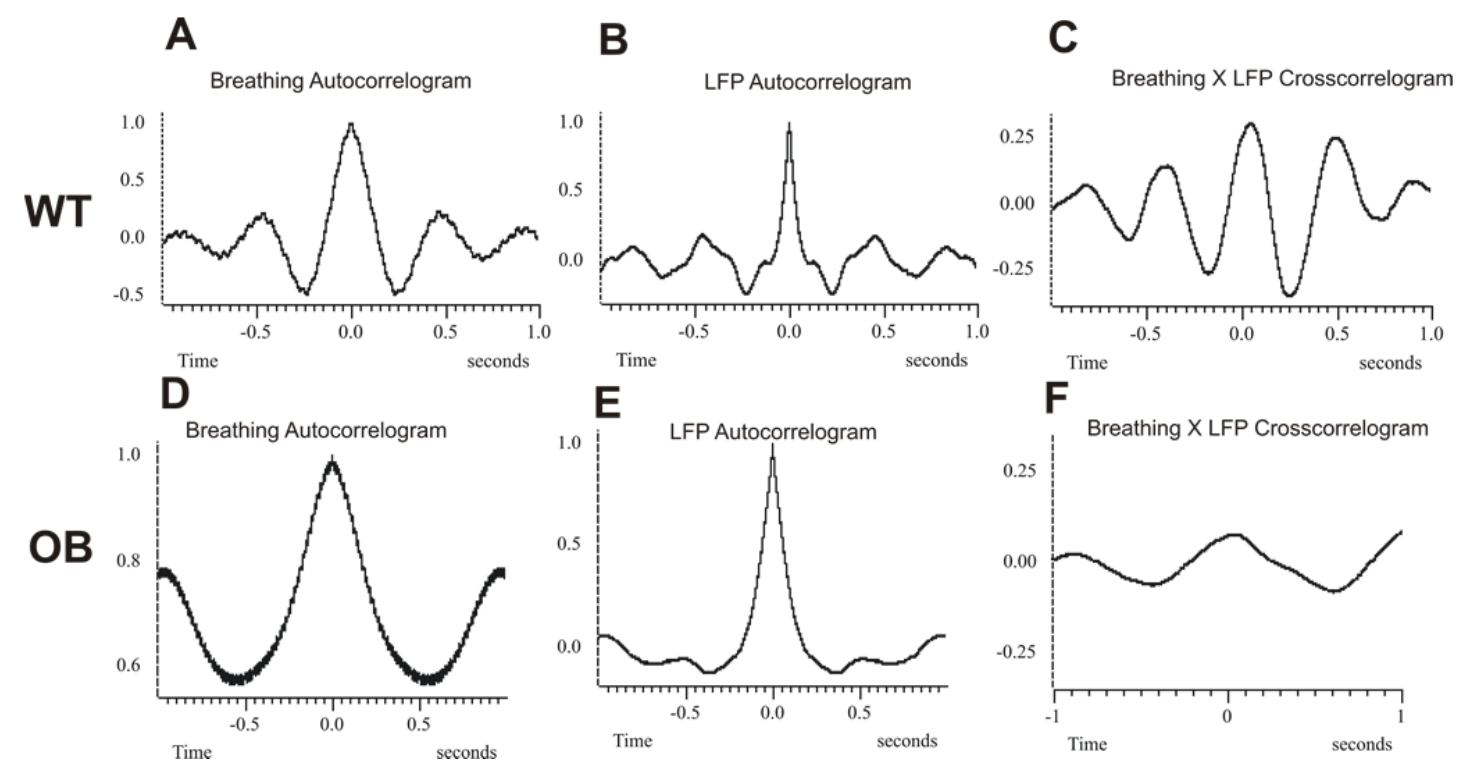

Figure 5.7 Comparison of breathing-LFP relationship in WT and OB mice.

(A) Auto correlation of breathing, (B) auto correlation of LFP and (C) cross correlation of LFP and breathing signals collected from WT animals. (D) auto correlation of breathing, (B) auto correlation of LFP and (C) cross correlation of LFP and breathing signal collected from OB mice. 

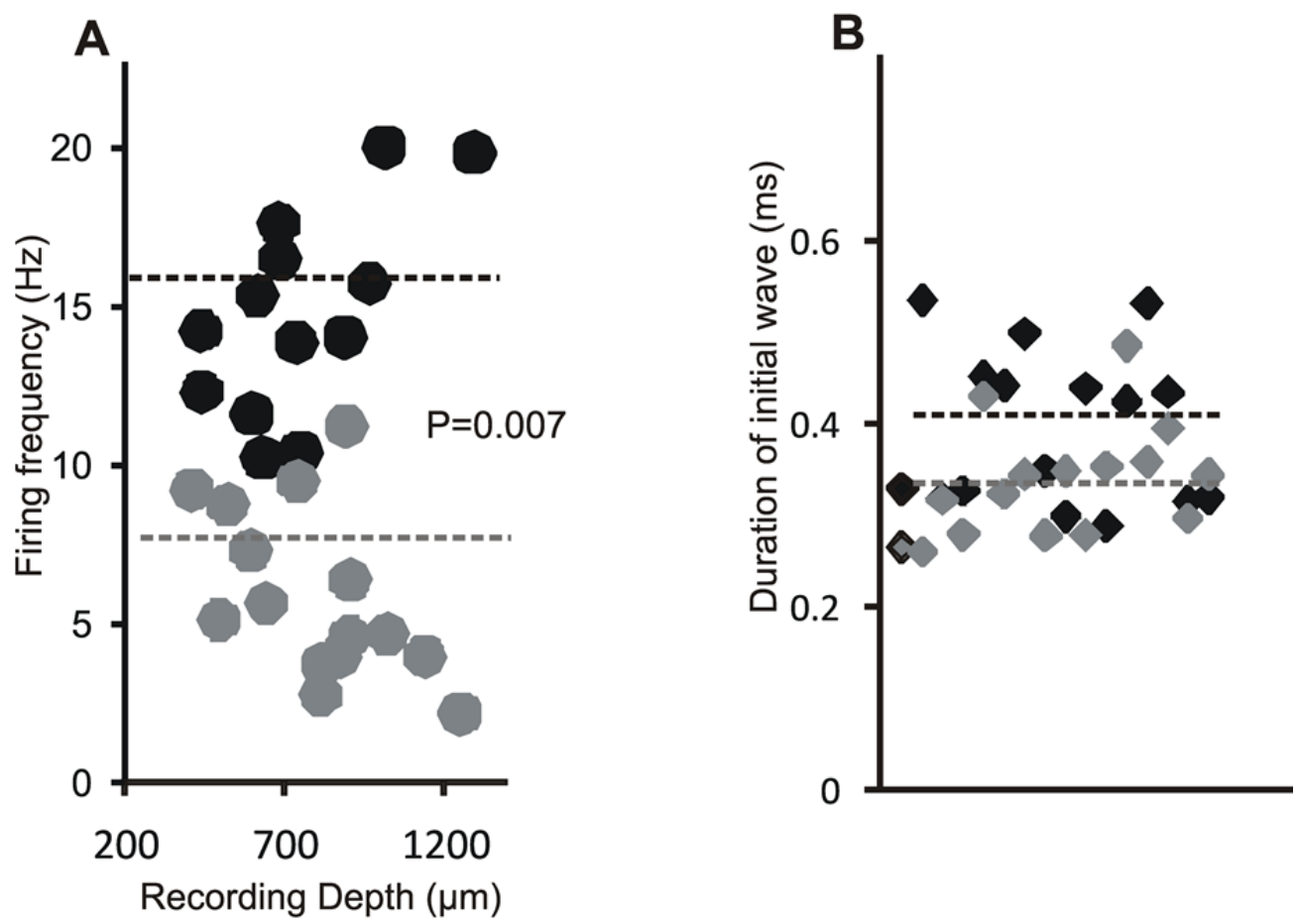

Figure 5.8 Spike frequency and spike characteristics analysis.

(A) Spike Frequency analysis in WT and Fmrl KO mice. (B) Duration of initial waves in WT and Fmrl KO mice. Dotted line shows the mean value. In both graphs black ink represents WT data and gray.ink represents KO data. 
were different $(\mathrm{P}=0.007)$ between these two genotypes. Averaged across layers the overall firing rates were WT: $16.49 \mathrm{~Hz}(\mathrm{~N}=16)$ and $\mathrm{KO}: 7.68 \mathrm{~Hz}(\mathrm{~N}=16)$. Firing frequency was not measured in a layer specific manner. Depths of all recordings were 300-1200 $\mu \mathrm{m}$ below the pia, based on microdrive depth readings. Recording depth was estimated from the vertical distance between the surface of the microdrive and recording spot. The duration of initial wave was measured as mentioned by Simons to verify the cell variability (Simons 1978). From each data file average waveform was drawn from ten consecutive spikes in that file. Then duration of initial wave was measured from that average waveform. In our data, the duration of the initial waves collected from WT and $\mathrm{KO}$ mice were in the 300-500 $\mu$ s range. According to a previous published report, waveforms within the duration range of 350-500 $\mu$ s were considered as regular cortical spikes (RS) (Mountcastle et al. 1957). This data (Figure 5.8B) confirms that all data collected in extracellular recordings were from pyramidal cells those produce RS

\section{Rhythm Abnormalities in Fmr1 KO Mice}

Breathing signals were also recorded from $\mathrm{KO}$ mice. Breathing data revealed that most of the time KO mice breath arhythmically. $3 \mathrm{~Hz}$ oscillations were absent in the autocorrelograms of local field potentials recorded from barrel cortex of KO mice (Figure 5.5).

\section{Discussion}

Very little is known about cortical circuit dysfunction in Fmrl KO mice. This in vivo study of cortical activity is the $1^{\text {st }}$ study performed on totally awake Fragile $\mathrm{X}$ animals.

\section{Relative Power of the LFP Signals in Different Frequency Bands}

Synchronous and oscillatory neuronal activity patterns on a millisecond to hundred of milliseconds time scale are characteristic features of the normal function of mammalian neocortical networks (Salinas and Sejnowski 2001). Synchronous and oscillatory neuronal activities in the neocortex has been linked to basic sensori-motor processing (Baker et al. 2001; Grammont and Riehle 2003; Murthy and Fetz 1992) and higher cognitive processes and cognition (Engel et al. 2001; Fries et al. 2001; Fries 2005; Singer 1993; Varela et al. 2001; Ward 2003). Synchronized oscillations are very important for normal brain functions. So, abnormal or uncontrolled synchronization could be disadvantageous or even pathological (Schnitzler and Gross 2005; Uhlhaas and Singer 2006b). The relative power comparison of the LFP signals in different frequency bands revealed that Fmrl KO mice had significantly lower power in the delta frequency band and significantly higher power in the beta frequency band compared to $\mathrm{KO}$ mice.

The functional significance of delta oscillations is not fully understood. Delta 
oscillations dominate the EEG of waking reptiles. In humans, they are prominent only in early developmental stages and during slow-wave sleep (Knyazev 2012). Increase of delta power has been documented in a wide array of developmental disorders and pathological conditions. Pizzagalli et al. had showed that a subtype of depression was associated with increased delta activity in the subgenual prefrontal cortex (Pizzagalli et al. 2004). Wacker et al. showed that delta activity in the rostral anterior cingulated cortex correlates negatively with the nucleus accumbens responses to reward and is positively associated with anhedonia scores (Wacker et al. 2009). Knyazev showed that when subjects expected bad news, delta power and connectivity increased in a network of cortical areas (Knyazev 2011). This increase was more pronounced in subjects with higher scores on state anxiety. Increase of delta power and coherence were also observed during tonic experimental muscle pain (Le et al. 2000), in patients with chronic pancreatitis (Olesen et al. 2011), and in migraine patients (Bjork et al. 2009; Genco et al. 1994; Muellbacher and Mamoli 1994; Ramelli et al. 1998). All these data show an increase of delta power associated with pathological states. But decrease of delta power has not been reported yet.

The cellular and network mechanisms underlying the generation of increased beta oscillation ( $\beta$ ) power in cortical LFP activity are unknown. It has been shown that in Parkinson's disease (PD) patients, synchronization of the oscillatory activities of single neurons and/or neuronal populations in cortex, subthalamic nucleus (STN) and internal pallidum preferentially occurs at $\beta$ frequencies (Brown 2006; Hammond et al. 2007). Using a clinically relevant rat model of PD, Mallet et al. demonstrated that oscillatory activities in globus pallidus neuronal networks becomes excessively and selectively synchronized at beta frequencies in a spatially widespread and brain state-dependent manner after lesion of dopamine neurons (Mallet et al. 2008). However, they found that although synchronization of globus pallidus unit activity increased by almost 100 -fold during beta oscillations, the mean firing rate of globus pallidus neurons decreased compared with controls. Wang and colleagues reported that phosphorylation in response to D1 receptor stimulation was reduced in cultured Fmr1 KO prefrontal cortex (PFC) neurons (Wang et al. 2008). Their study identified FMRP as a key messenger for dopamine modulation in the forebrain. Fulks et al (Fulks et al. 2010) compared electrically evoked dopamine release and uptake in Fmr1 KO and WT mice using fastscan cyclic voltammetry at carbon-fiber microelectrodes in striatal brain slices. At 10 weeks of age, dopamine release per pulse, which is dopamine release corrected for differences in uptake, was unchanged between two genotypes. However, at 15 weeks of age or older, dopamine per pulse and the maximum rate of dopamine uptake was diminished in Fmrl KO mice compared to WT mice. So, lower level dopamine of release could be the cause of higher beta power.

\section{Relationship between Respiration and $3 \mathrm{~Hz}$ Oscillation}

In our previous study, we found that the rhythms of respiratory and whisking movements were correlated during low-frequency whisking and respiration (Cao et al. 2012). In the present study we also collected breathing data while recording LFP from the 
whisker barrel cortex of both WT and KO mice. Breathing data revealed that WT mice breath rhythmically at around $3 \mathrm{~Hz}$ frequency and the breathing signals were highly correlated to LFP signals. $3 \mathrm{~Hz}$ oscillation was also present in the autocorrelograms of LFP signals recorded from healthy WT animals. These findings implied that in mice $3 \mathrm{~Hz}$ respiratory activity could directly modulate $3 \mathrm{~Hz}$ oscillations of LFP signals in whisker barrel cortex. When the animals were briefly exposed to hypoxic air, the delta band LFP frequency was increased parallel with the respiratory rhythm. The coherence between the respiratory rhythm and the LFP activity remained stable during increased respiratory frequency. This result confirmed that $3 \mathrm{~Hz}$ respiratory activity directly modulates $3 \mathrm{~Hz}$ oscillations in LFP signals recorded from barrel cortex of mice. The physiological mechanism linking respiratory and local field potential activity, i.e. the modulation of mass neuronal activity phase-locked with the respiratory cycle is unknown.

\section{Role of Olfactory Bulb in Delta Band Oscillation}

Recently, Phillips et al. reported that during respiration, air flow through nostril produces rhythmic activity in the entire olfactory system, driving neurons in the olfactory epithelium, olfactory bulb (OB), and cortex. Thus, respiration drives distinct network activities that functionally modulate sensory processing in the OB (Phillips et al. 2012). Our respiration and LFP data collected from olfactory bulbectomized mice revealed that removal of the olfactory bulb reduces the coherence between respiration and delta band LFP oscillations This suggests that respiration-locked oscillatory activity in the olfactory bulb drives delta band oscillations in the neocortex.

\section{Abnormalities in Fmr 1 Brain and Its Impact on Spontaneous Firing}

In this study, we found that the spontaneous firing frequency of neurons in barrel cortex was slower in Fmrl KO mice compared to WT mice. Depths of all recordings were 300-1200 $\mu \mathrm{m}$ below the pia, based on microdrive depth readings. Recording depth was estimated from the vertical distance between the surface of the microdrive and recording spot. As the surface of the barrel cortex is curved this depth calculation is not very reliable. Long time ago Simons (Simons 1978) categorized all different cortical spikes in two different groups. According to him, "Regular" cortical spikes (RS) were observed throughout layers II-VI and "fast" cortical spikes (FS) were less frequently encountered and largely restricted to layer IV(Simons 1978). Furthermore our data is showing no layer specific effect on the firing frequency. The duration of initial wave was measured as mentioned by Simons (Simons 1978) to verify the cell variability. All the durations were within 300-500 $\mu$ s range. According to Mountcastle et al. (Mountcastle, DAVIES, \& BERMAN 1957) duration range 350-500 $\mu$ s considered as regular cortical spikes (RS) and the waveforms which were initially negative waves lasting approximately $150 \mu$ s are designated as fast spikes (FS) (Simons 1978). So my data confirms that all of my extracellular recordings were collected from regular spiking pyramidal neurons. 
Spontaneous firing plays a central role in transforming synaptic input into spike output. So spontaneous firing is not only a prominent feature of many neuronal networks but also serve useful functional roles, contributing to regulating information flow in different microcircuits in the brain (Hausser et al. 2004). Altered spontaneous rate could be the indication of abnormal information flow in different microcircuits in the Fmrl KO brain. Recently, Hays et al. measured the spontaneous firing in active states (UP state) from layer 4 of primary somatosensory cortex (Hays et al. 2011). They used acute neocortical slices obtained from 3- to 4-week-old WT and Fmrl KO mice, and detected $18 \%$ decrease in the UP state frequency in KO slices compared to WT slices. But when they recorded UP state activity from the somatosensory cortex of anesthetized mice in vivo, they found that the frequency of UP states was not detectably different. So difference in vitro may reflect way they generated spontaneous activity.

Bureau and colleagues mapped the ascending excitatory circuits impinging onto L3 neurons in the barrel cortex of developing Fmrl KO mice and reported that the major features of the circuits were similar in wild-type and Fmrl KO mice (Bureau et al. 2008). Thus, FMRP does not prevent the development of the normal columnar organization of functional cortical circuits. However, they observed several important alterations in the ascending circuits. First, the strength of the L4 to L3 projection was decreased by $40 \%$ in the Fmrl KO mice. This defect was likely caused by a reduction in the connection probability between L4 stellate cells and L3 pyramidal cells. Second, L4 axons were abnormally diffuse in the L2/3 of young Fmrl KO mice. Thus, FMRP plays a role in axon guidance or axon pruning in the neocortex. Thus, reduced connectivity in the whisker barrel circuit may explain the reduced spiking activity of neurons in the Fmrl KO mice.

\section{Rhythm Abnormalities in Fmr1 KO Mice}

In this study, several rhythm abnormalities especially in delta range (1-4 Hz) were found in $\mathrm{KO}$ mice. In adult humans, delta oscillations are most evident during the slowwave sleep (Knyazev 2012). Majority of delta oscillation-related publications concerns sleep. But in our study we collected data from awake behaving mice. Now, the important question is whether slow-wave sleep delta and waking delta represent the same oscillation. Studies correlating positron emission tomography (PET) and EEG showed a positive correlation between waking delta and PET metabolism in the medial frontal cortex (Alper et al. 1998; Alper et al. 2006). On the other hand, the Maquet group studied slow-wave sleep using PET and found decreased brain activity during slow-wave sleep sleep (Maquet 2000). Thus slow-wave sleep delta differs from waking delta in its relation to brain metabolism (Alper 1999). Wisniewski and colleague performed a waking EEG study in the group of Fragile X subjects and found nonspecific and diffuse disturbances in cerebral activity, with the most common constellation of abnormalities consisting of slow background rhythm and abnormal intermittent, bilateral rhythmic theta or delta activity (Wisniewski et al. 1991). Till now no reports are available with these rhythm abnormalities in Fragile X patients. 
When I analyzed breathing data collected from awake $\mathrm{KO}$ mice (while recording LFP from the whisker barrel cortex), I found that KO mice breathe arhythmically. These breathing signals were highly correlated to LFP signals recorded from whisker barrel cortex. $3 \mathrm{~Hz}$ oscillation was also not present in the autocorrelograms of LFP signals recorded from $\mathrm{KO}$ animals. This finding suggested that in $\mathrm{KO}$ mice, absence of $3 \mathrm{~Hz}$ respiratory rhythm could be causally linked to the reduction of delta rhythm of LFP signals in cortex. 


\section{CHAPTER 6. SUMMARY}

Sensory system in mice and somatosensory processing is abnormal in patients. The Fmrl KO mouse, in which the Fmrl gene is inactivated, is a widely accepted animal model for FXS which I used here to investigate the behavioral and possible underlying neuro-physiological abnormalities associated with FXS. Ideally, animal models of FXS would exhibit the hallmark behavioral and cognitive deficits observed in affected humans. Several behavioral characterizations have been performed for Fmrl KO mice previously. But the orofacial motor abnormalities in mouse model have previously been overlooked. Furthermore, nothing was known about neuronal circuit dysfunction in the awake state as most experiments targeting cortical function were performed in vitro or in anesthetized preparations. In this dissertation, I performed phenotypic and electrophysiologic characterizations of Fmrl KO mice while they were awake. I organized the following summary of my work according to the specific aims of this study.

\section{Review of Aims}

\section{Specific Aim 1}

In specific aim 1, it was hypothesized that as fragile $\mathrm{X}$ patients suffer from oral motor control deficits resulting in speech abnormalities, related deficits might be expressed in orofacial motor activities and ultrasonic vocalization behaviors of $\mathrm{Fmrl}$ mice. It was also hypothesized that fragile $\mathrm{X}$ mice might show abnormalities in whisking behavior, because the mystacial vibrissae system is a major sensory system in mice and somatosensory processing is abnormal in patients.

To find oromotor abnormalities, I used a long-term fluid licking assay. Fluid licking in rodents involves coordination of oromotor movements, such as tongue protrusion and retraction and jaw opening and closing. So, licking constitutes an ideal behavior al paradigm for the study of orofacial motor control. It is an easily quantifiable natural behavior of rodents (Heck, Zhao, Roy, LeDoux, \& Reiter 2008). Our data from the long term fluid licking assay revealed that Fmrl KO mice had significantly slower rhythmic fluid-licking movement compared to their WT littermates. The licking rhythms were more variable in KO mice than WT mice. As tongue movement is very important for licking, Flower and Mortell concluded after their study that tongue movements modulate lick rhythm (Fowler and Mortell 1992). Overall, our lick results suggest that loss of Fmrl expression may influence tongue dynamics of KO mice. Although fluid consumption is a more complex behavior than just the protrusion and retraction of the tongue, the analysis looks at just the licking for simplicity. During the fluid-consumption, the mouse must lick, swallow, and breathe. Cerebellum coordinates the timing and occurrence of all of the events that occur during fluid-consumption. Bowman and Aldes had showed that the cerebellum can influence the motor aspects of fluid licking (Bowman 
and Aldes 1980). Pharmacological inactivation of the deep cerebellar nuclei causes a significant reduction of licking frequencies in mice and rats. Most interestingly significant reduction of sizes of two deep cerebellar nuclei (medial and interpositus) have been found in Fmrl KO mice (Ellegood, Pacey, Hampson, Lerch, \& Henkelman 2010). We predict that our observed altered licking pattern in Fmrl KO mouse may be due the reduced volumes of deep cerebellar nuclei.

At the beginning, long term fluid licking assay was performed in FVB background. Fmrl KO mice are also available in another background C57BL/6(B6). There are some contradictory reports on the behavior of Fmr1 KO mice when studied in different genetic backgrounds. Not only the behavioral differences, studies have demonstrated that the Fmrl mutation had opposite effects on the cortical spine morphology. In the occipital cortex significantly increased dendritic spine density observed in individuals with FXS (Irwin, Patel, Idupulapati, Harris, Crisostomo, Larsen, Kooy, Willems, Cras, Kozlowski, Swain, Weiler, \& Greenough 2001) and in adult Fmr1 $\mathrm{KO}$ mice bred in a C57BL/6 background(McKinney, Grossman, Elisseou, \& Greenough 2005) did not reach statistical significance in Fmr1 KO mice bred in an FVB background (Irwin, Idupulapati, Gilbert, Harris, Chakravarti, Rogers, Crisostomo, Larsen, Mehta, Alcantara, Patel, Swain, Weiler, Oostra, \& Greenough 2002). According to Mckinney (McKinney, Grossman, Elisseou, \& Greenough 2005), Fmrl KO mice bred in a C57BL/6 background may more closely model the human FXS condition than those bred in an FVB background. It appears that the genetic background modulated the effects of the Fmrl deletion. Like all other research groups (Pietropaolo, Guilleminot, Martin, D'Amato, \& Crusio 2011) we also came to the conclusion that the C57BL/6 background may be more suitable for further research. So I performed rest of my study using Fmr I $\mathrm{KO}$ mice on C57BL/6 background.

Mouse pups produce different types of ultrasonic vocalizations (USVs) when they are isolated from their mother and littermates. Zippelius and Schleidt first reported that infant mice produce USVs when separated from their mother and litter (Zippelius and Schleidt 1956). Since then, several studies have shown that measuring USVs can provide new insights into emotion and motivation as well as communication in mice and rats. I hypothesized that KO mice would suffer from USV articulation problems, which would be reflected in qualitative and quantitative characteristics of their ultrasonic vocalizations. After analyzing all the USVs through the sonograms, I found that Fmrl KO mouse pups have several call-type specific deficits in isolation-induced USVs. The neuronal mechanisms controlling human speech articulation and mouse oromotor/ vocalization behavior are poorly understood. Several lines of evidence suggest that the cerebellum may play an important role in oromotor and vocalization/ articulation in both species. In mice, the cerebellum has been shown to be critically involved in the generation of ultrasonic vocalizations (Fujita, Tanabe, Shiota, Ueda, Suwa, Momoi, \& Momoi 2008b). In humans, speech articulation deficits (dysarthria) are common in patients with cerebellar disorders (Gordon 1996). Cerebellar neuropathologies, which are consistently found in fragile X patients (Mostofsky, Mazzocco, Aakalu, Warsofsky, Denckla, \& Reiss 1998; Zingerevich, Greiss-Hess, Lemons-Chitwood, Harris, Hessl, Cook, \& Hagerman 2009), might be partially responsible for speech articulation deficits in FXS patients 
(Abbeduto, Brady, \& Kover 2007; Barnes, Roberts, Mirrett, Sideris, \& Misenheimer 2006; Newell, Sanborn, \& Hagerman 1983; Paul, Dykens, Leckman, Watson, Breg, \& Cohen 1987). In previous studies we found oromotor deficits in a Ube $3 a$ deficient mouse model of Angelman syndrome (Heck, Zhao, Roy, LeDoux, \& Reiter 2008) and in Fmrl KO mice (Roy, Zhao, Allensworth, Farook, Ledoux, Reiter, \& Heck 2011b). Sensory mapping studies and recordings in awake behaving rodents have shown that the orofacial area is strongly represented in the cerebellum of rats and mice (Bryant, Boughter, Gong, Ledoux, \& Heck 2010; Shambes, Gibson, \& Welker 1978; Welsh, Lang, Suglhara, \& Llinas 1995). Thus, cerebellar deficiency due to the reduced volume of the medial and interposed nuclei of Fmr I-KO mouse (Ellegood, Pacey, Hampson, Lerch, \& Henkelman 2010) likely contributes to USV articulation deficits in mouse. Cerebellar neuropathology is also a common finding in fragile X patients (Reiss, Aylward, Freund, Joshi, \& Bryan 1991) and may thus contribute to speech articulation deficits in humans.

My detailed study on the whisker movements of adult mice using 3D whisker trajectory allowed me to determine potential deficiencies in whiskers movements associated with loss of Fmrl expression. In this study I compared the in-air whisker movements in two genotypes, as they are typically observed during free exploration. Our ability to track whisker positions allowed quantitative assessment of kinematic parameters of the whisker movement and quantification of asymmetries and asynchronies between whiskers on either side of the face. Power spectral density analysis of whisking frequency revealed that whisker movements occur at modal frequencies of $11-16 \mathrm{~Hz}$ in each dimension for both genotypes. The average frequency of whisker movements in our hands was in the same range as reported by Voigts and colleagues (Voigts, Sakmann, \& Celikel 2008). Voigts group performed whisker tracking using high-speed video cameras in freely behaving animals during haptic object exploration. Peak frequencies of largeamplitude whisker movements were mostly distributed between 10 and $15 \mathrm{~Hz}$. Furthermore our power spectral density analysis of whisking frequency showed one extra peak at the frequency range of $5-10 \mathrm{~Hz}$ in each dimension only for $\mathrm{KO}$ mice. This appearance of one additional peak in each dimension for $\mathrm{KO}$ mice indicated that the dynamics of 3-D whisker movements were different in KO mice than their WT littermates. We assumed that the loss of Fmrl expression in mice might have resulted in the impairment of whisker movement which is important for sensory exploration. Whisker motor neurons have been shown to be located in the lateral facial nucleus and their cellular properties contribute to the rhythmicity of whisking (Brecht et al. 2006). Miller and colleague found direct involvement of cranial nerves in autism (Miller et al. 1998). Another study with zebrafish had found the effects of fmr1 expression on trigeminal neuron number and craniofacial pattern, which suggest a role for this gene in cranial neural crest specification and possibly migration (Tucker et al. 2006). Based on the above findings the abnormal whisking abnormalities in $\mathrm{KO}$ mice could be attributed to the disruption of motor control circuits due to the absence of Fmrl gene. But how observed deficits in the $\mathrm{KO}$ mice affect sensory processing remains to be shown. 


\section{Specific Aim 2}

How abnormal spine development in neocortical neurons in FXS affect the cortical network was the main question for the second aim of this study. In this study, I mainly focused on network synchronization and oscillatory neuronal activity. It was hypothesized that in Fmrl KO mice, synchronous and oscillatory neuronal activities would be abnormal due to disruption of short and long range neuronal connectivities. Most of the research done so far on network activities in the barrel cortex of fragile $\mathrm{X}$ mice took place either on slices or on anesthetized animals, which I believe is different from studying the system during normal behavior. The recording of neuronal activities in awake and behaving mice is very important for this type of neurophysiological investigation. Anesthesia might differentially affect the activities in $\mathrm{KO}$ and WT mice, and would introduce an uncontrolled variable. Here I recorded single and multiunit spike activities and local field potentials from whisker barrel cortex of awake mice.

Analysis of single unit spike data revealed that the spontaneous firing frequency of neurons in barrel cortex was lower in Fmrl KO mouse compared to their WT littermates. Spontaneous firing arises from specific combinations of intrinsic membrane currents expressed by spontaneously active neurons (Llinas 1988). Spontaneous firing plays a central role in transforming synaptic input into spike output. So spontaneous firing is not only a prominent feature of many neuronal networks but may also serve useful functional roles, contributing to regulating information flow in different microcircuits in the brain (Hausser, Raman, Otis, Smith, Nelson, du, Loewenstein, Mahon, Pennartz, Cohen, \& Yarom 2004). So, altered spontaneous rate could be the indication of the abnormal information flow in different microcircuits in the Fmrl KO brain. Slice recordings from layer 4 of primary somatosensory cortices have shown an $18 \%$ decrease of firing frequency in KO mice compared to WT (Hays, Huber, \& Gibson 2011). My in vivo data is in accordance with the slice data produced by Hays et al.

We recorded local field potential (LFP) in parallel with cortical spiking activity. Our goal was to investigate whether FXS mice suffer from any abnormality in neuronal activity across the network and thus impair network function. The cortical LFP reflects the summed dendritic currents of the pyramidal cells in a local neuronal assembly (Bressler, Richter, Chen, \& Ding 2007; Elul 1971); LFP is an indicator for the underlying network activity that typically exhibits prominent oscillatory features and has been shown to display modulations that contain information about relevant behavior (Mehring et al. 2003; Roux et al. 2006). The oscillatory nature of the cortical LFP is commonly interpreted as a reflection of synchronized network activity (Denker et al. 2011). I performed relative power comparison of the LFP signals in different frequency bands which revealed that compared to WT mice, Fmrl KO mice had significantly lower power in the delta frequency band and significantly higher power in the beta frequency band. $3 \mathrm{~Hz}$ oscillation was also absent from the autocorrelograms of LFP signals of KO animals. In the cortex, inhibitory neurotransmission is mediated by a diverse population of interneurons characterized by their distinct morphological, biochemical and electrophysiological properties (Markram, Toledo-Rodriguez, Wang, Gupta, Silberberg, \& Wu 2004). Paluszkiewicz et al (Paluszkiewicz et al. 2011b) investigated activity- 
driven inhibition by low-threshold-spiking (LTS) interneurons in layer II/III of somatosensory cortex in Fmrl KO mice. They found that, under control conditions, spontaneous inhibitory postsynaptic current (sIPSC) frequency was not significantly different in WT and Fmrl KOs. Bath application of the group I metabotropic glutamate receptor (mGluR) agonist DHPG in WT mice led to a large increase in sIPSC frequency. DHPG also increased event frequency in Fmrl KOs. Interestingly, however, sIPSC frequency in the presence of DHPG was significantly lower in Fmrl KOs, as compared to WT, which indicates that group I mGluR-dependent inhibition is dampened in FmrI KOs. This finding revealed a functional defect in a single subtype of cortical interneuron in Fmrl KO mouse. Dendrite-targeting interneurons in cortical layer II/III contribute to the synchronization of cell networks over a range of frequencies, including theta, beta, and gamma (Blatow et al. 2003; Szabadics et al. 2001). Functional defects in interneurons could be one possible reason for higher beta power. Lower level of dopamine release in Fmrl mouse brain (Fulks, O'Bryhim, Wenzel, Fowler, Vorontsova, Pinkston, Ortiz, \& Johnson 2010) could be another possible reason for higher beta power. Fulks et al used 6OHDA-lesioned rats, a rodent model of Parkinson's disease (PD), to investigate the neural basis of abnormal synchronized oscillations in globus pallidus (GP) and subthalamic nucleus (STN) after dopamine loss. They found that 6-OHDA lesions and thus loss of cortical dopamine release profoundly increased beta oscillations in both cortex and GP.

The mechanisms behind the reduced power in delta frequency range in LFP signals in KO mice remain to be identified. It was also found that in the case of healthy WT mice this delta band oscillation in barrel cortex was phased locked to the respiratory rhythm. In KO mice it was found that breathing was very arrhythmic. When respiratory rates of the healthy WT animals were increased due to brief exposure to hypoxic air, the resulting frequency of the delta/theta band LFP oscillations was also increased which indicated that in mice respiratory activity directly modulated delta band LFP oscillations. Respiratory arrhythmia in the KO mice thus could be causally linked with the reduced power in the LFP delta frequency range. Recently Phillips and colleagues (Phillips, Sachdev, Willhite, \& Shepherd 2012) have reported that respiration, specially nasal air flow, drives distinct network oscillations in the olfactory bulb (OB) in rodents. The rhythmic natures of this activity are believed to be critical components of sensory processing. Furthermore, recently a group performed morphological analysis of granule cells (GCs) of OB in the Fmrl KO mice and found an increase in spine density without a change in spine length (Scotto-Lomassese et al. 2011). So the abnormalities of OB cells in Fmrl mice could cause reduced OB oscillatory activity and thus contribute to the reduction of delta rhythm in the cortical LFP signals in KO mice.

\section{Conclusions}

Identified behavioral and neuro-physiological deficits in the Fmr1 KO mouse model of fragile $\mathrm{X}$ syndrome and conclusions:

1. Loss of the Fmrl gene causes a significant slowing in lick rhythm and an 
increase in variability of the licking rhythm.

2. Fmrl KO of mice have reduced number of ultrasonic vocalizations in a specific type call (downward).

3. The base frequencies of their ultrasonic calls are higher than their WT littermates.

4. The dynamics of whisker movements is abnormal in Fmrl KO mice.

5. Cortical neurons of $\mathrm{KO}$ mice have a slower baseline firing rate than WT mice.

6. Loss of Fmrl expression is associated with changes in the relative powers of the delta and beta rhythms of local field potential activities. 


\section{LIST OF REFERENCES}

Abbeduto, L., Brady, N., \& Kover, S.T. 2007. Language development and fragile X syndrome: profiles, syndrome-specificity, and within-syndrome differences.

Ment.Retard.Dev.Disabil.Res.Rev., 13, (1) 36-46 available from: PM:17326110.

Abrahams, B.S. \& Geschwind, D.H. 2008. Advances in autism genetics: on the threshold of a new neurobiology. Nat.Rev.Genet., 9, (5) 341-355 available from: PM:18414403.

Alper, K., Gunther, W., Prichep, L.S., John, E.R., \& Brodie, J. 1998. Correlation of qEEG with PET in schizophrenia. Neuropsychobiology, 38, (1) 50-56 available from: PM:9701722.

Alper, K.R. 1999. The EEG and cocaine sensitization: a hypothesis. J.Neuropsychiatry Clin.Neurosci., 11, (2) 209-221 available from: PM:10333992.

Alper, K.R., John, E.R., Brodie, J., Gunther, W., Daruwala, R., \& Prichep, L.S. 2006. Correlation of PET and qEEG in normal subjects. Psychiatry Res., 146, (3) 271-282 available from: PM:16603341.

Arieli, A., Sterkin, A., Grinvald, A., \& Aertsen, A. 1996. Dynamics of ongoing activity: explanation of the large variability in evoked cortical responses. Science, 273, (5283) 1868-1871 available from: PM:8791593.

Asanuma, C., Thach, W.T., \& Jones, E.G. 1983. Brainstem and spinal projections of the deep cerebellar nuclei in the monkey, with observations on the brainstem projections of the dorsal column nuclei. Brain Res., 286, (3) 299-322 available from: PM:6189563.

Ashley, C.T., Jr., Wilkinson, K.D., Reines, D., \& Warren, S.T. 1993. FMR1 protein: conserved RNP family domains and selective RNA binding. Science, 262, (5133) 563 566 available from: PM:7692601.

Baker, S.N., Spinks, R., Jackson, A., \& Lemon, R.N. 2001. Synchronization in monkey motor cortex during a precision grip task. I. Task-dependent modulation in single-unit synchrony. J.Neurophysiol., 85, (2) 869-885 available from: PM:11160519.

Bakker, C.E., Verheij, C., Willemsen, R., Helm, R., Oerlemans, F., Vermey, M., Bygrave, A., Hoogeveen, A.T., Oostra, B.A., Reyniers, E., De Boule, A., D'Hooge, R., Patrick C., Velzen, D.V., Nagels, G., Martin, J.J., Deyn, P.P., Darby, J.K.a., W, \& lems, P.J. 1994. Fmr1 knockout mice: a model to study fragile X mental retardation. The Dutch-Belgian Fragile X Consortium. Cell, 78, (1) 23-33 available from: PM:8033209. 
Barnes, E.F., Roberts, J., Mirrett, P., Sideris, J., \& Misenheimer, J. 2006. A comparison of oral structure and oral-motor function in young males with fragile $\mathrm{X}$ syndrome and Down syndrome. J.Speech Lang Hear.Res., 49, (4) 903-917 available from: PM:16908884.

Belmonte, M.K. \& Bourgeron, T. 2006. Fragile X syndrome and autism at the intersection of genetic and neural networks. Nat.Neurosci., 9, (10) 1221-1225 available from: PM:17001341.

Bermejo, R., Vyas, A., \& Zeigler, H.P. 2002. Topography of rodent whisking--I. Twodimensional monitoring of whisker movements. Somatosens.Mot.Res., 19, (4) 341-346 available from: PM:12590835.

Bernardet, M. \& Crusio, W.E. 2006. Fmr1 KO mice as a possible model of autistic features. Scientific WorldJournal., 6, 1164-1176 available from: PM:16998604.

Berry-Kravis, E. 2002. Epilepsy in fragile X syndrome. Dev.Med.Child Neurol., 44, (11) 724-728 available from: PM:12418611.

Berry-Kravis, E., Raspa, M., Loggin-Hester, L., Bishop, E., Holiday, D., \& Bailey, D.B. 2010. Seizures in fragile X syndrome: characteristics and comorbid diagnoses.

Am.J.Intellect.Dev.Disabil., 115, (6) 461-472 available from: PM:20945999.

Bjork, M.H., Stovner, L.J., Engstrom, M., Stjern, M., Hagen, K., \& Sand, T. 2009. Interictal quantitative EEG in migraine: a blinded controlled study. J.Headache Pain, 10, (5) 331-339 available from: PM:19705061.

Blatow, M., Rozov, A., Katona, I., Hormuzdi, S.G., Meyer, A.H., Whittington, M.A., Caputi, A., \& Monyer, H. 2003. A novel network of multipolar bursting interneurons generates theta frequency oscillations in neocortex. Neuron, 38, (5) 805-817 available from: PM:12797964.

Bowes, C., Li, T., Frankel, W.N., Danciger, M., Coffin, J.M., Applebury, M.L., \& Farber, D.B. 1993. Localization of a retroviral element within the rd gene coding for the beta subunit of cGMP phosphodiesterase. Proc.Natl.Acad.Sci.U.S.A, 90, (7) 2955-2959 available from: PM:8385352.

Bowman, J.P. \& Aldes, L.D. 1980. Organization of the cerebellar tongue representation in the monkey. Exp.Brain Res., 39, (3) 249-259 available from: PM:6772461.

Brecht, M. 2007. Barrel cortex and whisker-mediated behaviors. Curr.Opin.Neurobiol., 17, (4) 408-416 available from: PM:17702566.

Brecht, M., Grinevich, V., Jin, T.E., Margrie, T., \& Osten, P. 2006. Cellular mechanisms of motor control in the vibrissal system. Pflugers Arch., 453, (3) 269-281 available from: PM:16736208. 
Bressler, S.L., Richter, C.G., Chen, Y., \& Ding, M. 2007. Cortical functional network organization from autoregressive modeling of local field potential oscillations. Stat.Med., 26, (21) 3875-3885 available from: PM:17551946.

Brouette-Lahlou, I., Vernet-Maury, E., \& Vigouroux, M. 1992. Role of pups' ultrasonic calls in a particular maternal behavior in Wistar rat: pups' anogenital licking. Behav.Brain Res., 50, (1-2) 147-154 available from: PM:1449642.

Brown, P. 2006. Bad oscillations in Parkinson's disease. J.Neural Transm.Suppl. (70) 2730 available from: PM: 17017505.

Brudzynski, S.M., Kehoe, P., \& Callahan, M. 1999. Sonographic structure of isolationinduced ultrasonic calls of rat pups. Dev.Psychobiol., 34, (3) 195-204 available from: PM:10204095.

Brunelli, S.A., Shair, H.N., \& Hofer, M.A. 1994. Hypothermic vocalizations of rat pups (Rattus norveg.icus) elicit and direct maternal search behavior. J.Comp Psychol., 108, (3) 298-303 available from: PM:7924260.

Bryant, J.L., Boughter, J.D., Gong, S., Ledoux, M.S., \& Heck, D.H. 2010. Cerebellar cortical output encodes temporal aspects of rhythmic licking movements and is necessary for normal licking frequency. Eur.J.Neurosci., 32, (1) 41-52 available from: PM:20597972.

Bryant, J.L., Roy, S., \& Heck, D.H. 2009. A technique for stereotaxic recordings of neuronal activity in awake, head-restrained mice. J.Neurosci.Methods, 178, (1) 75-79 available from: PM:19073214.

Bureau, I., Shepherd, G.M., \& Svoboda, K. 2008. Circuit and plasticity defects in the developing somatosensory cortex of FMR1 knock-out mice. J.Neurosci., 28, (20) 51785188 available from: PM:18480274.

Cao, Y., Roy, S., Sachdev, R.N., \& Heck, D.H. 2012. Dynamic correlation between whisking and breathing rhythms in mice. J.Neurosci., 32, (5) 1653-1659 available from: PM:22302807.

Carvell, G.E. \& Simons, D.J. 1990. Biometric analyses of vibrissal tactile discrimination in the rat. J.Neurosci., 10, (8) 2638-2648 available from: PM:2388081.

Chen, L. \& Toth, M. 2001. Fragile X mice develop sensory hyperreactivity to auditory stimuli. Neuroscience, 103, (4) 1043-1050 available from: PM:11301211.

Cifra, A., Nani, F., Sharifullina, E., \& Nistri, A. 2009. A repertoire of rhythmic bursting produced by hypoglossal motoneurons in physiological and pathological conditions. Philos.Trans.R.Soc.Lond B Biol.Sci., 364, (1529) 2493-2500 available from:

PM:19651651. 
Comery, T.A., Harris, J.B., Willems, P.J., Oostra, B.A., Irwin, S.A., Weiler, I.J., \& Greenough, W.T. 1997. Abnormal dendritic spines in fragile X knockout mice: maturation and pruning deficits. Proc.Natl.Acad.Sci.U.S.A, 94, (10) 5401-5404 available from: PM:9144249.

Crawford, D.C., Acuna, J.M., \& Sherman, S.L. 2001. FMR1 and the fragile X syndrome: human genome epidemiology review. Genet.Med., 3, (5) 359-371 available from: PM:11545690.

David, S.V., Malaval, N., \& Shamma, S.A. 2010. Decoupling action potential bias from cortical local field potentials. Comput.Intell.Neurosci. 393019 available from: PM:20169096.

de Vries, B.B., van den Ouweland, A.M., Mohkamsing, S., Duivenvoorden, H.J., Mol, E., Gelsema, K., van, R.M., Halley, D.J., Sandkuijl, L.A., Oostra, B.A., Tibben, A., \& Niermeijer, M.F. 1997. Screening and diagnosis for the fragile X syndrome among the mentally retarded: an epidemiological and psychological survey. Collaborative Fragile X Study Group. Am.J.Hum.Genet., 61, (3) 660-667 available from: PM:9326332.

de Vrij, F.M., Levenga, J., van der Linde, H.C., Koekkoek, S.K., De Zeeuw, C.I., Nelson, D.L., Oostra, B.A., \& Willemsen, R. 2008. Rescue of behavioral phenotype and neuronal protrusion morphology in Fmr1 KO mice. Neurobiol.Dis., 31, (1) 127-132 available from: PM:18571098.

Denker, M., Roux, S., Linden, H., Diesmann, M., Riehle, A., \& Grun, S. 2011. The local field potential reflects surplus spike synchrony. Cereb.Cortex, 21, (12) 2681-2695 available from: PM:21508303.

Devys, D., Lutz, Y., Rouyer, N., Bellocq, J.P., \& Mandel, J.L. 1993. The FMR-1 protein is cytoplasmic, most abundant in neurons and appears normal in carriers of a fragile $\mathrm{X}$ premutation. Nat.Genet., 4, (4) 335-340 available from: PM:8401578.

Dobkin, C., Rabe, A., Dumas, R., El, I.A., Haubenstock, H., \& Brown, W.T. 2000. Fmr1 knockout mouse has a distinctive strain-specific learning impairment. Neuroscience, 100, (2) 423-429 available from: PM:11008180.

Ehret, G. 1992. Categorical perception of mouse-pup ultrasounds in the temporal domain. Animal Behaviour, 43, (3) 409-416.

Ehret, G. \& Bemecker, C. 1986. Low-frequency sound communication by mouse pups (Mus Musculus): wriggling calls release maternal behaviour. Animal Behaviour, 34, (3) 821-827.

Ellegood, J., Pacey, L.K., Hampson, D.R., Lerch, J.P., \& Henkelman, R.M. 2010. Anatomical phenotyping in a mouse model of fragile $\mathrm{X}$ syndrome with magnetic resonance imaging. Neuroimage., 53, (3) 1023-1029 available from: PM:20304074. 
Elul, R. 1971. The genesis of the EEG. Int.Rev.Neurobiol., 15, 227-272 available from: PM:4949975.

Engel, A.K., Fries, P., \& Singer, W. 2001. Dynamic predictions: oscillations and synchrony in top-down processing. Nat.Rev.Neurosci., 2, (10) 704-716 available from: PM:11584308.

Farrell, W.J. \& Alberts, J.R. 2002. Stimulus control of maternal responsiveness to Norway rat (Rattus norvegicus) pup ultrasonic vocalizations. J.Comp Psychol., 116, (3) 297-307 available from: PM:12234080.

Feng, Y., Absher, D., Eberhart, D.E., Brown, V., Malter, H.E., \& Warren, S.T. 1997. FMRP associates with polyribosomes as an $\mathrm{mRNP}$, and the $\mathrm{I} 304 \mathrm{~N}$ mutation of severe fragile X syndrome abolishes this association. Mol.Cell, 1, (1) 109-118 available from: PM:9659908.

Feng, Y., Lakkis, L., Devys, D., \& Warren, S.T. 1995. Quantitative comparison of FMR1 gene expression in normal and premutation alleles. Am.J.Hum.Genet., 56, (1) 106-113 available from: PM:7825564.

Fiala, J.C., Spacek, J., \& Harris, K.M. 2002. Dendritic spine pathology: cause or consequence of neurological disorders? Brain Res.Brain Res.Rev., 39, (1) 29-54 available from: PM:12086707.

Fowler, S.C. \& Mortell, C. 1992. Low doses of haloperidol interfere with rat tongue extensions during licking: a quantitative analysis. Behav.Neurosci., 106, (2) 386-395 available from: PM:1590957.

Frankland, P.W., Wang, Y., Rosner, B., Shimizu, T., Balleine, B.W., Dykens, E.M., Ornitz, E.M., \& Silva, A.J. 2004. Sensorimotor gating abnormalities in young males with fragile X syndrome and Fmr1-knockout mice. Mol.Psychiatry, 9, (4) 417-425 available from: PM:14981523.

Fries, P. 2005. A mechanism for cognitive dynamics: neuronal communication through neuronal coherence. Trends Cogn Sci., 9, (10) 474-480 available from: PM:16150631.

Fu, Y.H., Kuhl, D.P., Pizzuti, A., Pieretti, M., Sutcliffe, J.S., Richards, S., Verkerk, A.J., Holden, J.J., Fenwick, R.G., Jr., Warren, S.T., \& . 1991. Variation of the CGG repeat at the fragile X site results in genetic instability: resolution of the Sherman paradox. Cell, 67, (6) 1047-1058 available from: PM:1760838.

Fujita, E., Tanabe, Y., Shiota, A., Ueda, M., Suwa, K., Momoi, M.Y., \& Momoi, T. 2008. Ultrasonic vocalization impairment of Foxp2 (R552H) knockin mice related to speechlanguage disorder and abnormality of Purkinje cells. Proc.Natl.Acad.Sci.U.S.A, 105, (8) 3117-3122 available from: PM:18287060. 
Fulks, J.L., O'Bryhim, B.E., Wenzel, S.K., Fowler, S.C., Vorontsova, E., Pinkston, J.W., Ortiz, A.N., \& Johnson, M.A. 2010. Dopamine Release and Uptake Impairments and Behavioral Alterations Observed in Mice that Model Fragile X Mental Retardation Syndrome. ACS Chem.Neurosci., 1, (10) 679-690 available from: PM:21116467.

Galvez, R., Gopal, A.R., \& Greenough, W.T. 2003. Somatosensory cortical barrel dendritic abnormalities in a mouse model of the fragile $\mathrm{X}$ mental retardation syndrome. Brain Res., 971, (1) 83-89 available from: PM:12691840.

Galvez, R. \& Greenough, W.T. 2005. Sequence of abnormal dendritic spine development in primary somatosensory cortex of a mouse model of the fragile $\mathrm{X}$ mental retardation syndrome. Am.J.Med.Genet.A, 135, (2) 155-160 available from: PM:15880753.

Ganguly, K. \& Kleinfeld, D. 2004. Goal-directed whisking increases phase-locking between vibrissa movement and electrical activity in primary sensory cortex in rat. Proc.Natl.Acad.Sci.U.S.A, 101, (33) 12348-12353 available from: PM:15297618.

Genco, S., de, T.M., Prudenzano, A.M., Savarese, M., \& Puca, F.M. 1994. EEG features in juvenile migraine: topographic analysis of spontaneous and visual evoked brain electrical activity: a comparison with adult migraine. Cephalalgia, 14, (1) 41-46 available from: PM:8200025.

Gibson, J.R., Bartley, A.F., Hays, S.A., \& Huber, K.M. 2008. Imbalance of neocortical excitation and inhibition and altered UP states reflect network hyperexcitability in the mouse model of fragile X syndrome. J.Neurophysiol., 100, (5) 2615-2626 available from: PM:18784272.

Gordon, N. 1996. Speech, language, and the cerebellum. Eur.J.Disord.Commun., 31, (4) 359-367 available from: PM:9059570.

Gray, C.M., Konig, P., Engel, A.K., \& Singer, W. 1989. Oscillatory responses in cat visual cortex exhibit inter-columnar synchronization which reflects global stimulus properties. Nature, 338, (6213) 334-337 available from: PM:2922061.

Grossman, A.W., Aldridge, G.M., Weiler, I.J., \& Greenough, W.T. 2006. Local protein synthesis and spine morphogenesis: Fragile X syndrome and beyond. J.Neurosci., 26, (27) 7151-7155 available from: PM:16822971.

Gunter, C., Paradee, W., Crawford, D.C., Meadows, K.A., Newman, J., Kunst, C.B., Nelson, D.L., Schwartz, C., Murray, A., Macpherson, J.N., Sherman, S.L., \& Warren, S.T. 1998. Re-examination of factors associated with expansion of CGG repeats using a single nucleotide polymorphism in FMR1. Hum.Mol.Genet., 7, (12) 1935-1946 available from: PM:9811938.

Hagerman, P.J. \& Stafstrom, C.E. 2009. Origins of epilepsy in fragile X syndrome. Epilepsy Curr., 9, (4) 108-112 available from: PM:19693328. 
Hagerman, R., Hoem, G., \& Hagerman, P. 2010. Fragile X and autism: Intertwined at the molecular level leading to targeted treatments. Mol.Autism, 1, (1) 12 available from: PM:20858229.

Hagerman, R.J. \& Hagerman, P.J. 2002. Fragile X Syndrome: Diagnosis, Treament, and Research, 3rd ed. Baltimore, Johns Hopkins University Press.

Hagerman, R.J., Hall, D.A., Coffey, S., Leehey, M., Bourgeois, J., Gould, J., Zhang, L., Seritan, A., Berry-Kravis, E., Olichney, J., Miller, J.W., Fong, A.L., Carpenter, R., Bodine, C., Gane, L.W., Rainin, E., Hagerman, H., \& Hagerman, P.J. 2008. Treatment of fragile X-associated tremor ataxia syndrome (FXTAS) and related neurological problems. Clin.Interv.Aging, 3, (2) 251-262 available from: PM:18686748.

Hagerman, R.J., Ono, M.Y., \& Hagerman, P.J. 2005. Recent advances in fragile X: a model for autism and neurodegeneration. Curr.Opin.Psychiatry, 18, (5) 490-496 available from: PM:16639106.

Hahn, M.E. \& Lavooy, M.J. 2005. A review of the methods of studies on infant ultrasound production and maternal retrieval in small rodents. Behav. Genet., 35, (1) 31 52 available from: PM:15674531.

Hammond, C., Bergman, H., \& Brown, P. 2007. Pathological synchronization in Parkinson's disease: networks, models and treatments. Trends Neurosci., 30, (7) 357-364 available from: PM:17532060.

Harris, S.W., Hessl, D., Goodlin-Jones, B., Ferranti, J., Bacalman, S., Barbato, I., Tassone, F., Hagerman, P.J., Herman, H., \& Hagerman, R.J. 2008. Autism profiles of males with fragile X syndrome. Am.J.Ment.Retard., 113, (6) 427-438 available from: PM:19127654.

Hausser, M., Raman, I.M., Otis, T., Smith, S.L., Nelson, A., du, L.S., Loewenstein, Y., Mahon, S., Pennartz, C., Cohen, I., \& Yarom, Y. 2004. The beat goes on: spontaneous firing in mammalian neuronal microcircuits. J.Neurosci., 24, (42) 9215-9219 available from: PM:15496653.

Hayar, A., Bryant, J.L., Boughter, J.D., \& Heck, D.H. 2006. A low-cost solution to measure mouse licking in an electrophysiological setup with a standard analog-to-digital converter. J.Neurosci Methods, 2, (153) 203-207.

Hays, S.A., Huber, K.M., \& Gibson, J.R. 2011. Altered neocortical rhythmic activity states in Fmr1 KO mice are due to enhanced mGluR5 signaling and involve changes in excitatory circuitry. J.Neurosci., 31, (40) 14223-14234 available from: PM:21976507.

Heck, D.H., Zhao, Y., Roy, S., LeDoux, M.S., \& Reiter, L.T. 2008. Analysis of cerebellar function in Ube3a-deficient mice reveals novel genotype-specific behaviors. Hum.Mol.Genet., 17, (14) 2181-2189 available from: PM:18413322. 
Hinton, V.J., Brown, W.T., Wisniewski, K., \& Rudelli, R.D. 1991. Analysis of neocortex in three males with the fragile X syndrome. Am.J.Med.Genet., 41, (3) 289-294 available from: PM:1724112.

Huber, K.M. 2006. The fragile X-cerebellum connection. Trends Neurosci., 29, (4) 183 185 available from: PM:16500716.

Irwin, S.A., Idupulapati, M., Gilbert, M.E., Harris, J.B., Chakravarti, A.B., Rogers, E.J., Crisostomo, R.A., Larsen, B.P., Mehta, A., Alcantara, C.J., Patel, B., Swain, R.A., Weiler, I.J., Oostra, B.A., \& Greenough, W.T. 2002. Dendritic spine and dendritic field characteristics of layer $\mathrm{V}$ pyramidal neurons in the visual cortex of fragile-X knockout mice. Am.J.Med.Genet., 111, (2) 140-146 available from: PM:12210340.

Irwin, S.A., Patel, B., Idupulapati, M., Harris, J.B., Crisostomo, R.A., Larsen, B.P., Kooy, F., Willems, P.J., Cras, P., Kozlowski, P.B., Swain, R.A., Weiler, I.J., \& Greenough, W.T. 2001. Abnormal dendritic spine characteristics in the temporal and visual cortices of patients with fragile-X syndrome: a quantitative examination. Am.J.Med.Genet., 98, (2) 161-167 available from: PM:11223852.

Ivanco, T.L. \& Greenough, W.T. 2002. Altered mossy fiber distributions in adult Fmr1 (FVB) knockout mice. Hippocampus, 12, (1) 47-54 available from: PM:11918288.

Jin, P. \& Warren, S.T. 2003. New insights into fragile X syndrome: from molecules to neurobehaviors. Trends Biochem.Sci., 28, (3) 152-158 available from: PM:12633995.

Kayser, C., Petkov, C.I., \& Logothetis, N.K. 2007. Tuning to sound frequency in auditory field potentials. J.Neurophysiol., 98, (3) 1806-1809 available from: PM:17596418.

Kirkpatrick, L.L., McIlwain, K.A., \& Nelson, D.L. 2001. Comparative genomic sequence analysis of the FXR gene family: FMR1, FXR1, and FXR2. Genomics, 78, (3) 169-177 available from: PM:11735223.

Knyazev, G.G. 2011. Cross-frequency coupling of brain oscillations: an impact of state anxiety. Int.J.Psychophysiol., 80, (3) 236-245 available from: PM:21458502.

Knyazev, G.G. 2012. EEG delta oscillations as a correlate of basic homeostatic and motivational processes. Neurosci.Biobehav.Rev., 36, (1) 677-695 available from: PM:22020231.

Koekkoek, S.K., Yamaguchi, K., Milojkovic, B.A., Dortland, B.R., Ruigrok, T.J., Maex, R., De, G.W., Smit, A.E., VanderWerf, F., Bakker, C.E., Willemsen, R., Ikeda, T., Kakizawa, S., Onodera, K., Nelson, D.L., Mientjes, E., Joosten, M., De, S.E., Oostra, B.A., Ito, M., \& De Zeeuw, C.I. 2005. Deletion of FMR1 in Purkinje cells enhances parallel fiber LTD, enlarges spines, and attenuates cerebellar eyelid conditioning in Fragile X syndrome. Neuron, 47, (3) 339-352 available from: PM:16055059. 
Koukoui, S.D. \& Chaudhuri, A. 2007. Neuroanatomical, molecular genetic, and behavioral correlates of fragile X syndrome. Brain Res.Rev., 53, (1) 27-38 available from: PM:16844227.

Kremer, E.J., Pritchard, M., Lynch, M., Yu, S., Holman, K., Baker, E., Warren, S.T., Schlessinger, D., Sutherland, G.R., \& Richards, R.I. 1991. Mapping of DNA instability at the fragile X to a trinucleotide repeat sequence p (CCG)n. Science, 252, (5013) 17111714 available from: PM:1675488.

Krueger, D.D., Osterweil, E.K., Chen, S.P., Tye, L.D., \& Bear, M.F. 2011. Cognitive dysfunction and prefrontal synaptic abnormalities in a mouse model of fragile $\mathrm{X}$ syndrome. Proc.Natl.Acad.Sci.U.S.A, 108, (6) 2587-2592 available from: PM:21262808.

Kwon, B.S., Haq, A.K., Pomerantz, S.H., \& Halaban, R. 1987. Isolation and sequence of a cDNA clone for human tyrosinase that maps at the mouse c-albino locus.

Proc.Natl.Acad.Sci.U.S.A, 84, (21) 7473-7477 available from: PM:2823263.

Land, P.W. \& Simons, D.J. 1985. Cytochrome oxidase staining in the rat SmI barrel cortex. J.Comp.Neurol., 238, (2) 225-235 available from: PM:2413086.

Lawrence E.Wineski 1983. Movements of the cranial vibrissae in the Golden hamster (Mesocricetus auratus). J.Zool. (Lond), 200, 261-280.

Le, P.D., Svensson, P., Valeriani, M., Watanabe, I., Arendt-Nielsen, L., \& Chen, A.C. 2000. Long-lasting effect evoked by tonic muscle pain on parietal EEG activity in humans. Clin.Neurophysiol., 111, (12) 2130-2137 available from: PM:11090762.

Lee, A.D., Leow, A.D., Lu, A., Reiss, A.L., Hall, S., Chiang, M.C., Toga, A.W., \& Thompson, P.M. 2007. 3D pattern of brain abnormalities in Fragile X syndrome visualized using tensor-based morphometry. Neuroimage, 34, (3) 924-938 available from: PM:17161622.

Leopold, D.A. \& Logothetis, N.K. 2003. Spatial patterns of spontaneous local field activity in the monkey visual cortex. Rev.Neurosci., 14, (1-2) 195-205 available from: PM:12929926.

Lesniak-Karpiak, K., Mazzocco, M.M. \& Ross, J.L. 2003. Behavioral Assessment of Social Anxiety in Females with Turner or Fragile X Syndrome . Journal of Autism and Developmental Disorders, 33, 55-67.

Llinas, R.R. 1988. The intrinsic electrophysiological properties of mammalian neurons: insights into central nervous system function. Science, 242, (4886) 1654-1664 available from: PM:3059497.

Loesch, D.Z. \& Hay, D.A. 1988. Clinical features and reproductive patterns in fragile X female heterozygotes. J.Med.Genet., 25, (6) 407-414 available from: PM:3398009. 
Madison, L.S., George, C., \& Moeschler, J.B. 1986. Cognitive functioning in the fragile$\mathrm{X}$ syndrome: a study of intellectual, memory and communication skills.

J.Ment.Defic.Res., 30 ( Pt 2), 129-148 available from: PM:3735410.

Mallet, N., Pogosyan, A., Marton, L.F., Bolam, J.P., Brown, P., \& Magill, P.J. 2008.

Parkinsonian beta oscillations in the external globus pallidus and their relationship with subthalamic nucleus activity. J.Neurosci., 28, (52) 14245-14258 available from:

PM:19109506.

Maquet, P. 2000. Functional neuroimaging of normal human sleep by positron emission tomography. J.Sleep Res., 9, (3) 207-231 available from: PM:11012860.

Markram, H., Toledo-Rodriguez, M., Wang, Y., Gupta, A., Silberberg, G., \& Wu, C. 2004. Interneurons of the neocortical inhibitory system. Nat.Rev.Neurosci., 5, (10) $793-$ 807 available from: PM:15378039.

McKinney, B.C., Grossman, A.W., Elisseou, N.M., \& Greenough, W.T. 2005. Dendritic spine abnormalities in the occipital cortex of C57BL/6 Fmr1 knockout mice. Am.J.Med.Genet.B Neuropsychiatr.Genet., 136B, (1) 98-102 available from: PM:15892134.

McNaughton, C.H., Moon, J., Strawderman, M.S., Maclean, K.N., Evans, J., \& Strupp, B.J. 2008. Evidence for social anxiety and impaired social cognition in a mouse model of fragile X syndrome. Behav.Neurosci., 122, (2) 293-300 available from: PM:18410169.

Mehring, C., Rickert, J., Vaadia, E., Cardosa de, O.S., Aertsen, A., \& Rotter, S. 2003. Inference of hand movements from local field potentials in monkey motor cortex. Nat.Neurosci., 6, (12) 1253-1254 available from: PM:14634657.

Meis, S., Endres, T., \& Lessmann, V. 2012. Postsynaptic BDNF signalling regulates long-term potentiation at thalamo-amygdala afferents. J.Physiol., 590, (Pt 1) 193-208 available from: PM:22083603.

Miller, L.J., McIntosh, D.N., McGrath, J., Shyu, V., Lampe, M., Taylor, A.K., Tassone, F., Neitzel, K., Stackhouse, T., \& Hagerman, R.J. 1999. Electrodermal responses to sensory stimuli in individuals with fragile $\mathrm{X}$ syndrome: a preliminary report. Am.J.Med.Genet., 83, (4) 268-279 available from: PM:10208160.

Miller, M.T., Strömland, K., Gillberg, C., Johansson, M., \& Nilsson, E.W. 1998. The puzzle of autism: an ophthalmologic contribution. Trans Am. Ophthalmol. Soc., 96, 369387.

Mines, M.A., Yuskaitis, C.J., King, M.K., Beurel, E., \& Jope, R.S. 2010. GSK3 influences social preference and anxiety-related behaviors during social interaction in a mouse model of fragile X syndrome and autism. PLoS.One., 5, (3) e9706 available from: PM:20300527. 
Mineur, Y.S., Huynh, L.X., \& Crusio, W.E. 2006. Social behavior deficits in the Fmr1 mutant mouse. Behav.Brain Res., 168, (1) 172-175 available from: PM:16343653.

Mineur, Y.S., Sluyter, F., de, W.S., Oostra, B.A., \& Crusio, W.E. 2002. Behavioral and neuroanatomical characterization of the Fmr1 knockout mouse. Hippocampus, 12, (1) 3946 available from: PM:11918286.

Mostofsky, S.H., Mazzocco, M.M., Aakalu, G., Warsofsky, I.S., Denckla, M.B., \& Reiss, A.L. 1998. Decreased cerebellar posterior vermis size in fragile X syndrome: correlation with neurocognitive performance. Neurology, 50, (1) 121-130 available from: PM:9443468.

Mountcastle, V.B., Davies, P.W., \& Berman, A.L. 1957. Response properties of neurons of cat's somatic sensory cortex to peripheral stimuli. J.Neurophysiol., 20, (4) 374-407 available from: PM:13439409.

Moxon, K.A. 2008. Natural whisking. Focus on "variability in velocity profiles during free-air whisking behavior of unrestrained rats". J.Neurophysiol., 100, (2) 551-553 available from: PM:18562552.

Muellbacher, W. \& Mamoli, B. 1994. Prolonged impaired consciousness in basilar artery migraine. Headache, 34, (5) 282-285 available from: PM:8026947.

Murthy, V.N. \& Fetz, E.E. 1992. Coherent 25- to 35-Hz oscillations in the sensorimotor cortex of awake behaving monkeys. Proc.Natl.Acad.Sci.U.S.A, 89, (12) 5670-5674 available from: PM:1608977.

Musumeci, S.A., Bosco, P., Calabrese, G., Bakker, C., De Sarro, G.B., Elia, M., Ferri, R., \& Oostra, B.A. 2000. Audiogenic seizures susceptibility in transgenic mice with fragile X syndrome. Epilepsia, 41, (1) 19-23 available from: PM:10643918.

Musumeci, S.A., Elia, M., Ferri, R., Scuderi, C., \& Del, G.S. 1994. Evoked spikes and giant somatosensory evoked potentials in a patient with fragile-X syndrome.

Ital.J.Neurol.Sci., 15, (7) 365-368 available from: PM:7698895.

Musumeci, S.A., Hagerman, R.J., Ferri, R., Bosco, P., Dalla, B.B., Tassinari, C.A., De Sarro, G.B., \& Elia, M. 1999. Epilepsy and EEG findings in males with fragile X syndrome. Epilepsia, 40, (8) 1092-1099 available from: PM:10448821.

Newell, K., Sanborn, B., \& Hagerman, R. J. 1983, "Speech and language dysfunction in the fragile X syndrome.," In The fragile X syndrome: Diagnosis, biochemistry and intervention., R. J. Hagerman \& P. M. McBogg, eds., Dillon, Co.: Spectra Publishing, pp. 175-200. 
Nielsen, D.M., Derber, W.J., McClellan, D.A., \& Crnic, L.S. 2002. Alterations in the auditory startle response in Fmr1 targeted mutant mouse models of fragile $\mathrm{X}$ syndrome. Brain Res., 927, (1) 8-17 available from: PM:11814427.

Nimchinsky, E.A., Oberlander, A.M., \& Svoboda, K. 2001. Abnormal development of dendritic spines in FMR1 knock-out mice. J.Neurosci., 21, (14) 5139-5146 available from: PM:11438589.

Nimchinsky, E.A., Sabatini, B.L., \& Svoboda, K. 2002. Structure and function of dendritic spines. Annu.Rev.Physiol, 64, 313-353 available from: PM:11826272.

Nistri, A., Ostroumov, K., Sharifullina, E., \& Taccola, G. 2006. Tuning and playing a motor rhythm: how metabotropic glutamate receptors orchestrate generation of motor patterns in the mammalian central nervous system. J.Physiol, 572, (Pt 2) 323-334 available from: PM:16469790.

Olesen, S.S., Hansen, T.M., Graversen, C., Steimle, K., Wilder-Smith, O.H., \& Drewes, A.M. 2011. Slowed EEG rhythmicity in patients with chronic pancreatitis: evidence of abnormal cerebral pain processing? Eur.J.Gastroenterol.Hepatol., 23, (5) 418-424 available from: PM:21399506.

Paluszkiewicz, S.M., Martin, B.S., \& Huntsman, M.M. 2011a. Fragile X syndrome: the GABAergic system and circuit dysfunction. Dev.Neurosci., 33, (5) 349-364 available from: PM:21934270.

Paluszkiewicz, S.M., Olmos-Serrano, J.L., Corbin, J.G., \& Huntsman, M.M. 2011 b. Impaired inhibitory control of cortical synchronization in fragile $\mathrm{X}$ syndrome. J.Neurophysiol., 106, (5) 2264-2272 available from: PM:21795626.

Paradee, W., Melikian, H.E., Rasmussen, D.L., Kenneson, A., Conn, P.J., \& Warren, S.T. 1999. Fragile X mouse: strain effects of knockout phenotype and evidence suggesting deficient amygdala function. Neuroscience, 94, (1) 185-192 available from: PM:10613508.

Paul, R., Dykens, E., Leckman, J.F., Watson, M., Breg, W.R., \& Cohen, D.J. 1987. A comparison of language characteristics of mentally retarded adults with fragile $\mathrm{X}$ syndrome and those with nonspecific mental retardation and autism. J.Autism Dev.Disord., 17, (4) 457-468 available from: PM:3479423.

Persico, A.M. \& Bourgeron, T. 2006. Searching for ways out of the autism maze: genetic, epigenetic and environmental clues. Trends Neurosci., 29, (7) 349-358 available from: PM:16808981.

Pesaran, B., Nelson, M.J., \& Andersen, R.A. 2008. Free choice activates a decision circuit between frontal and parietal cortex. Nature, 453, (7193) 406-409 available from: PM:18418380. 
Phillips, M.E., Sachdev, R.N., Willhite, D.C., \& Shepherd, G.M. 2012. Respiration drives network activity and modulates synaptic and circuit processing of lateral inhibition in the olfactory bulb. J.Neurosci., 32, (1) 85-98 available from: PM:22219272.

Pietropaolo, S., Guilleminot, A., Martin, B., D'Amato, F.R., \& Crusio, W.E. 2011. Genetic-background modulation of core and variable autistic-like symptoms in Fmr1 knock-out mice. PLoS.One., 6, (2) e17073 available from: PM:21364941.

Pizzagalli, D.A., Oakes, T.R., Fox, A.S., Chung, M.K., Larson, C.L., Abercrombie, H.C., Schaefer, S.M., Benca, R.M., \& Davidson, R.J. 2004. Functional but not structural subgenual prefrontal cortex abnormalities in melancholia. Mol.Psychiatry, 9, (4) 325, 393-325, 405 available from: PM:14699431.

Qin, M., Kang, J., \& Smith, C.B. 2005. A null mutation for Fmr1 in female mice: effects on regional cerebral metabolic rate for glucose and relationship to behavior.

Neuroscience, 135, (3) 999-1009 available from: PM:16154294.

Ramelli, G.P., Sturzenegger, M., Donati, F., \& Karbowski, K. 1998. EEG findings during basilar migraine attacks in children. Electroencephalogr.Clin.Neurophysiol., 107, (5) 374-378 available from: PM:9872440.

Reiss, A.L., Patel, S, Kumar, A \& Freund, L 1988. Neuroanatomical Variations of the Posterior Fossa in Men With the Fragile X (Martin-Bell) Syndrome. Am.J.Med.Genet., 31, 407-488.

Reiss, A.L., Aylward, E., Freund, L.S., Joshi, P.K., \& Bryan, R.N. 1991. Neuroanatomy of fragile X syndrome: the posterior fossa. Ann.Neurol., 29, (1) 26-32 available from: PM:1996876.

Rogers, S.J., Wehner, D.E., \& Hagerman, R. 2001. The behavioral phenotype in fragile $\mathrm{X}$ : symptoms of autism in very young children with fragile $\mathrm{X}$ syndrome, idiopathic autism, and other developmental disorders. J.Dev.Behav.Pediatr., 22, (6) 409-417 available from: PM:11773805.

Rojas, D.C., Maharajh, K., Teale, P., \& Rogers, S.J. 2008. Reduced neural synchronization of gamma-band MEG oscillations in first-degree relatives of children with autism. BMC.Psychiatry, 8, 66 available from: PM:18673566.

Roux, S., Mackay, W.A., \& Riehle, A. 2006. The pre-movement component of motor cortical local field potentials reflects the level of expectancy. Behav.Brain Res., 169, (2) 335-351 available from: PM:16530860.

Roy, S., Bryant, J.L., Cao, Y., \& Heck, D.H. 2011a. High-precision, three-dimensional tracking of mouse whisker movements with optical motion capture technology. Front Behav.Neurosci., 5, 27 available from: PM:21713124 
Roy, S., Zhao, Y., Allensworth, M., Farook, M.F., Ledoux, M.S., Reiter, L.T., \& Heck, D.H. 2011b. Comprehensive motor testing in Fmr1-KO mice exposes temporal defects in oromotor coordination. Behav.Neurosci., 125, (6) 962-969 available from: PM:22004265.

Rubenstein, J.L. \& Merzenich, M.M. 2003. Model of autism: increased ratio of excitation/inhibition in key neural systems. Genes Brain Behav., 2, (5) 255-267 available from: PM:14606691.

Rudelli, R.D., Brown, W.T., Wisniewski, K., Jenkins, E.C., Laure-Kamionowska, M., Connell, F., \& Wisniewski, H.M. 1985. Adult fragile X syndrome. Cliniconeuropathologic findings. Acta Neuropathol., 67, (3-4) 289-295 available from: PM:4050344.

Salinas, E. \& Sejnowski, T.J. 2001. Correlated neuronal activity and the flow of neural information. Nat.Rev.Neurosci., 2, (8) 539-550 available from: PM:11483997.

Santoro, M.R., Bray, S.M., \& Warren, S.T. 2012. Molecular mechanisms of fragile X syndrome: a twenty-year perspective. Annu.Rev.Pathol., 7, 219-245 available from: PM:22017584.

Scattoni, M.L., Crawley, J., \& Ricceri, L. 2009. Ultrasonic vocalizations: a tool for behavioural phenotyping of mouse models of neurodevelopmental disorders. Neurosci.Biobehav.Rev., 33, (4) 508-515 available from: PM:18771687.

Scattoni, M.L., Gandhy, S.U., Ricceri, L., \& Crawley, J.N. 2008. Unusual repertoire of vocalizations in the BTBR T+tf/J mouse model of autism. PLoS.One., 3, (8) e3067 available from: PM:18728777.

Scattoni, M.L., Ricceri, L., \& Crawley, J.N. 2011. Unusual repertoire of vocalizations in adult BTBR T $+\mathrm{tf} / \mathrm{J}$ mice during three types of social encounters. Genes Brain Behav., 10, (1) 44-56 available from: PM:20618443.

Schnitzler, A. \& Gross, J. 2005. Normal and pathological oscillatory communication in the brain. Nat.Rev.Neurosci., 6, (4) 285-296 available from: PM:15803160.

Scotto-Lomassese, S., Nissant, A., Mota, T., Neant-Fery, M., Oostra, B.A., Greer, C.A., Lledo, P.M., Trembleau, A., \& Caille, I. 2011. Fragile X mental retardation protein regulates new neuron differentiation in the adult olfactory bulb. J.Neurosci., 31, (6) 22052215 available from: PM:21307257.

Shair, H.N. 2007. Acquisition and expression of a socially mediated separation response. Behav.Brain Res., 182, (2) 180-192 available from: PM:17379325.

Shambes, G.M., Gibson, J.M., \& Welker, W. 1978. Fractured somatotopy in granule cell tactile areas of rat cerebellar hemispheres revealed by micromapping. Brain Behav.Evol., 15, (2) 94-140 available from: PM:638731. 
Siegel, M., Donner, T.H., Oostenveld, R., Fries, P., \& Engel, A.K. 2008. Neuronal synchronization along the dorsal visual pathway reflects the focus of spatial attention. Neuron, 60, (4) 709-719 available from: PM:19038226.

Simons, D.J. 1978. Response properties of vibrissa units in rat SI somatosensory neocortex. J.Neurophysiol., 41, (3) 798-820 available from: PM:660231.

Singer, W. 1993. Synchronization of cortical activity and its putative role in information processing and learning. Annu.Rev.Physiol, 55, 349-374 available from: PM:8466179.

Slegtenhorst-Eegdeman, K.E., de Rooij, D.G., Verhoef-Post, M., van de Kant, H.J., Bakker, C.E., Oostra, B.A., Grootegoed, J.A., \& Themmen, A.P. 1998. Macroorchidism in FMR1 knockout mice is caused by increased Sertoli cell proliferation during testicular development. Endocrinology, 139, (1) 156-162 available from: PM:9421410.

Smith JC 1976. Responses to adult mice to models infant calls. J.Comp.Physio.Psychol., 90, (12) 1105-1115.

Spencer, C.M., Alekseyenko, O., Serysheva, E., Yuva-Paylor, L.A., \& Paylor, R. 2005. Altered anxiety-related and social behaviors in the Fmrl knockout mouse model of fragile X syndrome. Genes Brain Behav., 4, (7) 420-430 available from: PM:16176388.

Spencer, K.A. \& Slocomb, D.L. 2007. The neural basis of ataxic dysarthria. Cerebellum, 6, (1) 58-65 available from: PM:17366266.

Szabadics, J., Lorincz, A., \& Tamas, G. 2001. Beta and gamma frequency synchronization by dendritic gabaergic synapses and gap junctions in a network of cortical interneurons. J.Neurosci., 21, (15) 5824-5831 available from: PM:11466454.

Teune, T.M., van der Burg, J., van der Moer, J., Voogd, J., \& Ruigrok, T.J. 2000. Topography of cerebellar nuclear projections to the brain stem in the rat. Prog.Brain Res., 124, 141-172 available from: PM:10943123.

Travers, J.B., DiNardo, L.A., \& Karimnamazi, H. 1997. Motor and premotor mechanisms of licking. Neurosci.Biobehav.Rev., 21, (5) 631-647 available from: PM:9353796.

Tucker, B., Richards, R.I., \& Lardelli, M. 2006. Contribution of mGluR and Fmr1 functional pathways to neurite morphogenesis, craniofacial development and fragile $\mathrm{X}$ syndrome. Hum.Mol.Genet., 15, (23) 3446-3458 available from: PM:17065172.

Uhlhaas, P.J., Pipa, G., Lima, B., Melloni, L., Neuenschwander, S., Nikolic, D., \& Singer, W. 2009. Neural synchrony in cortical networks: history, concept and current status. Front.Integr.Neurosci., 3, 17 available from: PM:19668703. 
Uhlhaas, P.J. \& Singer, W. 2006a. Neural synchrony in brain disorders: relevance for cognitive dysfunctions and pathophysiology. Neuron, 52, (1) 155-168 available from: PM:17015233.

Uhlhaas, P.J. \& Singer, W. 2006b. Neural synchrony in brain disorders: relevance for cognitive dysfunctions and pathophysiology. Neuron, 52, (1) 155-168 available from: PM:17015233.

Vajnerova, O., Zhuravin, I.A., \& Brozek, G. 2000. Functional ablation of deep cerebellar nuclei temporarily impairs learned coordination of forepaw and tongue movements. Behav.Brain Res., 108, (2) 189-195 available from: PM:10701662.

Verkerk, A.J., Pieretti, M., Sutcliffe, J.S., Fu, Y.H., Kuhl, D.P., Pizzuti, A., Reiner, O., Richards, S., Victoria, M.F., \& Zhang, F.P. 1991. Identification of a gene (FMR-1) containing a CGG repeat coincident with a breakpoint cluster region exhibiting length variation in fragile X syndrome. Cell, 65, (5) 905-914 available from: PM:1710175.

Voigts, J., Sakmann, B., \& Celikel, T. 2008. Unsupervised whisker tracking in unrestrained behaving animals. J.Neurophysiol., 100, (1) 504-515 available from: PM:18463190.

Wacker, J., Dillon, D.G., \& Pizzagalli, D.A. 2009. The role of the nucleus accumbens and rostral anterior cingulate cortex in anhedonia: integration of resting EEG, fMRI, and volumetric techniques. Neuroimage, 46, (1) 327-337 available from: PM:19457367.

Wang, H., Wu, L.J., Kim, S.S., Lee, F.J., Gong, B., Toyoda, H., Ren, M., Shang, Y.Z., Xu, H., Liu, F., Zhao, M.G., \& Zhuo, M. 2008. FMRP acts as a key messenger for dopamine modulation in the forebrain. Neuron, 59, (4) 634-647 available from: PM:18760699.

Weijnen, J.A., Wouters, J., \& van Hest, J.M. 1984. Interaction between licking and swallowing in the drinking rat. Brain Behav.Evol., 25, (2-3) 117-127 available from: PM:6534500.

Welker, W.I. 1964. Analysis of sniffing of the albino rat. Behaviour, 22, 223-243.

Welsh, J.P., Lang, E.J., Suglhara, I., \& Llinas, R. 1995. Dynamic organization of motor control within the olivocerebellar system. Nature, 374, (6521) 453-457 available from: PM:7700354.

Wilson, B.M. \& Cox, C.L. 2007. Absence of metabotropic glutamate receptor-mediated plasticity in the neocortex of fragile X mice. Proc.Natl.Acad.Sci.U.S.A, 104, (7) 24542459 available from: PM:17287348. 
Wisniewski, K.E., Segan, S.M., Miezejeski, C.M., Sersen, E.A., \& Rudelli, R.D. 1991. The $\operatorname{Fra}(\mathrm{X})$ syndrome: neurological, electrophysiological, and neuropathological abnormalities. Am.J.Med.Genet., 38, (2-3) 476-480 available from: PM:2018089.

Wohr, M., Roullet, F.I., \& Crawley, J.N. 2011a. Reduced scent marking and ultrasonic vocalizations in the BTBR T+tf/J mouse model of autism. Genes Brain Behav., 10, (1) 35-43 available from: PM:20345893.

Wohr, M., Roullet, F.I., Hung, A.Y., Sheng, M., \& Crawley, J.N. 2011b. Communication impairments in mice lacking Shank1: reduced levels of ultrasonic vocalizations and scent marking behavior. PLoS.One., 6, (6) e20631 available from: PM:21695253.

Woolsey, T.A. \& Van der Loos, H. 1970. The structural organization of layer IV in the somatosensory region (SI) of mouse cerebral cortex. The description of a cortical field composed of discrete cytoarchitectonic units. Brain Res., 17, (2) 205-242 available from: PM:4904874.

Yan, Q.J., Asafo-Adjei, P.K., Arnold, H.M., Brown, R.E., \& Bauchwitz, R.P. 2004. A phenotypic and molecular characterization of the fmr1-tm1Cgr fragile X mouse. Genes Brain Behav., 3, (6) 337-359 available from: PM:15544577.

Yang, M., Scattoni, M.L., Zhodzishsky, V., Chen, T., Caldwell, H., Young, W.S., McFarlane, H.G., \& Crawley, J.N. 2007. Social approach behaviors are similar on conventional versus reverse lighting cycles, and in replications across cohorts, in BTBR $\mathrm{T}+\mathrm{tf} / \mathrm{J}, \mathrm{C} 57 \mathrm{BL} / 6 \mathrm{~J}$, and vasopressin receptor 1B mutant mice. Front.Behav.Neurosci., 1, 1 available from: PM:18958184.

Young, D.M., Schenk, A.K., Yang, S.B., Jan, Y.N., \& Jan, L.Y. 2010a. Altered ultrasonic vocalizations in a tuberous sclerosis mouse model of autism. Proc.Natl.Acad.Sci.U.S.A, 107, (24) 11074-11079 available from: PM:20534473.

Young, D.M., Schenk, A.K., Yang, S.B., Jan, Y.N., \& Jan, L.Y. 2010b. Altered ultrasonic vocalizations in a tuberous sclerosis mouse model of autism. Proc.Natl.Acad.Sci.U.S.A, 107, (24) 11074-11079 available from: PM:20534473.

Zajac, D.J., Roberts, J.E., Hennon, E.A., Harris, A.A., Barnes, E.F., \& Misenheimer, J. 2006. Articulation rate and vowel space characteristics of young males with fragile $X$ syndrome: preliminary acoustic findings. J.Speech Lang Hear.Res., 49, (5) 1147-1155 available from: PM:17077221.

Zeskind, P.S.\&.Marshall, T.R. 1988. The relation between variations in pitch and maternal perceptions of infant crying. Child Development, 59, (1) 193-196.

Zhang, J., Hou, L., Klann, E., \& Nelson, D.L. 2009. Altered hippocampal synaptic plasticity in the FMR1 gene family knockout mouse models. J.Neurophysiol., 101, (5) 2572-2580 available from: PM:19244359. 
Zhang, Y., O'Connor, J.P., Siomi, M.C., Srinivasan, S., Dutra, A., Nussbaum, R.L., \& Dreyfuss, G. 1995. The fragile X mental retardation syndrome protein interacts with novel homologs FXR1 and FXR2. EMBO J., 14, (21) 5358-5366 available from:

PM:7489725.

Zhao, X., Pak, C., Smrt, R.D., \& Jin, P. 2007. Epigenetics and Neural developmental disorders: Washington DC, September 18 and 19, 2006. Epigenetics, 2, (2) 126-134 available from: PM:17965627.

Zingerevich, C., Greiss-Hess, L., Lemons-Chitwood, K., Harris, S.W., Hess1, D., Cook, K., \& Hagerman, R.J. 2009. Motor abilities of children diagnosed with fragile X syndrome with and without autism. J.Intellect.Disabil.Res., 53, (1) 11-18 available from: PM:18771512.

Zippelius, H.M. \& Schleidt, W.H. 1956. Ultraschall-Lavte bei jungen Mausen. Naturwissenschaften, 43, 503-508.

Zoghbi, H.Y. 2003. Postnatal neurodevelopmental disorders: meeting at the synapse? Science, 302, (5646) 826-830 available from: PM:14593168.

Zupan, B. \& Toth, M. 2008. Wild-type male offspring of fmr-1(+/-) mothers exhibit characteristics of the fragile X phenotype. Neuropsychopharmacology, 33, (11) 26672675 available from: PM:18172434. 


\section{VITA}

Snigdha Roy was born in Calcutta, India. She completed her undergraduate studies with Physics major from Calcutta University. She earned her post graduate degree in computer science from CMC, Calcutta, India. In 2005, she earned her master's degree from the University of Memphis. In 2007, she enrolled in Integrated Program in Biomedical Sciences at the University of Tennessee Health Science Center. 